Portland State University

PDXScholar

$1-1-2010$

\title{
A Structural and Functional Analysis of Codeswitching in Mi Vida Gitana 'My Gypsy Life,' a Bilingual Play
}

Gustavo Javier Fernandez

Portland State University

Follow this and additional works at: https://pdxscholar.library.pdx.edu/open_access_etds

Part of the Applied Linguistics Commons

Let us know how access to this document benefits you.

\section{Recommended Citation}

Fernandez, Gustavo Javier, "A Structural and Functional Analysis of Codeswitching in Mi Vida Gitana 'My Gypsy Life,' a Bilingual Play" (2010). Dissertations and Theses. Paper 397.

https://doi.org/10.15760/etd.397

This Thesis is brought to you for free and open access. It has been accepted for inclusion in Dissertations and Theses by an authorized administrator of PDXScholar. Please contact us if we can make this document more accessible: pdxscholar@pdx.edu. 
A Structural and Functional Analysis of Codeswitching in Mi Vida Gitana 'My Gypsy Life,' a Bilingual Play

by

Gustavo Javier Fernández

A thesis submitted in partial fulfillment of the requirements for the degree of

\author{
Master of Arts \\ in \\ Teaching English to Speakers of Other Languages
}

Thesis Committee:

Keith Walters, Chair

Eva Núñez

Lynn Santelmann

Portland State University

2010 


\begin{abstract}
The present study analyzed the language in the script of the bilingual play $M i$ Vida Gitana 'My Gypsy Life’ (Malán, 2006) in order to better understand issues relating to codeswitching (CS). The analysis was done from a structural and a functional perspective and utilized various models developed by renowned CS scholars.
\end{abstract}

For the structural analysis, I utilized concepts and ideas put forth in the threetiered typology created by Muysken (2000) and the Matrix Language Frame model developed by Myers-Scotton (1993). The results of this portion of the study showed that some form of CS, whether occurring between turns or within turns, was observed in $78 \%$ of all turns. With regard to CS types and elements most commonly observed in the data, the alternation of clauses and the insertion and alternation of nouns and noun phrases were the predominant phenomena occurring in the script.

I used Myers-Scotton's (1993) Markedness Model and Gumperz’s (1982) functions of conversational CS to guide the functional analysis conducted during this study. The results arising from this portion of the analysis showed that CS served an important function in terms of character development. Marked and unmarked CS helped create different characters and likely assisted audiences in understanding those characters. The data analyzed also showed that CS served a purpose with regard to the communication of the message to diverse audiences. The use of reiterations and conjunctions were determined to be important CS strategies that contributed to making the story accessible to bilingual as well as monolingual audiences. 
The results of this study are in line with previous research that has documented the types of structures found in English-Spanish CS and some of the functions served by this phenomenon. The implications of the study provide additional support for the recognition of $\mathrm{CS}$ as a possible factor in the language acquisition process and suggest that language educators acknowledge its occurrence and utilize it to further develop learners' language skills. 


\section{ACKNOWLEDGEMENTS}

I would like to gratefully acknowledge Dañel Malán’s permission to reproduce extracts from Mi Vida Gitana. Ms. Malán’s generosity in sharing her copyrighted materials was invaluable in making this study a reality. At the same time, I would like to acknowledge the important work Ms. Malán and the staff of Teatro Milagro do to bring high quality art performances to diverse audiences.

I would also like to thank my advisor, Professor Keith Walters, for his patience, support, and guidance during this process. Likewise, I want to thank Professors Eva Núñez and Lynn Santelmann for providing suggestions and comments to improve the quality of the study. I owe all three of them a special thank you for their continued words of encouragement.

Finally, thank you to all of you who have been involved throughout this process, whether listening to my ideas, sharing your thoughts and impressions about $\mathrm{CS}$, and/or providing me with your support. And a very special thanks to my wife, Evaluz, who loved me unconditionally and was there for me during this entire process. 


\section{TABLE OF CONTENTS}

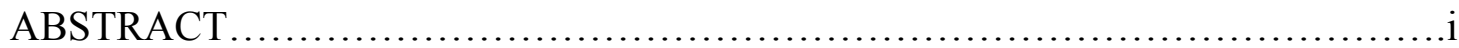

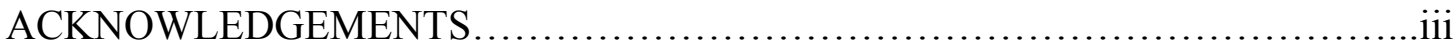

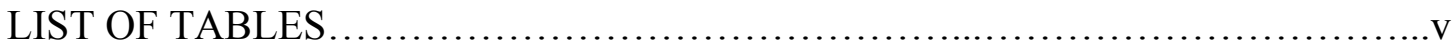

LIST OF FIGURES.............................................................

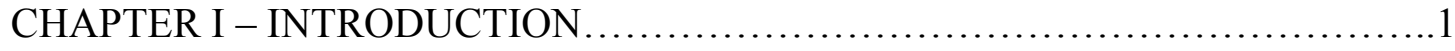

CHAPTER II - LITERATURE REVIEW..........................................5

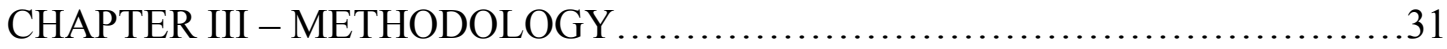

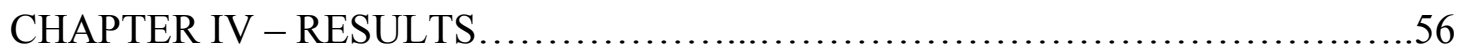

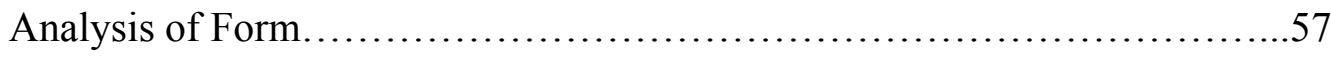

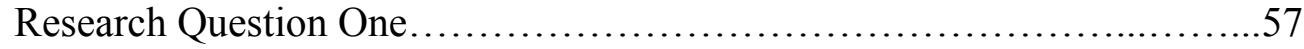

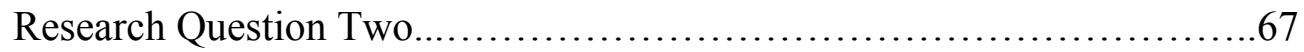

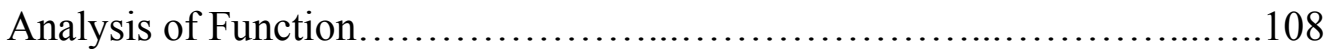

Research Question Three................................................109

Research Question Four...........................................120

CHAPTER V - CONCLUSION............................................. 130

REFERENCES........................................................ 144

APPENDIX - Mi Vida Gitana PLOT SYNOPSIS................................148 


\section{LIST OF TABLES}

TABLE 2.1 -DIAGNOSTIC FEATURES OF INSERTION.........................15

TABLE 2.2 -DIAGNOSTIC FEATURES OF ALTERNATION.....................16

TABLE 2.3 -DIAGNOSTIC FEATURES OF CONGRUENT

LEXICALIZATION............................................................... 18

TABLE 3.1. -EXAMPLES OF DATA CODING..................................46

TABLE 3.2 -ALTERNATIVE DATA CODING CHART, TURN 195...............50

TABLE 4.1 -BETWEEN-TURN CONTINUITY BY CHARACTER AND

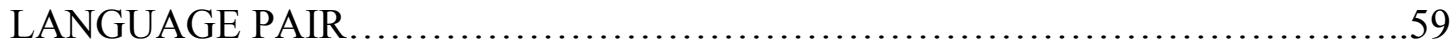

TABLE 4.2 -BETWEEN-TURN SWITCHES BY CHARACTER AND

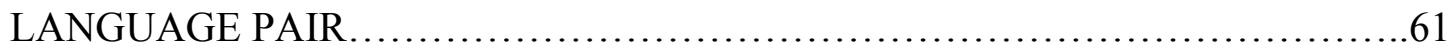

TABLE 4.3 -NUMBER AND PERCENTAGE OF TURN SWITCHES.............65

TABLE 4.4 -CS OCCURRENCES BY CHARACTER AND BY TYPE OF

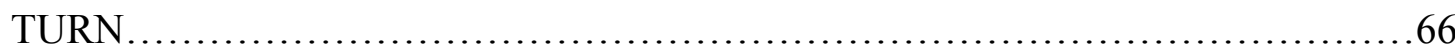

TABLE 4.5 -INSERTION BY SYNTACTIC FORM, INCLUDING NUMBER OF TYPES AND TOKENS ......................................68

TABLE 4.6 -FUNCTIONS OF INSERTED NOUNS (N) AND NOUN

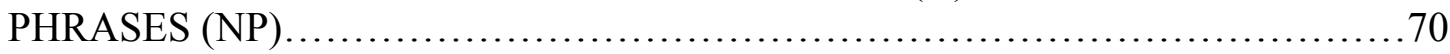

TABLE 4.7 -ALTERNATION IN WITHIN-TURN AND BETWEEN-TURN

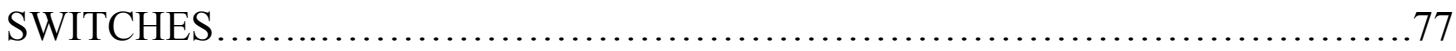

TABLE 4.8 -FUNCTIONS OF ALTERNATED ADVERBS (ADV) AND ADVERBIAL PHRASES (ADVP) ............................................... 80

TABLE 4.9 -FUNCTIONS OF ALTERNATED NOUNS (N) AND NOUN

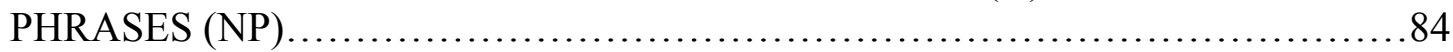

TABLE 4.10 -CONJUNCTIONS USED IN ALTERNATION......................98

TABLE 4.11 -LANGUAGE USAGE BY CHARACTER, BY WORDS..............110 


\section{LIST OF FIGURES}

FIGURE 2.1 -EXAMPLES OF MLF CONSTITUENT TYPES/EXAMPLES

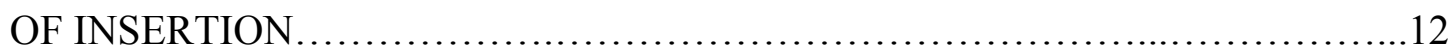

FIGURE 2.2 -EXAMPLE OF ALTERNATION..................................14

FIGURE 2.3 -EXAMPLE OF CONGRUENT LEXICALIZATION..................15

FIGURE 2.4 -EXAMPLE OF SYNTACTIC EQUIVALENCE......................19

FIGURE 2.5 -EXAMPLE OF CONVERSATIONAL FUNCTIONS OF CS.........21

FIGURE 2.6 -EXAMPLE OF SEQUENTIAL UNMARKED CS...................23

FIGURE 2.7 -EXAMPLE OF UNMARKED CS................................24

FIGURE 2.8 -EXAMPLES OF MARKED CS...................................24

FIGURE 2.9 -EXAMPLE OF EXPLORATORY CS ...............................25

FIGURE 3.1 -EXAMPLE OF BETWEEN-TURN SWITCH............................36

FIGURE 3.2 -EXAMPLE OF BETWEEN-TURN CONTINUITY ..................36

FIGURE 3.3 -EXAMPLE OF WITHIN-TURN SWITCH..........................37

FIGURE 3.4 -EXAMPLE OF MULTIPLE CS OCCURRENCES IN

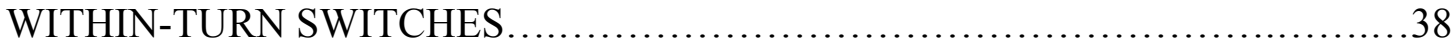

FIGURE 3.5 -EXAMPLES OF PHONOLOGICAL TRANSCRIPTION ...............39

FIGURE 3.6 -EXAMPLES OF LANGUAGE CATEGORIZATION _...................39

FIGURE 3.7 -INSERTION (A), ALTERNATION (B), AND CONGRUENT LEXICALIZATION (C) OF NPS ............................................ 40

FIGURE 3.8 -EMBEDDED LANGUAGE: SINGLE ELEMENT (A) AND

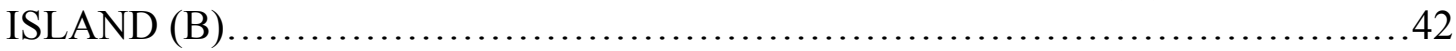

FIGURE 3.9 -TURN 195: LILIANA.............................................48

FIGURE 3.10 -MARKED (A) AND UNMARKED (B) LANGUAGE

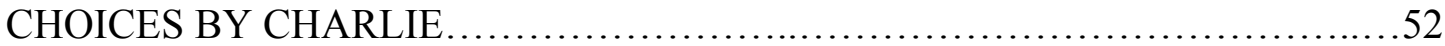


FIGURE 3.11 -EXAMPLE OF REITERATION ................................54

FIGURE 3.12 -EXAMPLE OF GAP-FILLING................................54

FIGURE 3.13 -EXAMPLE OF CONJUNCTION.................................55

FIGURE 4.1 -EXAMPLE OF IMPOSSIBILITY OF CONTINUITY AND

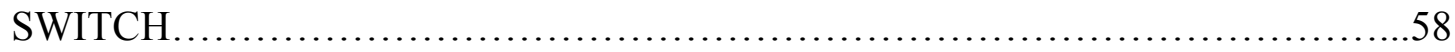

FIGURE 4.2 -EXAMPLES OF BETWEEN-TURN CONTINUITY ..................60

FIGURE 4.3 -EXAMPLES OF BETWEEN-TURN SWITCHES....................60

FIGURE 4.4 -EXAMPLES OF BETWEEN-TURN SWITCHES

INVOLVING FRENCH OR ROMANI ALONG WITH ENGLISH

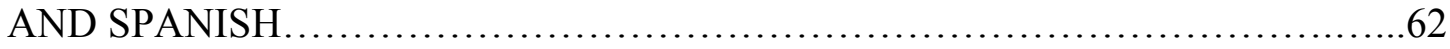

FIGURE 4.5 -EXAMPLE OF WITHIN-TURN SWITCHES........................64

FIGURE 4.6-EXAMPLE OF BETWEEN-TURN AND WITHIN-TURN

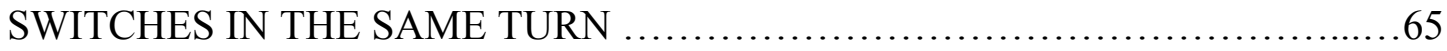

FIGURE 4.7 -INSERTED ADJECTIVES..........................................68

FIGURE 4.8 -INSERTED NOUNS AS SUBJECTS ...............................71

FIGURE 4.9 -INSERTED NOUNS AS DIRECT OBJECTS..........................71

FIGURE 4.10 -INSERTED NOUNS AS OBJECTS OF PREPOSITIONAL

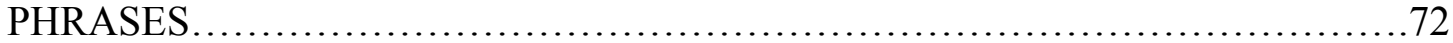

FIGURE 4.11 -INSERTED NOUN PHRASES.................................73

FIGURE 4.12 -INSERTED PREPOSITIONAL PHRASES........................75

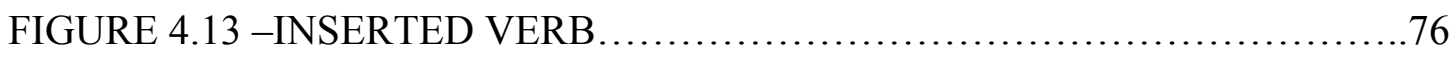

FIGURE 4.14 -ADVERB ALTERNATION IN BETWEEN-TURN

SWITCHES INVOLVING FRENCH OR ROMANI ALONG WITH

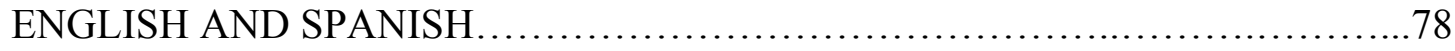

FIGURE 4.15 -ALTERNATED ADVERBS AND ADVERBIAL

PHRASES IN RESPONSE TO COMMANDS ....................................... 80 
FIGURE 4.16 -ALTERNATED ADVERBS AND ADVERBIAL PHRASES IN RESPONSE TO QUESTIONS.

FIGURE 4.17 -ALTERNATED ADVERBIAL PHRASES AS DISCOURSE MARKERS.

FIGURE 4.18 -NOUN AND NOUN PHRASE ALTERNATION INVOLVING ARABIC, FRENCH, OR ROMANI ALONG WITH ENGLISH AND SPANISH .83

FIGURE 4.19 -ALTERNATED NOUNS AND NOUN PHRASES AS INTRA-SENTENTIAL ELEMENTS. 84

FIGURE 4.20 -ALTERNATED NOUN PHRASES AS EXTRASENTENTIAL ELEMENTS .87

FIGURE 4.21 -ALTERNATED PREPOSITIONAL PHRASES 89

FIGURE 4.22 -ALTERNATED VERB PHRASES: COMPOUND PHRASE (A), FOLLOWED BY DIRECT OBJECT (B) ................................. 91

FIGURE 4.23 -ALTERNATED VERB PHRASE: SELF-REPAIR.................91

FIGURE 4.24 -EXAMPLES OF INTERJECTION “OH”,........................93

FIGURE 4.25 -EXAMPLES OF INTERJECTIONS..............................93

FIGURE 4.26 -EXAMPLES OF TERM OF ADDRESS............................95

FIGURE 4.27 - EXAMPLES OF INDEPENDENT CLAUSE

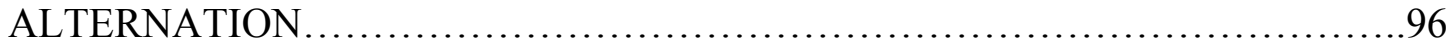

FIGURE 4.28 -EXAMPLES OF CLAUSE ALTERNATION WITH

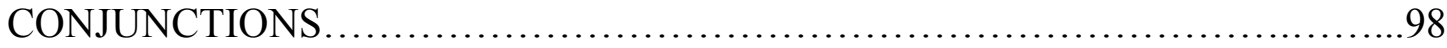

FIGURE 4.29 -EXAMPLES OF CLAUSE ALTERNATION WITH

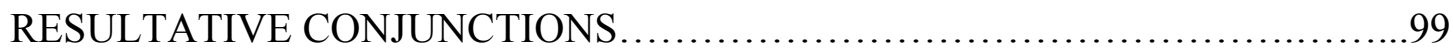

FIGURE 4.30 -EXAMPLES OF CLAUSE ALTERNATION WITH ADVERBS. 100

FIGURE 4.31 -ALTERNATION OF DEPENDENT AND INDEPENDENT CLAUSES. 101 
FIGURE 4.32 -OCCURRENCES OF CONGRUENT LEXICALIZATION

FIGURE 4.33 -EXAMPLES OF ROMANI WORDS TRANSLATED OR EXPLAINED IN THE SCRIPT

FIGURE 4.34 -REITERATIONS BY THE SAME CHARACTER..................121

FIGURE 4.35 -REITERATIONS BETWEEN TWO CHARACTERS..............123

FIGURE 4.36 -CONJUNCTIONS AND REITERATIONS........................125

FIGURE 4.37 -RESPONSES TO QUESTIONS WITH ADVERBS.................126

FIGURE 4.38 -RESPONSES TO QUESTIONS WITH ADVERBS AND

REITERATIONS

FIGURE 4.39 -RESPONSES TO QUESTIONS WITH REITERATIONS...........128 


\section{Chapter I}

\section{INTRODUCTION}

As the population in the United States continues to become more and more heterogeneous, the famous melting pot, each ethnic group that makes it up possesses and contributes unique characteristics. One of those characteristics is, undoubtedly, the language(s) each group uses and how its members utilize them. As a member of the Latino community, I rely on English, Spanish, or both, to communicate with family, peers, and colleagues. My studies at Portland State University have made me more aware of my own language usage and the prevalence of certain linguistic phenomena occurring when languages come in contact.

This study examines the use of codeswitching (CS) and borrowing (B) in a bilingual play in order to further knowledge and understanding in the field of linguistics with regard to these two phenomena, as well as to document how playwrights make use of CS and B to tell a story. The analysis of the script of the bilingual play Mi Vida Gitana 'My Gypsy Life’ (Malán, 2006) provided me an opportunity to systematically study these two phenomena. One obvious challenge playwrights face is developing a compelling plot that attracts and engages audiences, but closely tied to those artistic issues are the language choices they make to convey said story. These language choices are even more important when audiences consist of speakers with knowledge of various languages because careless choices have the potential to leave audiences feeling lost and unaware of critical elements from the story. Dañel Malán-founder, artistic director, and primary playwright at Teatro 
Milagro in Portland, Oregon-faces these challenges. With the growth of immigrants accessing cultural events and other community members becoming proficient in various languages, bilingual audiences are on the rise; however, there is still a group of theatregoers who are monolingual in English or Spanish. Reaching all sectors of the audience necessitates a careful use of both languages. One way to achieve this goal is by having characters engage in CS.

\section{Research Questions}

There have been numerous theories developed to try to explain the grammatical and structural implications of CS and B (Callahan, 2002, 2004; Lipski, 1985; Muysken, 2000; Myers-Scotton, 1993a; Poplack, 1980). At the same time, sociolinguists have approached these two phenomena from the perspective of functionality, identity formation, and social consequences (Gumperz, 1982; Jonsson, 2010; Myers-Scotton, 1993, 1998a, 1998b, 1998c). In recent years, a movement toward the analysis of CS and B from both perspectives has started. Toribio (2002) acknowledged the importance of concentrating on the two perspectives guiding CS research "the syntactic, providing insights into the linguistic principles that underlie the form that code-switched speech takes, and the sociolinguistic, which relates linguistic form to function in specific social contexts" (p. 89). The specific models used in the current study and the motivation for selecting them will be further explained in the next two chapters, but I was particularly attracted to Muysken's (2000) three-tiered typology because of its novelty and its apparent thoroughness in accounting for CS occurrences. 
In light of the existing research on the topic, which will be shortly presented in the literature review, the purpose of this study is to provide additional data regarding $\mathrm{CS}$ and B involving English and Spanish by combining the structural and functional/sociolinguistic perspectives. I will focus the analysis on relevant data to answer the following research questions:

1. What is the frequency with which CS occurs throughout the script?

2. What specific types of elements are most commonly codeswitched, and how are they used?

3. What is the function, if any, of CS with respect to character development?

4. How does CS contribute to communicating an understandable message to diverse audiences?

Chapter 2 consists of a review of literature pertaining to the two approaches commonly used to analyze CS and B. It concludes with a discussion about CS and B in literary discourse and the possibility of combining various approaches to provide a unique, more complete understanding of these linguistic phenomena. Chapter 3 discusses, in detail, the research methods used to collect, code, and analyze data in order to generate answers to the research questions noted above. The results of this study are presented and discussed in Chapter 4. Chapter 5 is the final chapter and contains the answers to each research question posited in this study, accompanied by a 
summary of the results from the previous chapter. The study concludes with a discussion of the research's relevance in relation to the teaching of languages and CS research, the applicability of the models to current data, the limitations of the study, and suggestions for further research. 


\section{Chapter II}

\section{LITERATURE REVIEW}

In order to justify the current study, this review of the relevant literature is organized into five sections: definitions of codeswitching (CS) and borrowing (B), CS from a structural point of view, CS from a functional/sociolinguistic viewpoint, and CS in literary discourse. The fifth and final section describes the motivation behind this study based on the information from the four preceding sections.

\section{Definitions}

This brief section presents the points of view of various scholars in relation to CS and B and concludes with a discussion of the difficulties in accurately distinguishing occurrences as instances of one or the other phenomenon.

\section{Codeswitching}

In her introductory textbook to bilingualism, Myers-Scotton (2006) provided a general definition of CS as "the use of two language varieties in the same conversation" (p. 239). Other scholars have also identified this language phenomenon and labeled it likewise. Silva-Corvalán (1982) defined CS “as the use of two or more languages by one speaker in the same turn of speech or at turn-taking points" (p. 73). Muysken (2000) echoed Myers-Scotton's and Silva-Corvalán's definitions of CS by using the term to mean "the rapid succession of several languages in a single speech event" (p. 1). He also pointed out the importance of identifying the occurrence of multiple languages in one sentence and used the term "code-mixing to refer to all cases where lexical items and grammatical features from two [or more] languages 
appear in one sentence" (p. 1). Making a similar distinction but using different labels, Myers-Scotton continued her explanation of CS by making a distinction between intersentential and intra-sentential switches, that is, alternations occurring between sentences and within sentences, respectively. While analyzing English-Spanish CS, Lipski (1985) also made this distinction and explained it by saying

intersentential switching consists of shifting languages at sentence boundaries which are frequently principal discourse markers.... [while] intrasentential language shifting involves the shift from L1 to L2 in the middle of a sentence, often with no interruptions, hesitations, pauses, or other indications of a major categorical shift. (p. 2)

The script of Mi Vida Gitana 'My Gypsy Life' contains instances of both types of CS, inter-sentential and intra-sentential; however, the two categories will not be considered separately for this study, unless a specific point is being made.

\section{Borrowing}

Myers-Scotton (2006) also devoted a chapter of her textbook to the issue of B, which she defined as "the process when one language takes in words from another language" (p. 209). Once again, other scholars have shared this perspective and understanding of $\mathrm{B}$. While discussing issues of transferability and interference in relation to language acquisition, Silva-Corvalán (1990) considered B "the replacement of a form in language $\mathrm{S}$ with a form from language $\mathrm{F}$, or the incorporation from language $\mathrm{F}$ into language $\mathrm{S}$ of a form (with or without its associated meaning) previously absent in S" (pp. 163-164). In addition to these definitions, Myers-Scotton (2002) has also provided two categories to better understand occurrences of this phenomenon: cultural and core. She offered a simple, yet useful definition for both 
types: "cultural borrowings are words for objects and concepts new to the culture.... [while] core borrowings are words that more or less duplicate already existing words in the L1" (p. 41). As was the case with inter-sentential and intra-sentential CS, for the purposes of this study, both types of B will be analyzed as cases of a single phenomenon.

\section{Distinguishing Codeswitching from Borrowing}

In many cases, $\mathrm{CS}$ and $\mathrm{B}$ are analyzed as separate, unique phenomena. One reason for this distinction is the distinct level of integration evidenced in these processes. Gumperz (1982) contended that "borrowing[s] are incorporated into the grammatical system of the borrowing language.... They are treated as part of its lexicon, take on its morphological characteristics and enter into its syntactic structures" (p. 66). In addition, phonological integration has been considered a determining factor in differentiating CS from B by many analysts, including Poplack (1980). In her seminal study of English-Spanish CS, she argued utterances "which preserve English phonological patterns, were considered examples of code-switching . .. while segments ... which are adapted to Puerto Rican Spanish patterns, were considered to be instances of monolingual Spanish discourse" (p. 583), and, therefore, treated as B.

Myers-Scotton challenged Poplack's claim directly (and Gumperz's argument indirectly) by presenting data showing that not all cases of B showed phonological integration (1992, p. 31). Based on her data, she also argued that CS and B "undergo similar, if not identical, morphosyntactic procedures" (p. 37). It is the work of Myers- 
Scotton that has motivated other scholars to view CS and B as processes along a single continuum. In the introduction to her book, Eastman (1992) earlier stated "there is very little reason to make a distinction between the processes. Neither morphosyntactic nor phonological integration criteria remain viable ways to decide whether embedded language material is the result of borrowing or codeswitching" ( $\mathrm{p}$. 3). Likewise, McClure (1998) noted that words and phrases did not fit perfectly into a formula that accurately categorized them as CS and B. She quoted Gardner-Chloros (1987) as saying

if it is an innovation on the speaker's part, it is code-switching. . . . If it is frequently used in that community then it is at least on its way to becoming a loan [in other words, borrowing]. In short, a loan is a codeswitch with a full-time job.(as cited in McClure, 1998, p. 131)

Thus, borrowed forms have become part of a language's lexicon, as Gumperz noted. For example, the words "data," "seraphim," "institution," "pasta," and "burrito" are all borrowings into English. Such well-established borrowings are not a concern of this study. Nonetheless, in light of the similarities that characterize CS and B, this study will identify and highlight instances of both, but it will not seek to explain how they behave differently with respect to structural and grammatical issues or how they accomplish social functions dissimilarly. In addition, I will employ the term CS as a cover term to refer to both $\mathrm{CS}$ and $\mathrm{B}$, that is, occurrences of phenomena resulting from two or more languages coming into contact, unless I need to make a specific claim and labeling occurrences as B would make such a claim clearer. 


\section{Codeswitching from a Structural Point of View}

Some earlier linguists considered CS a haphazard and erratic linguistic characteristic of bilingual speakers. While providing a chronological account of CS research, Hughes, Shaunessy, Brice, Ratliff, and Alvarez McHatton quoted the work of Cheng and Butler "code switching is considered a sign of limited language proficiency in one or both languages" (1989, as quoted in Hughes et al., 2006, p. 8). However, other scholars saw this linguistic behavior in a completely different light. Jacobson (1998) stated:

the alternation of codes in bilingual discourse is more than a random phenomenon occurring now in a language and then in the other but is rather a structured mechanism of selection of two or more languages in the construction of sentences. (p. 1)

Likewise, Lipski (1985) argued "code switching is a rule-governed form of linguistic behavior, and not an unprincipled confusion" (p. 17). Two decades later, Liebscher and Dailey-O'Cain (2005) echoed this statement and went even further by claiming "it is clear that code-switching ... is a characteristic feature of bilinguals' speech rather than a sign of deficiency in one language or the other" (p. 235). Throughout the eighties and early nineties, scholars were interested in developing a theory or framework that could explain the grammatical structures observed in these phenomena. It was not uncommon for scholars to make claims about the universality of grammatical rules governing CS. Poplack (1980) was one such scholar who proposed two constraints applicable in CS analysis: the free morpheme and the equivalence constraint. The first constraint stated "codes may be switched after any constituent in discourse provided that constituent is not a bound morpheme" (pp. 585- 
586). The equivalence constraint declared "code-switches will tend to occur at points in discourse where juxtaposition of $\mathrm{L}_{1}$ and $\mathrm{L}_{2}$ elements does not violate a syntactic rule of either language" (p. 586). Although these principles held true for Poplack's data, Jacobson (1998) guided his readers through some of the shortcomings of these constraints and mentioned that neither one held true when researchers analyzed nonIndo-European languages. He then made reference to Myers-Scotton's models and how they seemed to apply across languages. However, he cautioned readers "that one does not yet have enough information on all language settings where codeswitching occurs to make sweeping statements in terms of what is universally valid" (p. 3). These words of caution were influential in narrowing the scope of this current study and they were kept in mind when, and if, any generalizations or claims were made beyond what was observed in the data analyzed.

\section{Myers-Scotton's Matrix Language Frame (MLF) Model}

Even though Myers-Scotton recognized the changing nature of her models, in terms of how new findings were utilized to assess and update those models, she generated a model of syntactic constraints on CS that facilitated the analysis performed in this study. The Matrix Language Frame (MLF) model was developed in the 1990's and "its centerpiece argument is that codeswitching takes place within a frame set by the Matrix Language" (1992, p. 21). Myers-Scotton and many other scholars have used the MLF model to explain CS in such diverse language contexts as French-Dutch (Treffers-Daller, 1992), Hindi-English (Kuehlhorn, 2008), SardinianItalian (Rindler Schjerve, 1998), Swahili-English (Myers-Scotton, 2002), and even 
Spanish-English (Myers-Scotton, 2002; Callahan, 2002, 2004). Due to the success that these studies attained while applying the MLF model, I provide a brief explanation of it. Myers-Scotton has repeatedly noted that the MLF model was based on "two oppositions: the Matrix Language (ML)-Embedded Language (EL) opposition and the content-system morpheme opposition" (2002, p. 15). The first opposition means that the dominant language, the ML, is more activated and contributes more abstract structure and structure of a certain type. ... [it] sets the grammatical frame. .. . The less dominant language (the Embedded Language) participates largely by supplying lexical elements that are integrated into that frame. (pp. 15-16)

The second opposition addresses the difference between content and system morphemes, which "refers to how lexical elements are organized in the mental lexicon and differently accessed in the language production process" (p. 16). It is important to define content and system morphemes in order to better understand this opposition. “Content morphemes are the main elements conveying semantic and pragmatic aspects of messages, and system morphemes largely indicate relations between the content morphemes" (Myers-Scotton, 2002, p. 15).

Using these two oppositions, Myers-Scotton expected three types of constituents to arise in CS: ML islands, ML and EL constituents, and EL islands. Examples to illustrate these constituent types are taken from the current study's data and presented in Figure 2.1, Examples of MLF constituent types/Examples of insertion. Whenever examples are presented in the current study, a transcription of the actual text is provided first and the translation of the utterance follows. The number appearing in parenthesis, the turn number, serves a dual purpose: it signals the text 
was taken directly from the script (those lines followed by a turn number), and it also gives the reader an idea as to where in the script the particular occurrence of CS took place. Indented lines without a turn number after them represent translations/glosses. In addition, whenever applicable, the particular CS elements relevant to the example illustrated are italicized for clarity.

Figure 2.1 Examples of MLF constituent types/Examples of insertion

a. ML island

Charlie: I wanna check it out... (\#7)

b. ML and EL constituents

i. Charlie: .... and what were you doing, mother...having a manicure with your españoles pals... (\#39)

Charlie: ....and what were you doing, mother...having a manicure with your Spanish pals...

ii. Liliana: ...We have always lived by our tradiciones. (\#181)

Liliana: ...We have always lived by our traditions.

c. EL island

Liliana: On the night of the wedding everyone brings gifts...todas cosas elegantes... (\#281)

Liliana: On the night of the wedding everyone brings gifts... all elegant things ...

Examples 'a' and 'c' in Figure 2.1 show that ML and EL islands are well formed according to their respective grammars. Examples 'b.i' and 'b.ii' in the same figure illustrate that the ML and EL constituents are well formed according to the ML grammar, which in both cases is English. In example 'b.i,' English provides the overall structure for the utterance-evidenced by the adjective-noun English word order-and Spanish simply contributes the content morpheme "españoles" 'Spanish.' Example 'b.ii' shows that English is also the ML because it sets up the structure of the sentence and provides all system morphemes, i.e., "we," "have," "-ed," "by," and 
"our." On the contrary, Spanish supplied only a single lexical item, the content morpheme "tradiciones" 'traditions,' and, therefore, was deemed the EL. The morpheme "our" is of particular importance in this example because, as the determiner of the noun phrase in which the EL element is inserted as its head, it signals even more clearly that English is the ML. Example ' $c$ ' is quite different from b because the Spanish EL island follows Spanish word order-noun-adjective-and contains two system morphemes from that language. The system morphemes are "todas" 'all' and the bound morpheme "-s," which is a necessary plural marking in the quantifier, noun, and adjective in order to make this a well-formed Spanish utterance. The occurrence of both system and content morphemes in the utterance however does not represent an issue for the MLF model. As Myers-Scotton stated, EL islands parallel ML islands and could contain system and content morphemes in order to result in a grammatically sound structure (1992, 1993a; Callahan, 2002, 2004).

\section{Muysken's Typology of CS Types}

Muysken is another scholar who has sought to explain CS phenomena from a structural perspective. Partly as a reaction to Myers-Scotton's work, he developed a framework to account structurally for instances of CS. He identified three separate processes-insertion, alternation, and congruent lexicalization-that could be at work depending on structural conditions and the specific bilingual setting (2000, p. 3). Here, I provide a preliminary definition of these categories and an illustration of each. However, in order to better understand the three processes identified by Muysken, an overview of the features and characteristics that signal the occurrence of insertion, 
alternation, and congruent lexicalization is presented later on. Insertion is the process by which elements from one language are put into a base structure of another language. Using earlier versions of Muysken's framework, Treffers-Daller (1998) classified certain CS occurrences as being of "the insertional type, in that a matrix structure can be distinguished into which elements of the guest language are inserted" (p. 180). Example b in Figure 2.1, Examples of MLF constituent types/Examples of insertion, illustrate this type of CS. Alternation is the process where two languages have a separate structure and elements from each language are uttered in succession and follow the constraints of the language they are drawn from. Treffers-Daller also found that in English-Spanish CS "alternation may be the predominant pattern. ... no clear base language can be distinguished" (p. 180). Figure 2.2 shows an occurrence of this CS type.

Figure 2.2 Example of alternation

Rose: ... fuimos de vacaciones, and then I felt like I was home again. I couldn't leave. Nunca lo entenderías. (\#20)

Rose: ...we went on vacation, and then I felt like I was home again. I couldn't leave. You would never understand it.

Congruent lexicalization is the third CS process in which lexical elements from each language enter into a shared grammatical structure. Muysken himself described congruent lexicalization as

a situation where the two languages share a grammatical structure which can be filled lexically with elements from either language. . . . [Some instances of CS] could be interpreted as a combination of alternations and insertions, but the going back and forth suggests that there may be more going on. (2000, pp. 6-7) 
Figure 2.3, Example of congruent lexicalization, presents an example from the current study.

Figure 2.3 Example of congruent lexicalization

Liliana: ...tienes que cuidar a tu madre like tu papá said. (\#412)

Liliana: ... you have to take care of your mother like your father said.

\section{Insertion}

With respect to insertion, the most common elements observed are single constituents. The constituent exhibits a "nested $a b a$ structure" (where elements from language $a$ are grammatically related); it usually involves content words rather than function words; it shows various degrees of morphological integration; and, from a syntactic point of view, it tends to occur in selected functions such as objects and complements (Muysken, 2000, p. 63). Table 2.1 summarizes the various characteristics needed to classify occurrences to this category and provides examples found in the script, whenever available.

\section{Table 2.1. Diagnostic features of insertion.}

Overall Premise: A Matrix Language is maintained throughout and determines the structure of the entire utterance.

\begin{tabular}{|c|c|}
\hline Features & Examples and 'gloss" \\
\hline - $\quad$ Single Constituents & $\begin{array}{l}\text { Rose: After a week of walking veinte kilómetros a } \\
\text { day we... ( } \# 20) \\
\text { 'After a week of walking twenty kilometers a day } \\
\text { we...' }\end{array}$ \\
\hline $\begin{array}{l}\text { Exhibit a nested } a b \text { a structure ( } a \text { are } \\
\text { grammatically related or part of the same } \\
\text { clause) }\end{array}$ & $\begin{array}{l}\text { Don Armando: it will be very costly to send } m i \\
\text { primo away for an adequate... (\#364) } \\
\text { 'it will be very costly to send my cousin away for an } \\
\text { adequate...' }\end{array}$ \\
\hline Content words rather than function words & $\begin{array}{l}\text { Charlie: Having a manicure with your españoles } \\
\text { pals. (\#39) } \\
\text { 'Having a manicure with your Spanish pals.' }\end{array}$ \\
\hline $\begin{array}{l}\text { Selected Elements (usually objects and } \\
\text { complements rather than adjuncts) }\end{array}$ & $\begin{array}{l}\text { Liliana: I see pretty gypsy girl in future of gadje boy } \\
\text { (\#139) } \\
\text { 'I see pretty gypsy girl in future of non-gypsy boy' }\end{array}$ \\
\hline Show Morphological Integration & No examples found in current data. \\
\hline
\end{tabular}




\section{Alternation}

In cases of alternation, Muysken recognized that several constituents are switched. These constituents are longer and more complex, sometimes involving full sentences or clauses; they do not exhibit a nested structure because elements on either side are not related; they are often discourse particles and adverbs; they could be analyzed as tag- or emblematic switching; and, they tend to occur in peripheral positions, in other words, they are "dislocated element[s], or . . conjoined clauses" (2000, pp. 96-102). I utilized these guidelines to develop the necessary diagnostic criteria to carry on the categorization required for the current study. Table 2.2 expands on the guidelines presented above and includes a more detailed list of characteristics needed to classify occurrences to this category along with relevant examples found in the script, if available.

\section{Table 2.2. Diagnostic features of alternation.}

Overall Premise: Each element alternated, whenever it has internal structure, follows the structure of its own language; in other words, there are two Matrix Languages, each determining the structure of specific elements.

\begin{tabular}{|c|c|}
\hline Features & Examples and 'gloss' \\
\hline - $\quad$ Several Constituents in Sequence & $\begin{array}{l}\text { Rose: we are going after mass. Estoy segura que } \\
\text { tendrán muy buenas ideas. (\#4) } \\
\text { 'we are going after mass. I'm sure they will have } \\
\text { very good ideas.' }\end{array}$ \\
\hline $\begin{array}{l}\text { - } \quad \text { Exhibit a non-nested } A B A \text { structure ( } A \\
\text { are elements from the same language but } \\
\text { not grammatically related) }\end{array}$ & $\begin{array}{l}\text { Liliana: tienes que hablar con Don Armando and } \\
\text { make proposal...y entonces podemos casarnos. } \\
\text { (\#277) } \\
\text { 'you have to talk to Don Armando and make } \\
\text { proposal... and then we can get married.' }\end{array}$ \\
\hline - $\quad$ Lengthy and Complex Switches & $\begin{array}{l}\text { Don Armando: Era un arreglo perfecto. Now } \\
\text { another meeting will have to be set. (\#44) } \\
\text { 'It was a perfect arrangement. Now another meeting } \\
\text { will have to be set.' }\end{array}$ \\
\hline $\begin{array}{l}\text { - Specific Types of Elements (Syntactically } \\
\text { unintegrated, such as discourse particles } \\
\text { and adverbs). }\end{array}$ & $\begin{array}{l}\text { Liliana: } A \text { ver, it's all a [sic] français so let me } \\
\text { translate. (\#199) } \\
\text { 'Let's see, it's all in French so let me translate.' }\end{array}$ \\
\hline $\begin{array}{l}\text { - } \quad \text { Tag-Switching, Extra-Sentential, or } \\
\text { Emblematic Switching }\end{array}$ & $\begin{array}{l}\text { Charlie: Hasta la vista Frenchy. Come on mother. } \\
\text { (\#104) } \\
\text { 'See you later Frenchy. Come on mother.' }\end{array}$ \\
\hline
\end{tabular}


Table 2.2. (Con't.) Diagnostic features of alternation.

\begin{tabular}{|c|c|}
\hline Features & Examples and 'gloss' \\
\hline $\begin{array}{l}\text { - } \begin{array}{l}\text { Peripheral Switches } \\
0 \quad \text { Adverbial modification }\end{array}\end{array}$ & $\begin{array}{l}\text { Liliana: Hace mucho tiempo en la France a company } \\
\text { of soldiers was closing in... (\#289) } \\
\text { 'A long time ago in France a company of soldiers } \\
\text { was closing in...' }\end{array}$ \\
\hline $\begin{array}{l}\text { O Coordination, either phrasal or } \\
\text { clausal }\end{array}$ & $\begin{array}{l}\text { Rose: I was the famous Rosalía de la Luna, pero me } \\
\text { meti en un problema... (\#427) } \\
\text { 'I was the famous Rosalía de la Luna, but I got into } \\
\text { a problem...' }\end{array}$ \\
\hline o $\quad$ Clefting & No examples found in current data. \\
\hline $\begin{array}{ll}\text { o Fronting of objects and } \\
\text { complements }\end{array}$ & No examples found in current data. \\
\hline o Left-dislocation & No examples found in current data. \\
\hline $\mathrm{O}$ Right-dislocation & No examples found in current data. \\
\hline $\begin{array}{ll} & \text { Flagging or Specially Marked Mixing }\end{array}$ & $\begin{array}{l}\text { Liliana: find another way out. } A y, \text { Grandmére, } \\
\text { espero que... (\#1) } \\
\text { 'find another way out. } O h \text {, Grandmother, I hope...' }\end{array}$ \\
\hline - $\quad$ Non-Selected Elements & $\begin{array}{l}\text { Liliana: Tú no estás solo, we are orphans together. } \\
\text { Atados por el destino. (\#213) } \\
\text { 'You're not alone, we are orphans together. United } \\
\text { by destiny.' }\end{array}$ \\
\hline - $\quad$ Correction or Self-Repair & $\begin{array}{l}\text { Charlie: Cas. Get married? (\#278) } \\
\text { 'Get marr. Get married?' }\end{array}$ \\
\hline $\begin{array}{l}\text { Embedding in Discourse (Alternation can } \\
\text { also take the form of across or between- } \\
\text { turns switching) }\end{array}$ & $\begin{array}{l}\text { Charlie: But didn’t you have... family? (\#176) } \\
\text { Liliana: Tenía a mis abuelos... (\#177) } \\
\text { "I had my grandparents...' }\end{array}$ \\
\hline - $\quad$ Doubling & $\begin{array}{l}\text { Liliana: ...por favor, please. }(\# 381) \\
\text { '...please, please.' }\end{array}$ \\
\hline
\end{tabular}

\section{Congruent Lexicalization}

The underlying characteristic of congruent lexicalization is that the languages

involved share a common syntactic structure which results in the following features:

linear and structural equivalence; multi-constituent switching, as well as non-

constituent mixing (single words within a shared structure); occurrence of non-nested

structures, because there is no matrix or dominant language; switches consisting of all

categories, including content and function words; bi-directional and back-and-forth

switching; and, in some cases, homophonous diamorphs and morphological

integration (Muysken, 2000, pp. 128-134). Similar to the tables presented for insertion 
and alternation, I organized the above guidelines in Table 2.3 in order to present the

features in a more visual manner along with relevant examples taken from the script.

\section{Table 2.3. Diagnostic features of congruent lexicalization.}

Overall Premises: Both languages share the grammatical structure of the sentence; the vocabulary comes from two or more different languages; the alignment of major constituents is shared (but not all internal structure of these constituents necessarily).

\begin{tabular}{|c|c|}
\hline Features & Examples and 'gloss' \\
\hline - $\quad$ Linear and Structural Equivalence & $\begin{array}{l}\text { Liliana: tal como tú vas a pelear en la guerra, mi } \\
\text { gente will risk everything hasta morir por amor. } \\
\text { (\#285) } \\
\text { 'just like you go to fight in a war, my people will risk } \\
\text { everything even dying for love.' }\end{array}$ \\
\hline Multi-constituent Switching & $\begin{array}{l}\text { Liliana: ...y mi mamá taught me how to read estos } \\
\text { poemas. (\#195) } \\
\text { '... and my mother taught me how to read these } \\
\text { poems.' }\end{array}$ \\
\hline Non-Constituent or "Ragged" Switching & $\begin{array}{l}\text { Liliana: Tú no entiendes, mi grandmére wrote. } \\
\text { (\#183) } \\
\text { 'You don't understand, my grandmother wrote.' }\end{array}$ \\
\hline $\begin{array}{l}\text { Non-nested } a b a \text { elements (because the } \\
\text { languages } a \text { and } b \text { are structurally equal) }\end{array}$ & $\begin{array}{l}\text { Liliana: Tú no entiendes, mi grandmére wrote. } \\
\text { (\#183) } \\
\text { 'You don't understand, my grandmother wrote.' }\end{array}$ \\
\hline $\begin{array}{l}\text { - All word categories can be switched: } \\
\text { Content and Function }\end{array}$ & $\begin{array}{l}\text { Liliana: porque tienes que cuidar a tu madre like tu } \\
\text { papá said. (\#412) } \\
\text { 'because you have to take of your mother like your } \\
\text { father said.' }\end{array}$ \\
\hline - $\quad$ Selected Elements & No examples found in current data. \\
\hline - $\quad$ Bi-directional Switching & $\begin{array}{l}\text { Don Armando: Todo el mundo knows that you killed } \\
\text { mi primo, y ningún Romani creerá... (\#348) } \\
\text { 'The entire world knows that you killed my cousin, } \\
\text { and not even one Romani will believe...' }\end{array}$ \\
\hline Frequent Back-and-Forth Switches & No examples found in current data. \\
\hline Presence of Homophonous Diamorphs & No examples found in current data. \\
\hline Morphological Integration & No examples found in current data. \\
\hline Triggering (or Priming) & No examples found in current data. \\
\hline Mixed Collocation and Idioms & No examples found in current data. \\
\hline
\end{tabular}

\section{Lipski's Model of CS}

A third scholar who developed a model to account for the structural aspects of CS was Lipski (1985). Although his research predates that of Myers-Scotton and Muysken, Lipski's research is especially relevant to this study because it analyzed occurrences of English-Spanish CS and his model falls somewhere between Myers- 
Scotton's MLF model and Muysken's typology. Lipski identified two major types of CS "the insertion of individual lexical items, to fill small gaps due to lexical unavailability or temporary unretrievability, and fluent intrasentential switching in which the discourse passes smoothly from one language to the other" (p. 15). He reported the grammatical constraints observed in earlier studies of intra-sentential CS between Spanish and English and analyzed spontaneous conversations occurring in a Houston radio program intended for the Mexican American community. Using these data, Lipski postulated and provided evidence for his syntactic equivalence hypothesis not only [does] the insertion of the switched material produce no ungrammaticality at the point of the switch, but also in order for a switch to occur, the major syntactic configurations of both Spanish and the equivalent English sentence [must] be essentially equivalent. (p. 44)

An example showing this situation is presented in Figure 2.4.

Figure 2.4 Example of syntactic equivalence

Liliana: ...y mi mamá taught me how to read estos poemas. (\#181)

Liliana: ... and my mother taught me how to read these poems.

While "taught me how to read" has a slightly different internal structure in Spanish“me enseñó cómo leer," literally, 'to me taught how to read'-, their placement within the sentence matches that of their English counterparts. Lipski's approach to explaining this type of occurrences was similar to Muysken's congruent lexicalization. "The syntactic structures following the switch point are identical in Spanish and in English, and both the English continuation and the Spanish equivalent are internally grammatical ... [even though] the internal structure of the constituents varies somewhat" (Lipski, 1985, p. 45). Lipski's study also analyzed switches according to the syntactic function characterizing the point of switch and found that the most 
frequent categories occurred at sentence or clause boundaries, before or after prepositions, with conjunctions and tag phrases, and frequently showed inserted nouns.

Given the widespread use of Myers-Scotton's model in the analysis of various language pairs compared to Muysken's typology relative novelty, I decided to employ the latter to a greater extent. Nonetheless, both frameworks were instrumental in the design of the current study and will be referred to as data collected are described and analyzed. In addition, taking into account that English and Spanish were the primary languages analyzed during this study, the results of this study will be compared to Lipski’s findings.

Codeswitching from a Functional/Sociolinguistic Point of View In addition to studying the structural aspect of CS, linguists have also sought to understand CS by analyzing the various social functions it serves or it could potentially serve. I focus the discussion here on the two models that provided the most relevant information for the current study: Gumperz's functions of conversational CS and Myers-Scotton's Markedness Model (MM). In the following section, I will mention two studies focused on English-Spanish CS involving literary texts.

\section{Gumperz's Functions of Conversational CS}

Gumperz (1982) observed switching taking place in two or more subsequent sentences as well as language changes happening within a single sentence. He argued that speakers were not necessarily conscious of or concerned with the grammaticality of such utterances, but rather they were interested in "the communicative effect of 
what they are saying" (p. 61). Using data from three language pairs-English-Hindi, English-Spanish, and German-Slovenian, Gumperz identified some of the conversational functions of CS. These were labeled quotations, addressee specification, interjections, reiterations, message qualification, and personalization versus objectivization (pp. 76-81). One of these functions, message qualification, is illustrated in Figure 2.5, in which Rose provided further explanation of what she meant when saying that Charlie was a gypsy.

Figure 2.5 Example of conversational functions of CS

Rose: ...you are a gypsy, because you are my son, el hijo de una pura gitana española... (\#425)

Rose: ...you are a gypsy, because you are my son, the son of a purebred Spanish gypsy...

While these functions were useful to discuss CS, Gumperz recognized that "to attempt to set up language usage rules which predict or reliably account for the incidence of code switching proves to be a highly difficult task" (p. 82). However, the communicative functions of CS identified by Gumperz are relevant to this study, particularly when considering how the artistic and literary message of the script is conveyed to the audience. At the same time, it is important to mention that functional accounts are by definition incomplete, in the sense that it is always possible that new functions will emerge. Likewise, any discussion of functions must be carefully conducted in order to avoid psychologizing, i.e., attributing motives to speakers in ways that can never be verified or falsified. Nonetheless, analyzing the functions served by CS could generate a new understanding of this language contact phenomenon. 
In a similar vein, Koike (1987) sought to "explore how Chicano bilinguals use the codes available to them in the context of a spontaneous oral narrative" (p. 148). The author suggested:

the ability to use the two codes is an option that the bilingual speaker can use to express ... [ [his or her] views and attitudes, and to make the narration more vivid to the bilingual listener by helping [to] recognize the transitions in the narrative. (p. 153)

The conclusions arrived at by Koike afforded a glimpse into some of the social functions of CS in a more naturalistic environment and, because of the languages studied, were of particular interest to the foundation of this study. Although some of the functions of CS identified in Gumperz and Koike's studies are applicable to this study, the nature of the data motivated me to search for an alternative model or approach for analyzing CS that could provide another perspective. Myers-Scotton's (1993b, 1998a, 1998b) Markedness Model (MM) was a useful model during the current investigation.

\section{Myers-Scotton's Markedness Model (MM)}

The basic claims of the MM are that of intentionality and optimization. In terms of intentionality, Myers-Scotton stated "speakers . . . are making choices that reflect their social group memberships or the type of speech event in which they are participating or the structure of the event" (1998a, p. 19). It should be noted that Myers-Scotton's notion of rational choice is, at best, metaphorical in that she gives no procedures for determining or assigning motives. With regard to optimization, she postulated that "under the MM, the goal of speakers is to enhance rewards and minimize costs; in two words, the goal is to optimize" (1998a, p. 19). In an earlier 
presentation of the same model, Myers-Scotton (1993b) summarized these two claims by saying "speakers have a sense of markedness ... but choose their codes based on the persona and/or relation with others which they wish to have in place" (p. 75).

In order to better understand the notions of markedness and unmarkedness, frequency of use comes into play. In Myers-Scotton's words “the more unmarked member of a set is that which occurs more frequently" (1998b, p. 5). Similarly, she claimed that marked and unmarked choices corresponded to the expectations and norms of specific communities and in specific contexts; in other words, the speakers and topics determined whether certain linguistic behavior was viewed as marked or unmarked (p. 5). She proposed, "all code choices can ultimately be explained in terms of such speaker motivations" (1993b, p. 113), in which "such speaker motivations" refer to indexing or bringing about a specific set of rights and obligations. This principle, she claimed, resulted in "one of four related types [of CS]: (1) CS as a sequence of unmarked choices; (2) CS itself as the unmarked choice; (3) CS as a marked choice; and (4) CS as an exploratory choice" (pp. 113-114). The first two types are related to the change or the continuation of situational factors, respectively, and are also labeled sequential unmarked CS and unmarked CS. An example of the first type is presented in Figure 2.6 in which Don Armando engages in CS to show his approval of Liliana's behavior.

\section{Figure 2.6 Example of sequential unmarked CS}

Liliana: ... Just how much money we can make is all I think of. (\#114)

Don Armando: Tienes una buena alma... I give you my permission... (\#115)

Don Armando: You have a good soul... I give you my permission... 
The conditions posed by Myers-Scotton (1993b) for the second type of CS, unmarked CS, to occur are present in many interactions between Don Armando and Liliana-the interaction must involve bilingual peers; CS symbolizes the dual membership of the speakers; and the speakers must positively evaluate the indexical values of the varieties (p. 119). Figure 2.7 illustrates this type of CS.

Figure 2.7 Example of unmarked CS

Liliana: No sé, Capitán...I could make some good money with him. (\#108) Don Armando: Cuidado, no puedes mahrime. We have too much invested to have you ruin it... (\#109)

Liliana: I don't know, captain...I could make some good money with him. Don Armando: Be careful, you can't become impure. We have too much invested to have you ruin it...

It should be noted that Myers-Scotton (1993b) also recognized a structural difference between sequential unmarked CS and unmarked CS. The former is typically found in inter-sentential occurrences, while the latter "may more typically include a good deal of intra-sentential switching" as well as alternating sentences (p. 125).

The third type of CS, labeled marked CS for short, "occurs when a speaker wishes to negotiate a rights and obligations set other than the unmarked one" (MyersScotton, 1993b, p. 149). Two examples showing this type of CS are presented in Figure 2.8.

Figure 2.8 Examples of marked CS

a. Liliana: ... That horrible gadje woman was so mean to me! (\#332)

Liliana: ... That horrible non-gypsy woman was so mean to me!

b. Liliana: What happened to your father? (\#207) Charlie: Murió en Irak, le dispararon. I'm supposed to go there too and die like him. (\#208)

Charlie: He died in Iraq, they shot him. I'm supposed to go there too and die like him. 
Throughout the script, the majority of utterances consisted of English and/or Spanish words; however, in example 'a,' the Romani word "gadje" 'non-gypsy' was used to refer to a character that did not belong to that ethnic group and using this word seemed to bring up a certain connotation. As Myers-Scotton put it, "marked CS [could] indicate a range of emotions from anger to affection" (1993b, p. 132); therefore, I considered "gadje" the marked choice in this context. With respect to example 'b,' this was also considered a case of marked CS. Charlie usually spoke English to Liliana and she had just spoken English to him. However, in this turn, Charlie began in Spanish arguably to generate more empathy from her. Myers-Scotton explained that "marked choices are meant to call attention to themselves.... the content of a marked choice is often a repetition of what has already been said" (1993b, p. 141). The repeated elements in this case were "murió" 'he died' and "die like him."

Exploratory CS, the last type identified by Myers-Scotton, was defined as the language choice made by speakers when they "are not sure of the expected or optimal communicative intent, or at least not sure which one will help achieve their social goals" (1993b, p. 142). The example presented in Figure 2.9 illustrates how Charlie employed French in one of his first encounters with Liliana upon learning that she comes originally from France.

Figure 2.9 Example of exploratory CS

Charlie: So where do you come from? (\#85)

Liliana: De la France. (\#86)

Charlie: Parlez-vous français? (\#87)

Liliana: Plus ou moins, more or less... (\#88)

Liliana: From France.

Charlie: Do you speak French?

Liliana: More or less, more or less... 
Codeswitching in Literary Discourse: A Structural and Functional Analysis Before concluding this literature review, it seems appropriate to briefly describe the works of Callahan $(2002,2004)$ and Jonsson $(2010)$ because of their relevance to the current study. Callahan successfully applied the MLF model, which was originally designed to account for CS occurring in conversation, to explain CS in written texts. She analyzed 30 literary texts containing various instances of CS and demonstrated that Matrix versus Embedded Language and content versus system morphemes distinctions were applicable to English-Spanish CS. Callahan also mentioned the difficulty of accounting for B as a separate process from CS by saying "reclassification of various words as borrowings in order to maintain the integrity of EL islands ... seems to have no merit other than the salvation of data" $(2002$, p. 12). It was this type of reasoning that validated my decision not to try to separate these two processes. Another point made by Callahan was that "a significant part of this corpus consists of representations of dialogue and oral style narrative, and so it is natural that codeswitching in such texts should mimic that heard in speech" (2002, p. 11). This argument was also considered when conducting the current study because of the similarity of the data and possible results.

Jonsson (2010) studied "how and why code-switching is used in Chicano theater" by analyzing three published plays written by Cherríe Moraga. Jonsson recognized "different playwrights can choose to represent Chicano discourse and code-switching in different ways. . . . some predominant aspects of Chicano speech may be left out whereas other features may be exaggerated in order to create a 
dramatic effect" (2010, p. 1297). Jonsson's focus was the functions served by CS; therefore, she based the analysis on previous work done by Gumperz. She mentioned that "three of the five loci where switching was frequent in the analyzed plays correspond to the functions that are included in Gumperz' typology . . quotations, interjections and reiterations" (Jonsson, 2010, p. 1298). The researcher was able to conclude from her data

CS fulfills creative, artistic, literary and stylistic functions in the plays and can be used to add emphasis . . . to add another level of meaning . . . to instruct the audience about a particular concept. . . CS is used to alter expressions and meanings. (2010, p. 1309)

The successes achieved by Callahan and Jonsson are of particular relevance because they involved the same languages, used one of the chosen frameworks, and/or analyzed data arising from literary texts as was done for the study at hand. It is in light of these achievements and in hopes of attaining similar results that the current study is undertaken.

\section{Making the Case}

The study of CS from a point of view that addresses both the structural and functional aspect of these phenomena has been a recent interest of linguists. Auer (1998) recognized that syntactic analysis was better suited for CS of the intrasentential type, whereas a sociolinguistic approach seemed to generate superior results when the object of study was inter-sentential CS (p. 3). Echoing Auer's claim that "neither the sociolinguistic approach not the grammatical approach explores the whole range of observed regularities in bilingual speech" (1998, p. 3), the current study seeks to provide additional insight by combining the two approaches. 
The nature of the data for this study-a script, that is, a literary text with the purpose of being performed on stage-and the diversity of typologies and models available to analyze CS motivated me to utilize a variety of elements to conduct the analysis of Mi Vida Gitana. When deciding on the best framework to use for the analysis of structural aspects of CS, I determined that elements from Muysken's threetiered typology and Myers-Scotton's MLF model, particularly the notions of matrix and embedded languages and the system-content morpheme distinction, could be combined to provide a clearer representation of CS. The rationale for this decision will be discussed in the following chapter addressing methodology.

In addition, it is important to mention that I designed my methodology in light of Kuehlhorn's (2008) study because of similarities between data. Although the languages involved were quite different, Hindi and English for her study and English and Spanish for mine, the sources of the data were comparable, a movie transcript and a theatre script, respectively. In addition, some of the goals of both studies were similar because they sought to obtain a deeper understanding of CS structures and functions. Finally, Kuehlhorn used the MLF model as a starting point for her analysis but adapted it in order to better account for the occurrences found in her data.

At first glance, the functions and concepts proposed by Gumperz and MyersScotton's MM did not appear to be applicable to the data collected for the study. As the name implies, discourse and conversation analysis is interested in naturally occurring instances of CS, but some of their claims could be used to analyze literary texts. In the words of Lipski (1985), 
while no one has claimed that written texts are equivalent, as sources of data, to spontaneous utterances, there is nonetheless a considerable amount of linguistic, psychological and aesthetic information to be obtained from a careful consideration of code switching in its literary form. (p. 74)

Likewise, Howard-Hill (1998) used the MM to successfully analyze a theatre script. He claimed characters were subject to the choices made by the playwright, but theatre audiences could still view these characters as rational actors. Furthermore, the audience could form expectations about the linguistic choices the actors would make and consider those choices marked or unmarked, in light of how the characters have been developed throughout the script (pp. 133-134). Similarly, during his discussion of linguistic choices in poems, Aviram (1998) observed:

the markedness of a literary text ... serves simultaneously to express intention and to provide the aesthetic pleasure of surprise . . but only insofar as such markedness is placed within its properly literary context and the reader [and audience] assumes the correct default expectations for what would be unmarked. (p. 102)

In light of the above claims, the same eclectic approach was used to ascertain the functions achieved by CS in the script of Mi Vida Gitana. A combination of theories served as the foundation for this portion of the study: the typology and claims put forward by Gumperz and the MM developed by Myers-Scotton proved valuable when explaining CS from a functional point of view.

Finally, it seems appropriate to warn readers that certain scholars would not consider Mi Vida Gitana a Chicano play. Martínez (2002) characterized those types of scripts by saying "Chicano Theater concerns itself with the experience of MexicanAmericans in the United States" and "personal and cultural problems or struggles 
associated with being Mexican-American in U.S. society are specifically a theme" (p. 22). Nonetheless, Mi Vida Gitana constitutes a bilingual play and, therefore, instances of CS can still be accounted for using the models described here and have similar communicative and sociolinguistic functions as those recognized by some of the scholars discussed in this review of the literature. 


\section{Chapter III}

\section{METHODOLOGY}

\section{Overall Design}

The current study is an analysis of Mi Vida Gitana 'My Gypsy Life,' a play written by Dañel Malán, founder and artistic director of Teatro Milagro. The analysis has two areas of focus; the first part focuses on form while the second examines function. With regard to the first analytic task, issues dealing with form, a thorough analysis was done to determine the frequency of CS as well as the CS processes and elements found in the script. First, I used the three categories of code-mixing developed by Muysken (2000), insertion, alternation, and congruent lexicalization, to determine the extent to which the various languages interacted with each other. Second, I classified CS occurrences according to their syntactic form and function and kept tallies in order to make claims about those most commonly used in the script.

The second analytic task examined the content of utterances in order to obtain information regarding CS beyond structural issues. I paid particular attention to the presence and/or absence of CS in the language used by the various characters in order to generate hypothesis about character development. Finally, I also examined the way words from various languages were repeated, translated, paraphrased, and utilized overall for the purpose of assessing the possible effects of CS on the audience's likely comprehension of the play. 


\section{Materials}

As mentioned above, the language of Mi Vida Gitana serves as the data for this study. The play is set in present day Spain and consists of seven scenes portraying the life of four characters and the relationships that develop among one another. A brief synopsis of the plot of Mi Vida Gitana is presented in the Appendix. Teatro Milagro performed the play from January to November 2006 for a variety of audiences. The company anticipated that some members of the audience would be bilingual in English and Spanish; another anticipated group within the audience would be English monolingual; and yet a third group attending the performances would be comprised of Spanish monolinguals. This diverse audience configuration could be considered a crucial factor in the language choices made by the author. In fact, I met with the author of the script and, based on her understanding of the goals of this study, we worked in conjunction to select this particular script because it provided a good example of a bilingual play that, on the one hand, contained multiple instances of CS and that, on the other, was designed for such a complex audience. The setting of the play and the national background of its characters were also determining factors in the selection of Mi Vida Gitana because it was expected that these elements would result in language use approximating the actual use of CS. In addition, the availability of this script in print and electronic format as well as a DVD documenting an actual performance of the play were factors taken into consideration when selecting the play. 


\section{Rationale for Selection of Structural Models}

As the literature review chapter showed, two models for explaining the structural aspects of CS were particularly relevant and of interest to this study. I employed Muysken's (2000) three-tiered typology because it incorporated various theories and models developed by earlier scholars and, most importantly, because the three categories provided me with a continuum for analyzing linguistic features found in CS. I also found that the Matrix Language Frame (MLF) model developed by Myers-Scotton (1993a) was particularly useful when examining insertion occurrences because it provided clear guidelines for distinguishing between the matrix language (ML) and the embedded language (EL) and between system and content morphemes, which were helpful to identify those elements that were inserted.

Even though the work of these two scholars provided the foundation for the study, I relied more heavily on Muysken's typology for the following reasons. I expected that a good portion of the data could be accounted for using these models as originally developed, but I also anticipated that some instances of CS would extend beyond the sentence level and would need to be accounted for in order to provide a more complete description of the type of CS found in the script. Muysken's typology, although focused on "intra-sentential code-mixing [CS] and how it can help us understand language interaction" (2000, p. 1), seemed more likely to accommodate all occurrences of CS in the script. Muysken's claim that alternation could occur not only intra-sententially, but also take the form of across or between-turns switching (p. 104) was specially appealing since I knew that I needed to account for switches taking 
place between characters. In contrast, the MLF model seemed better suited for analyzing CS at the sentence level and did not seem to contain clear indications on how to account for inter-sentential CS. This was my interpretation after considering Myers-Scotton's later claim regarding what the most telling element in the analysis of CS was, "the $\mathrm{CP}$ [complementizer projection] is the unit of analysis [to which the MLF model] is easiest to apply and the one that offers comparability across examples" (2002, p. 54). Another reason why I decided to use Muysken's work to a greater extent is that by doing so, I was able to better understand the three-tiered typology he developed. The final reason for using more extensively the work of one scholar over the other is that Myers-Scotton's model had already been applied to written texts involving English-Spanish CS (cf. Callahan's 2002, 2004), whereas Muysken's typology had not been extensively employed in this context and applying it to current data could generate noteworthy observations with respect to the data and the typology itself.

\section{Rationale for Selection of Functional Models}

Mi Vida Gitana was written with the purpose of being performed on stage.

Given the specific intent for which it was written, it could be argued that the language contained in the script needed to accomplish two goals: to reach and entertain audiences and to communicate a message clearly. Myers-Scotton's (1993b, 1998a, 1998b) Markedness Model (MM) was considered for this part of the study, particularly, those points that related to the analysis of literary or artistic language. As mentioned in the previous chapter, her model had been applied to written texts and 
was useful to establish how CS aided in accomplishing the two goals previously stated. In addition, my desire to investigate how CS could impact audience members that did not personally use this linguistic behavior prompted me to become familiar with the work of conversation and discourse analysts who had addressed the phenomena of CS. As a result, Gumperz's (1982) work was influential in the selection of a framework to be used for the functional analysis of CS; however, I was especially attracted to the work of Jonsson (2010) because, as presented in the previous chapter, her data set was similar to mine and she analyzed them successfully employing Gumperz's functions. I utilized Jonsson's work as a starting point but modified it and selected specific focus areas that were relevant and applicable to the data at hand.

\section{Data Collection and Coding}

An electronic version of the script was graciously provided by the author and was stored and organized using word processing and spreadsheet software. The script contained dialogues and monologues, some of which were voiceovers or pre-recorded utterances. In total, there were 459 turns distributed as follows among the characters:

- Charlie: 183 turns;

- Liliana: 157 turns;

- Rose: 80 turns;

- Don Armando: 36 turns; and

- Charlie's Dad: 3 turns.

I defined a turn as any utterance that showed a speaker change; for example, during a dialogue between Charlie and Liliana, every time that one character had the 
floor was considered a new turn. Each of the 459 turns was compared to the preceding turn, when applicable, in order to determine the frequency of between-turn switches and between-turn continuity. In other words, the focus was the transition between the end of an utterance and the following one. Examples of between-turn switches and between-turn continuity are illustrated in Figures 3.1 and 3.2, respectively.

Figure 3.1 Example of between-turn switch

Charlie: ... you call your violin grandpére? (\#194)

Liliana: Sí, era de grandpére...(\#195)

Charlie: ...you call your violin grandfather?

Liliana: Yes, it was grandfather's...

The situation presented in Figure 3.1, on the one hand, demonstrates how Charlie finished his turn in French, “grandpére” 'grandfather,' and Liliana started her turn in Spanish, "Sí" 'Yes.' Since Charlie's utterance is followed by the use of another language on the part of the interlocutor, this type of situation was considered a between-turn switch. On the other hand, the example illustrated in Figure 3.2 shows the opposite behavior: Charlie ended his turn with an English clause-"sorry I cared"and Liliana also began her turn with English-“I don't need..." Given that the language used by both interlocutors is the same one, this type of interaction was deemed between-turn continuity.

Figure 3.2 Example of between-turn continuity

Charlie: Well, excuse me for trying to help you out... sorry I cared. (\#67)

Liliana: I don't need hero gadjes looking out for me... (\#68)

Liliana: I don't need hero non-gypsy looking out for me... 
A third type of situation involving between-turn phenomena resulted when neither a switch nor continuity was a possibility. This was the case when the turn included one of the following characteristics:

- It began a new scene.

- It began a new dialogue or interaction; in other words, the previous utterance was not directly related to the current interaction.

- It was a voice-over; that is, a narrator rather than a character was speaking.

In addition to the coding and analysis performed in relation to between-turn phenomena, the language(s) used in each turn was identified to determine within-turn switches. An example of this type of linguistic behavior is presented in Figure 3.3, Example of Within-turn Switches, and exemplifies the use of multiple languages by the same character. In this particular case, Liliana used Spanish during a portion of her turn-“Mi mamá cargó todo lo demás" "My mother carried everything else'-and continued in English-"and we walked until..."

Figure 3.3 Example of within-turn switch

Liliana: ...Mi mamá cargo todo lo demás and we walked until... (\#195)

Liliana: ...My mother carried everything else and we walked until...

It is appropriate at this point to contrast the definition of turn presented earlier with that of occurrence. Each utterance-whether consisting of a single word, a phrase, or a clause-said in a language different from the previous element was considered an occurrence of CS. This definition of CS occurrence resulted in a one-to-one relationship among turn and occurrence in cases of between-turn switches; in other words, there could only be one occurrence of CS between turns. Conversely, in 
within-turn switches, multiple CS occurrences could take place within any given turn. Whenever a character used elements from various languages, at every switch point, a CS occurrence was identified and analyzed. Figure 3.4, Example of multiple CS occurrences in within-turn switches, shows that Liliana made multiple switches within a single turn; therefore, several occurrences were analyzed from this turn-one occurrence of insertion, "gadjes" 'non-gypsy;' and two occurrences of alternation, "puedo cuidarme sola" "I can take care of myself" and "You were fighting..."

Figure 3.4 Example of multiple CS occurrences in within-turn switches

Liliana: I don't need hero gadjes looking out for me, puedo cuidarme sola. You were fighting with mommy, hey? (\#68)

Liliana: I don't need hero non-gypsy looking out for me, I can take care of myself. You were fighting with mommy, hey?

CS occurrences were classified according to the language(s) used. Given my familiarity and knowledge of standard varieties of both English and Spanish, the majority of this classification process was done independently. I relied mostly on the script to determine the appropriate language to use during this step of the data coding process. However, there were certain elements that shared the same English and Spanish spelling; therefore, I resorted to the DVD in order to check the phonology and code those occurrences in the appropriate language category. The words "euros" and "Texas" are examples of these types of occurrences, so their phonological transcription is presented immediately following the end of the utterance whenever they are used as examples in the results chapter. An example of this treatment is illustrated in Figure 3.5, Examples of phonological transcription. 
Figure 3.5 Examples of phonological transcription

a. Liliana: ... ¿y solo tienes tres euros? /juəroz/ (\#161)

Liliana: ... and you only have three euros?

b. Liliana: Charlie is going to take me to Texas /tchas/ and marry me. (\#338)

Liliana: Charlie is going to take me to Texas and marry me.

When the phonological realization in both English and Spanish was the same, as in the case of the word "Romani(s)," I relied on surrounding elements to determine the most appropriate language category in which to place those occurrences. Figure 3.6, Example of language categorization, shows two examples in which "Romanis" was considered an English (example 'a') or a Spanish (example 'b') word because of the articles that preceded it and the overall language of the utterance.

Figure 3.6 Examples of language categorization

a. Liliana: .... Lorca wrote for the Romanis, he study [sic] and lived (\#241)

b. Liliana: ...los Romanis se casan por amor... (\#283)

Liliana: ...the Romanis marry for love...

The occurrence of Arabic, French, and Romani utterances required the assistance of an informant to aid in the classification process. The author of the script assisted the researcher and provided first-hand knowledge with regard to the meaning and purpose of utterances, whenever the language of those utterances was not clearly identified.

Each and all CS occurrences were categorized as either insertion, alternation, or congruent lexicalization according to Muysken's model. I followed the guidelines presented in chapter two-Tables 2.1, 2.2, and 2.3, Diagnostic features of insertion, alternation, and congruent lexicalization, respectively-to carry on the categorization 
required for this portion of the study. One of the main diagnostics I used to differentiate among insertion, alternation, and congruent lexicalization was that of constituency. Figure 3.7 provides examples of these categories using noun phrases (NPs).

Figure 3.7 Insertion (a), alternation (b), and congruent lexicalization (c) of NPs

a. Rose: ...After a week of walking veinte kilómetros a day we became... (\#20)

Rose: After a week of walking twenty kilometers a day we became...

b. Liliana: ... school is not for los Romanis. Mi gente lee las palmas... (\#255)

Liliana: ... school is not for Romanis. My people read palms...

c. Liliana: ...porque tienes que cuidar a tu madre like tu papá said. (\#412)

Liliana: ...because you have to take care of your mother like your dad said.

Whenever a CS occurrence formed a single constituent and after it the turn continued in the original language, the element was classified as a case of insertion as in Figure 3.7.a. The same was true for instances when the CS occurrence happened at the end of the turn. However, if the turn continued in the language of the CS occurrence, that is to say, more than one constituent was involved in CS, this type of occurrence was considered a case of alternation, as in Figure 3.7.b, which stretches across sentence boundaries. Cases of congruent lexicalization were identified when the CS occurrence was not a single constituent or when the occurrence formed more than a single constituent and the turn switched back to the original language, as Figure 3.7.c shows. These criteria were applied to the data in order to classify switches consistently and to organize data in a more meaningful way considering the purposes of the study. 
Although the diagnostic feature just described and many others seemed to provide clear guidelines for the correct and unambiguous classification of all cases of CS, applying this typology to the CS in the script of Mi Vida Gitana proved to be a difficult task. Some of the challenges dealt with similar criteria for different types of CS processes. For instance, insertion criteria included switches involving only content words and a nested structure-the switch would be embedded in a ML structure whereas for congruent lexicalization Muysken mentioned that all words-content and system/function-could be found in a shared matrix structure. Likewise, one criterion for alternation occurrences was that of several constituents in sequence while a similar criterion was put forth for congruent lexicalization cases, multi-constituent switching. Throughout the next two chapters, results and conclusion, I will be referring to these difficulties and mentioning others that relate to the specific issues being discussed.

Due to the high frequency of English-Spanish CS found in the script, I also used Myers-Scotton's MFL model to help me identify the matrix and embedded languages. This model was particularly helpful in cases of insertion because it allowed me to account for single words and phrases. I paid close attention to the type of elements involved and was able to observe that single-word insertions consisted of content morphemes instead of system morphemes. In light of this, I considered singleword content morphemes EL elements. The content versus system morpheme dichotomy was more difficult to apply to CS occurrences involving phrases. However, I followed Myers-Scotton's guidelines that EL islands could have internal structure and, therefore, contain content and system morphemes. Recognizing the existence of 
these EL islands helped me to still classify them as insertion occurrences. Figure 3.8 shows examples of Spanish content (example 'a,' "músico” 'musician') and Spanish system and content morphemes (example 'b,' "mi primo" 'my cousin') inserted in an English ML structure.

Figure 3.8 Embedded language: Single element (a) and island (b)

a. Liliana: ... you should be músico instead of soldier boy... (\#249) Liliana: ...you should be musician instead of soldier boy...

b. Don Armando: ... it will be very costly to send mi primo away for... (\#364) Don Armando: ... it will be very costly to send my cousin away for...

Once the language and the type of CS-insertion, alternation, or congruent lexicalization-were identified, the analysis moved to recognize the syntactic form of each occurrence. As previously mentioned in chapter two, one reason for choosing this method of analysis was the success attained by Kuehlhorn (2008) when conducting a similar study focused on Hindi-English codeswitching in a Bollywood film. Kuehlhorn modeled the analysis on a previous investigation performed by MyersScotton but recognized that "developing my own codes [for data analysis] ... helped me to 'get to know' the data" (2008, p. 34). It was my goal to accomplish similar levels of familiarity and success with current data as they were being collected, coded, and analyzed.

Single words and phrases were grouped into categories representing adjectives (adj), adverbs (adv), interjections (i), nouns (n), prepositions (p), verbs (v), and phrases involving these elements-e.g., "adjp" for adjectival phrases, "advp" for adverbial phrases, and so on. Clauses were treated separately and grouped into four mutually exclusive categories: dependent clauses (c-dep), whenever the independent 
clauses associated with them occurred in another language; independent clauses beginning with conjunctions (c-conj); independent clauses starting with adverbs (cadv); and independent clauses (c-ind), whenever one of the previous three categories did not apply. Finally, I paid attention to terms of address (TA)-a special type of noun or noun phrase-because they represented extra-sentential elements that could be used to answer some of the research questions posited in this study. Due to the intricate relationship exhibited by elements classified as congruent lexicalization, I did not use the categorization process described above but rather treated these occurrences as a unit.

Table 3.1, Examples of data coding, is presented to show how the classification and coding system was used with the actual data. I describe the organization of the table in two paragraphs, and then I walk the readers through an example from the table, turn 195. The first two columns of the table present bookkeeping information. "Tn.\#," turn number, refers to the 459 sequential turns found in the script. It was determined that maintaining a running total for the entire play instead of starting with a new number for each character would aid in the analysis, particularly when looking at between-turn switches and between-turn continuity. The next column, labeled "Ch.," character, provides the name of the character speaking during the turn. Columns three through seven present the language(s) used in the turn. The column labeled "Tn. Lang.," turn languages, lists the language(s) identified in the turn being analyzed. Whenever applicable, the language code that appears in parenthesis signifies the last language used in the preceding turn. The next four columns contain the actual 
text found in the script, organized by language-English, Spanish, French, and Romani, respectively. When more than one language occurred in the turn, the words and phrases are numbered sequentially at each language shift. Following the bracketed numbers will piece together the actual string of words uttered by the character.

The remaining columns illustrate the analysis performed for each turn. Columns eight and nine, "Between-Turn Switch" and "Between-Turn Continuity," respectively, present data that occur in complementary distribution. Whenever a character begins his or her turn in a different language from that evidenced in the previous turn's final word (an example of this type of situation was presented in Figure 3.1, Example of between-turn switch), an entry was made in the "BetweenTurn Switch" column. In contrast, if the character started his or her turn in the same language as the last word in the previous turn (an example of this type of situation was presented in Figure 3.2, Example of between-turn continuity), the entry was placed in the "Between-Turn Continuity" column. In terms of the information represented by the entries in these two columns, the column titled "Between-Turn Switch" shows the syntactic form of the elements occurring at the beginning of the turn. I did not deem necessary to label the type of CS because all between-turn switches were considered cases of alternation given that they took place among characters and, therefore, the existence of a shared structure was not possible. The codes used are included in the footnotes and consists of independent clause (c-ind), noun (n), and prepositional phrase (pp), to name a few. The next column, labeled "Between-Turn Continuity," is similar to the previous in that it identifies the syntactic form of occurrences at the 
beginning of the turn and it uses the same codes. On the other hand, it is different because the preceding and current languages are the same and, therefore, there is no CS to be accounted for. This column was necessary, nonetheless, to make sure that all turns were analyzed because between-turn continuity did not prevent CS from happening within the turn. Column ten, named "Within-Turn Switch," shows the type of CS employed and the syntactic form of elements occurring at every shift or switch point, other than the beginning of the turn. Uppercase letters indicate whether a case of insertion (I), alternation (A), or congruent lexicalization (CL) was identified.

Lowercase letters indicate the syntactic form such as independent clause (c-ind), noun (n), prepositional phrase (pp), and so on. The table's footnotes include a complete list of codes and their meanings. Finally, the last two columns of this table are labeled "Repeated Words" and show any repeated elements in English and Spanish, whether uttered by the same character or by another character in the immediately preceding turn. It is necessary to take these words into account because they could indicate a level of cohesion necessary for the understanding of the play on the part of monolingual audience members, and therefore, they would be analyzed in the context of reiterations. 
Table 3.1. Examples of data coding.

Tn.\#= Turn number; Ch. = Character; Tn. Lang. = Languages present in previous (X) and current turn X-X-X.

\begin{tabular}{|c|c|c|c|c|c|c|c|c|c|c|c|}
\hline \multirow[b]{2}{*}{ Tn.\# } & \multirow[b]{2}{*}{ Ch. } & \multirow[b]{2}{*}{$\begin{array}{l}\text { Tn. } \\
\text { Lang. }\end{array}$} & \multirow[b]{2}{*}{ English Item(s) } & \multirow[b]{2}{*}{ Spanish Item(s) } & \multirow[b]{2}{*}{$\begin{array}{l}\text { French } \\
\operatorname{Item}(\mathrm{s})\end{array}$} & \multirow[b]{2}{*}{$\begin{array}{l}\text { Romani } \\
\operatorname{Item}(\mathrm{s})\end{array}$} & \multirow{2}{*}{\begin{tabular}{|l|} 
Between- \\
Turn \\
Switch \\
\end{tabular}} & \multirow{2}{*}{$\begin{array}{c}\text { Between- } \\
\text { Turn } \\
\text { Continuity }\end{array}$} & \multirow{2}{*}{$\begin{array}{l}\text { Within- } \\
\text { Turn } \\
\text { Switch }\end{array}$} & \multicolumn{2}{|c|}{ Repeated Words } \\
\hline & & & & & & & & & & English & Spanish \\
\hline$\ldots$ & & & & & & & & & & & \\
\hline 4 & $\mathrm{R}$ & $\begin{array}{l}(\mathrm{E}) \mathrm{E}- \\
\mathrm{S} .\end{array}$ & $\begin{array}{l}{[1] \text { No, I called, they're }} \\
\text { expecting us and we are going } \\
\text { after mass. }\end{array}$ & $\begin{array}{l}\text { [2] Estoy segura que tendrán } \\
\text { muy buenas ideas. }\end{array}$ & & & & $1: \mathrm{adv}$ & 2:Ac & & \\
\hline 5 & C & $(\mathrm{S}) \mathrm{E}$ & $\begin{array}{l}\text { Don't rush me mother. I just } \\
\text { got here, at... where are we } \\
\text { again? }\end{array}$ & & & & c-ind & & & & \\
\hline$\ldots$ & & & & & & & & & & & \\
\hline 44 & DA & $\begin{array}{l}\text { (E)E- } \\
\text { S-E- } \\
\text { R-E- } \\
\text { S-E- } \\
\text { S-E-S }\end{array}$ & $\begin{array}{l}\text { [1] Then flirting with his } \\
\text { brother! [3] they must think } \\
\text { you are already [5] acting like } \\
\text { a [7] I feed you and give you } \\
\text { my floor to sleep on, and this } \\
\text { is how you repay me! [9] Now } \\
\text { another meeting will have to } \\
\text { be set. }\end{array}$ & $\begin{array}{l}\text { [2] A ese ya lo han prometido } \\
\text { a alguien más. Ahora [6] puta. } \\
\text { Sinvergüenza! ¿Qué se supone } \\
\text { que deba hacer contigo? } \\
\text { desgraciada, mal agradecida. } \\
{[8] \text {.....Era un arreglo }} \\
\text { perfecto... [10] Vas a trabajar } \\
\text { el resto de la semana sin } \\
\text { comida de mi mesa - puedes } \\
\text { mendigar por tu cena. }\end{array}$ & & $\begin{array}{l}{[4]} \\
\text { mahrime, }\end{array}$ & & $1: c-c o n j$ & $\begin{array}{l}\text { 2:Ac-ind; } \\
\text { 3:Ac-ind; } \\
\text { 4:In; 6:An; } \\
\text { 7:Ac-ind: } \\
\text { 8:Ac-ind; } \\
\text { 9:Ac-adv; } \\
\text { 10:Ac-ind }\end{array}$ & & \\
\hline 45 & $\mathrm{~L}$ & $\begin{array}{l}\text { (S)R- } \\
\text { S-R- } \\
\text { E-S. }\end{array}$ & [4] Yes, Sir & [2] Capitán, [5] Capitán, sí. & & $\begin{array}{l}{[1] \mathrm{Da}} \\
\text { Dom [3] } \\
\text { da. }\end{array}$ & $1: a d v$ & & $\begin{array}{l}\text { 2:TA; } \\
\text { 3:Aadv; } \\
\text { 4:Aadv; } \\
\text { 5:TA }\end{array}$ & yes & sí \\
\hline$\ldots$ & & & & & & & & & & & \\
\hline 63 & $\mathrm{C}$ & $(\mathrm{E}) \mathrm{E}$. & $\begin{array}{l}\text { What do you want me to do, } \\
\text { Captain? Captain! All I ever } \\
\text { wanted was to call you Dad. }\end{array}$ & & & & & c-ind & & & \\
\hline
\end{tabular}


Table 3.1. (Con't.) Examples of data coding.

Tn.\#= Turn number; Ch. = Character; Tn. Lang. = Languages present in previous (X) and current turn X-X-X.

\begin{tabular}{|c|c|c|c|c|c|c|c|c|c|c|c|}
\hline \multirow[b]{2}{*}{ Tn.\# } & \multirow[b]{2}{*}{ Ch. } & \multirow{2}{*}{$\begin{array}{l}\text { Tn. } \\
\text { Lang. }\end{array}$} & \multirow{2}{*}{ English Item(s) } & \multirow[b]{2}{*}{ Spanish Item(s) } & \multirow{2}{*}{$\begin{array}{l}\text { French } \\
\operatorname{Item}(\mathrm{s})\end{array}$} & \multirow{2}{*}{$\begin{array}{l}\text { Romani } \\
\text { Item(s) }\end{array}$} & \multirow{2}{*}{\begin{tabular}{|} 
Between- \\
Turn \\
Switch
\end{tabular}} & \multirow{2}{*}{$\begin{array}{l}\text { Between- } \\
\text { Turn } \\
\text { Continuity }\end{array}$} & \multirow{2}{*}{$\begin{array}{l}\text { Within- } \\
\text { Turn } \\
\text { Switch }\end{array}$} & \multicolumn{2}{|c|}{ Repeated Words } \\
\hline & & & & & & & & & & English & Spanish \\
\hline 64 & $\mathrm{~L}$ & $\begin{array}{l}\text { S-R- } \\
\text { S-E. }\end{array}$ & $\begin{array}{l}\text { [4] I won't make any money } \\
\text { with you here. You're scaring } \\
\text { away the customers. }\end{array}$ & [1] Oye [3] vete, & & [2] Gadje, & & & $\begin{array}{l}\text { 2:TA; } \\
\text { 3:Ac-ind; } \\
\text { 4:Ac-ind }\end{array}$ & & \\
\hline \multicolumn{12}{|l|}{$\ldots$} \\
\hline 195 & $\mathrm{~L}$ & $\begin{array}{l}\text { F-S-S- } \\
\text { F-E- } \\
\text { S-E- } \\
\text { S-E-S. } \\
\end{array}$ & \begin{tabular}{|l} 
[3] After the villagers burn \\
down our home, this was one \\
of the few things left. [5] and \\
we walked until we could \\
walk no longer. [7] taught me \\
how to read
\end{tabular} & $\begin{array}{l}\text { [1] Sí, era de [4] Fue la única } \\
\text { cosa que pude cargar, solo } \\
\text { tenía cinco años. Mi mamá } \\
\text { cargó todo lo demás, [6] Aquí } \\
\text { encontramos un lugar seguro } \\
\text { para vivir, y mi mamá [8] } \\
\text { estos poemas. }\end{array}$ & $\begin{array}{l}{[2]} \\
\text { grandpére. }\end{array}$ & & $1: \mathrm{adv}$ & & $\begin{array}{l}2: \text { In; } 3: A c- \\
\text { ind; } 4: A c- \\
\text { ind; } 5: A c- \\
\text { conj; } \\
6: A c-i n d \\
6,7,8: C L\end{array}$ & $\begin{array}{l}\text { one of the } \\
\text { few things }\end{array}$ & $\begin{array}{l}\text { la única } \\
\text { cosa }\end{array}$ \\
\hline \multicolumn{12}{|l|}{$\ldots$} \\
\hline 255 & $\mathrm{~L}$ & \begin{tabular}{l|} 
(E)S- \\
E-S- \\
E-S- \\
E-S- \\
E.
\end{tabular} & $\begin{array}{l}\text { [2] Besides [4] decides what is } \\
\text { best... [6] school is not for [8] } \\
\text { that is enough... }\end{array}$ & $\begin{array}{l}\text { [1] Yo no estoy sola. Tengo a } \\
\text { mi gente. [3] el Capitán [5] } \\
\text { Además [7] los Romanis. Mi } \\
\text { gente lee las palmas, no los } \\
\text { libros, aprenden a bailar, }\end{array}$ & & & 1:c-ind & & $\begin{array}{l}\text { 2:Ac-adv; } \\
\text { 3:Inp; } \\
\text { 5:Aadv; } \\
\text { 6:Ac-ind; } \\
\text { 7:Anp; } \\
\text { 8:Ac-ind }\end{array}$ & $\begin{array}{l}\text { on my } \\
\text { own (said } \\
\text { by C.) }\end{array}$ & estoy sola \\
\hline$\ldots$ & & & & & & & & & & & \\
\hline
\end{tabular}

Character $(\mathrm{Ch})$ codes: $\mathrm{C}=$ Charlie; $\mathrm{CD}=$ Charlie's Dad; DA = Don Armando; L = Liliana; R = Rose

Turn Language (Tn.Lang.) codes: $\mathrm{A}=$ Arabic; $\mathrm{E}=$ English; $\mathrm{F}=$ French; $\mathrm{R}=$ Romani; $\mathrm{S}=$ Spanish

Within-Turn Switch codes, CS type: I = Insertion; A = Alternation; CL = Congruent Lexicalization

Within-Turn Switch codes, syntactic form: $\operatorname{adj}=$ Adjective; $a d v=$ Adverb; advp = Adverbial Phrase; $n=$ Noun; $n p=$ Noun Phrase; $p p=$ Prepositional

Phrase; $v=$ Verb; vp = Verb Phrase; $c$-ind = Independent Clause; $c$-dep = Dependent Clause; c-conj= Clause beginning with conjunction; $c$-adv = Clause beginning with adverb; TA $=$ Term of Address; int = Interjection

Between-Turn Switch and Between-Turn Continuity codes, syntactic form: $\operatorname{adv}=$ Adverb; advp $=$ Adverbial Phrase; $\mathrm{n}=\mathrm{Noun} ; \mathrm{np}=\mathrm{Noun}$ Phrase; $\mathrm{pp}=$

Prepositional Phrase; $v p=$ Verb Phrase; $c$-ind = Independent Clause; $c$-dep $=$ Dependent Clause c-conj $=$ Clause beginning with conjunction; $\mathrm{c}$-adv $=$

Clause beginning with adverb; TA = Term of Address; int = Interjection 
By way of example, turn 195 is explained in the following paragraphs. Figure

3.9 shows the text as written in the original script and the corresponding translation.

The only difference is that numbers are included to signify each occurrence of CS.

Figure 3.9 Turn 195: Liliana

[1] Sí, era de [2] grandpére. [3] After the villagers burn down our home, this was one of the few things left. [4] Fue la única cosa que pude cargar, solo tenía cinco años. Mi mamá cargó todo lo demás, [5] and we walked until we could walk no longer. [6] Aquí encontramos un lugar seguro para vivir, y mi mamá [7] taught me how to read [8] estos poemas.

[1] Yes, it was [2] grandfather's. [3] After the villagers burn down our home, this was one of the few things left. [4] It was the only thing I could carry, I was only five years old. My mother carried everything else [5] and we walked until we could walk no longer. [6] Here we found a safe place to live and my mother [7] taught me how to read [8] these poems.

This turn, also presented in the example of data coding spreadsheet (Table 3.1), shows that Liliana's interlocutor finished his turn in French, as evidenced by the label (F) found in the "Tn. Lang." column. The progression of languages is shown in that same column and indicates switches among Spanish, French, and English (S-F-E-S-ES-E-S). The fact that Liliana begins her turn in Spanish is evidenced in the turn language column but is further reinforced by the number one in brackets located in the "Spanish Item(s)" column, which indicates that Spanish is the language she speaks turn initially. She then switches to French, as shown by the words included in the column "French Item(s)" and identified with number two in brackets. Bracketed number three is found in the "English Item(s)" column and indicates that she switches to English to begin that portion of the turn. She then switches between Spanish and English for the remainder of the turn, as can be seen by following numbers four through eight, in brackets, going from one column to the other. 
It is necessary to look at the columns labeled "Within-Turn Switch" and "Between-Turn Switch" in Table 3.1 in order to determine the CS type and syntactic form of each portion of turn 195. Number one-'Sí, era de" 'Yes, it was'-is an instance of adverb alternation; therefore, the entry is in the "Between-Turn Switch" column and labeled "adv." Number two-"grandpére" 'grandfather'-consists of insertion of a noun, thus the entry is found in the "Within-Turn Switch" column and written as "In." Parts three and four-“After the villagers..." and "Fue la única cosa..." 'It was the only thing...,' respectively-represent the alternation of two independent clauses; therefore, they are identified with the entry "Ac-ind." Number five begins "and we walked...;" it is also an alternated clause, but given that it begins with a conjunction, it is coded with the symbol "Ac-conj." Number six-“Aquí encontramos un lugar..." 'Here we found a place...'- shows another alternation of an independent clause and is labeled accordingly, "Ac-ind." The remainder of number six and numbers seven and eight-"y mi mamá taught me how to read estos poemas" 'and my mother taught me how to read these poems'-are considered an occurrence of congruent lexicalization and signaled with the label "CL." Table 3.1 also includes data in the "Repeated Words" columns for turn 195, which means that Liliana uses similar words in English and Spanish to communicate her message. Another way of representing the structural analysis performed on the data described in this paragraph is illustrated in Table 3.2, Alternative data coding chart, Turn 195. 
Table 3.2. Alternative data coding chart, Turn 195.

\begin{tabular}{|l|c|c|c|}
\hline & $\begin{array}{c}\text { Within- } \\
\text { Turn } \\
\text { Switch }\end{array}$ & $\begin{array}{c}\text { Between- } \\
\text { Turn } \\
\text { Switch }\end{array}$ & $\begin{array}{c}\text { Between- } \\
\text { Turn } \\
\text { Continuity }\end{array}$ \\
\hline [1] Sí, era de & adv & \\
\hline [2] grandpére & In & & \\
\hline $\begin{array}{l}\text { [3] After the villagers burn down our home, this } \\
\text { was one of the few things left. }\end{array}$ & Ac-ind & & \\
\hline $\begin{array}{l}\text { [4] Fue la única cosa que pude cargar, solo tenía } \\
\text { cinco años. Mi mamá cargó todo lo demás, }\end{array}$ & Ac-ind & & \\
\hline [5] and we walked until we could walk no longer. & Ac-conj & & \\
\hline [6] Aquí encontramos un lugar seguro para vivir, & Ac-ind & & \\
\hline [6] y mi mamá & CL $^{\mathrm{a}}$ & & \\
\hline [7] taught me how to read & CL $^{\mathrm{a}}$ & & \\
\hline [8] estos poemas. & CL $^{\mathrm{a}}$ & & \\
\hline
\end{tabular}

${ }^{\mathrm{a}} \mathrm{CS}$ classified as congruent lexicalization included multiple elements switched within themselves, but they were analyzed as a single occurrence.

\section{Data Analysis Procedures}

The first three research questions can be answered in part with the data organized and coded quantitatively using the system described in Table 3.1, Examples of data coding. In the case of research question one, the number of turns showing switches with respect to their preceding turn, between-turn switches, and the number of turns containing internal switches, within-turn switches, was calculated. Tallies documenting the lack of CS between turns, between-turn continuity, were also computed. These numbers were then compared to the total number of turns in order to obtain frequency figures and percentages. Although the number of occurrences was also considered and is of relevance to establish the use of CS in the script, I decided against calculating frequency numbers for occurrences due to the difficulty of 
generating consistent results. Some turns contained multiple occurrences whereas other turns did not show any occurrences of CS and, therefore, the calculation would not have included the latter.

I utilized the information contained in the "Within-Turn Switch" and "Between-Turn Switch" columns in order to answer research question two. I kept a running total of those switches classified as insertion, alternation, and congruent lexicalization. In addition, I organized the occurrences according to their syntactic form and these numbers were also tallied and computed. The second part of research question two-how the various CS elements are used-required the use of both quantitative and qualitative analyses to arrive at a satisfactory answer. Even though the quantitative method was useful to classify CS occurrences according to their syntactic form, I also wanted to find out the syntactic and/or semantic functions served by these occurrences. Therefore, I identified those functions through a qualitative process in which I tried to establish the relationship between elements of various languages. In summary, both form and function of the various CS occurrences found in the script along with representative examples are presented and described in the context of research question two.

A closer look at the frequency of switches by character and the content of those switches served to respond research question three. The numbers computed to answer research question one were expanded to obtain information for each character individually. This analysis was employed to create language-use profiles for each character, which were then compared among each other in order to determine if and 
how CS was utilized to develop characters' personas. It is important to point out that the two main characters-Charlie and Liliana-did not have the same first language. Consequently, when they uttered certain expressions in their non-native languageSpanish in Charlie's case and English in Liliana's situation, some of those utterances were not well formed.

Some of the postulations of Myers-Scotton's MM, as explained in the literature review chapter, were applied to the data for this portion of the study because the use of marked and unmarked language on the part of the characters could provide data relevant to the issue at hand. Figure 3.10 shows examples when Charlie used Spanish, a marked choice in his case, in order to plea with Liliana but replied to his mother in English, the unmarked choice in this context.

Figure 3.10 Marked (a) and unmarked (b) language choices by Charlie

a. Liliana: ...I should go. (\#167)

Charlie: No, por favor quédate... (\#168)

Charlie: No, please, stay...

b. Rose: ...I have your transcripts with me from school. (\#24) Charlie: They're worthless, Mother. I didn't finish...(\#25)

Lipski's claims regarding the value of CS in literary works are also relevant to this portion of the study. He stated that "literary code switches might not reflect the speech habits of any known bilingual community" but they "create powerful bilingual images" and contribute to the artistic or aesthetic value of the script (1985, pp. 74-75).

The first three research questions, whether focused on form or on function, provided information with regard to CS within the play; that is to say, what CS processes and elements were most frequently used and how they contributed to 
character development. I pose research question four in order to study the possible effects of CS on the audience with respect to comprehension or understanding. Gumperz argued:

[the] motivation for code switching seems to be stylistic and metaphorical rather than grammatical. The process by which meaning is conveyed must be studied in terms of the stylistic interrelationship of sentences or phrases within the passage as a whole, not in terms of the internal structure of particular sentences. (1982, p. 72)

Echoing Gumperz's claim, I developed a classification system that allowed me to analyze CS in the script beyond its structural aspects and focus rather on its content and how CS occurrences could contribute to the effective communication of the play's message. Gumperz's typology was arrived at from analyzing naturally occurring conversations, but given the nature of the data for this study-a literary work written for the exclusive purpose of performance, I decided to take only one of Gumperz's elements, namely, reiterations. Jonsson's (2010) research was similar to this study in terms of the origin and purpose of the data; therefore, I took some of the categoriesreiterations and filling gaps-she utilized with her data and applied them to mine. Finally, during the analysis carried out to answer research question two, it became apparent that some CS occurrences might have a definite effect on audience's comprehension; therefore, I utilized another category to investigate this phenomenon and labeled it "conjunctions and responses." In summary, the three categories used to organize data for research question four are reiterations, gap-filling, and conjunctions and responses. The following paragraphs provide definitions and examples for each of these categories. 
Reiterations consist of a message repeated in two languages, sometimes literally and sometimes modified, in order to clarify or expand its meaning or to emphasize a certain aspect of it (Gumperz, 1982, p. 78; Jonsson, 2010, pp. 13011303). Given that the script of Mi Vida Gitana contained several instances when words were repeated in various languages, special attention was paid to this use of CS. One example of reiterations is presented in Figure 3.11.

Figure 3.11 Example of reiteration

Liliana: I have to get married before it is too late. Tenemos que casarnos cuando somos todavía puras. (\#143)

Liliana: I have to get married before it is too late. We have to get married when we are still pure.

A second area of interest for this portion of the study was what Jonsson considered 'gaps.' The use of CS to fill gaps served a function in character development, as will be discussed in relation to research question three. Nonetheless, it is presented again in the context of research question four because incursions into the third most predominant language in the script, Romani, also contributed to helping the audience understand the story in Mi Vida Gitana. Figure 3.12 illustrates how this CS strategy was utilized in the script.

Figure 3.12 Example of gap-filling

Liliana: ... siempre tuvieron miedo de que tuviera el bibaxt. (\#189) Liliana: ...they were always afraid that she would have bad luck.

Finally, although it was not included in either of the studies previously mentioned, for the purposes of the current analysis, it was important to think about how conjunctions and responses to questions, whenever they happened in multiple 
languages, were a factor in the delivery of a comprehensible message. Figure 3.13 shows an instance of this use of CS.

\section{Figure 3.13 Example of conjunction}

Liliana: ...toco mi música, digo el futuro and acquire things for my people. (\#147) Liliana: ...I play my music, tell the future and acquire things for my people.

While research questions one, two, and three were answered through both quantitative and qualitative methods of analysis, it was clear that questions one and two were more focused on language form. On the other hand, question three, along with research question four, was focused on language function. The next chapter, Results, was designed to discuss the research questions in sequential order; therefore, prevalent mentions of form could be found in relation to the first two questions, followed by the third and fourth questions, where notions of function would be more commonly addressed. As expected, some overlap between the two focus areas occurred and was dealt with as necessary. 


\section{Chapter IV}

\section{RESULTS}

The results of the analysis are included in this chapter and organized around the four research questions posed earlier. The first two questions are presented in the first section, which addresses issues of form. Information relevant to the last two questions is presented in the section labeled analysis of function. The analysis of form section opens with a discussion of between-turn and within-turn phenomena in order to answer research question one. The next part of the analysis is directly related to research question two and presents the three types of CS processes found in the script: insertion, alternation, and congruent lexicalization. In this section, I describe and give examples of the CS occurrences observed in the script. This section concludes with a summary of the most commonly used elements in the CS that occurred in the play from a typological and a syntactic point of view.

The section titled analysis of function begins with a discussion arising directly from research question three regarding how CS is used to contribute to character development. The discussion moves on to address the issue raised in research question four, how CS contributes to communicating a comprehensible message to diverse audiences. This section closes with a summary of findings in relation to the communicative functions of CS.

Throughout the two sections, I will focus the discussion on issues relevant to the question presented in that particular section. However, as previously mentioned, some findings will have implications and relevance that extend beyond the question at 
hand. In these cases, I will include comments and observations relating to those other questions.

\section{Analysis of Form}

This section includes a discussion of phenomena exhibited in the script as it relates to turns. CS between turns and within turns is presented and used to calculate the frequency of CS in the script in order to answer research question one. The second part of this section contains numerical data and examples for each of the CS processes previously discussed: insertion, alternation, and congruent lexicalization. This information serves as the foundation for answering research question two.

\section{Research Question One}

Research Question 1. What is the frequency with which CS occurs throughout the script?

The discussion of research question one begins with a presentation of the three types of between-turn phenomena-impossibility of continuity and switch, betweenturn continuity, and between-turn switch-along with relevant examples and numerical data. The significance of characters' involvement in between-turn switches and continuity is then addressed. Next, I introduce examples and data related to withinturn phenomena for the entire script and for each character separately. Finally, between-turn and within-turn switches are summarized and utilized to generate frequency data. 


\section{Between-turn Phenomena}

Given the definition of turn presented in the methodology chapter, an utterance evidencing a speaker change, the first turn of the script was an example of a turn where the possibility of continuity or switch was nonexistent. Of the 459 turns found in the script, there were 32 where such a switch was not possible between turns for one of the reasons described in the methodology chapter and repeated here:

- The turn began a new scene.

- It began a new dialogue or interaction; in other words, the previous utterance was not directly related to the current interaction.

- It was a voice-over; that is, a narrator rather than a character was speaking and, therefore, the turn was not related to its preceding utterance.

Figure 4.1, Example of impossibility of continuity and switch, shows a case in which Don Armando began his turn in Spanish after Charlie had finished his in English. However, Charlie's utterance was not directed at Don Armando; therefore, Don Armando's words signaled the beginning of a new dialogue or interaction. The fact that Don Armando's utterance was intended for Liliana is another reason illustrating the impossibility of continuity and switch.

Figure 4.1 Example of impossibility of continuity and switch

Charlie: I think you need church more than me, hypocrite! (\#41)

Don Armando: Qué horrible melodía... Tocabas como si estuvieras en un funeral... (\#42)

Don Armando: What a horrible melody... You were playing as if you were in a funeral... 
The remaining 427 turns showed between-turn switches taking place 267 times, or $63 \%$ of the time, compared to 160 times, or $37 \%$, when a switch was possible but did not occur, that is, cases of between-turn continuity. It is important to reiterate here that classification into the categories between-turn switches and between-turn continuity was determined based on the last and first word of a turn and not on the occurrence of switches within a particular turn. This caveat is important because close to half of the 32 turns that did not have a related preceding utterance contained one or more within-turn switches as did close to half of the 160 turns that began in the same language as the previous turn. The actual numbers were 14 and 75 turns respectively, or $44 \%$ and $47 \%$. Based on these high percentages, it could be argued that the playwright was mindful of the audience's linguistic abilities and considered that this high incidence of switches would likely contribute to a better understanding of the story, an issue to which I later return.

Table 4.1. Between-turn continuity by character and language pair.

\begin{tabular}{|c|c|c|c|c|}
\hline Character & (E)E & $(\mathrm{F}) \mathrm{F}$ & (S)S & Total \\
\hline Charlie & 63 & 1 & 8 & 72 \\
\hline Don Armando & 6 & 0 & 4 & 10 \\
\hline Liliana & $34^{\mathrm{a}}$ & 1 & 6 & 41 \\
\hline Rose & $30^{\mathrm{b}}$ & 0 & 7 & 37 \\
\hline Total & 133 & 2 & 25 & 160 \\
\hline
\end{tabular}

Table 4.1 shows that 133 turns began in English after the previous turn had also ended in English. Both this high number and the characters whose turns are 
represented in this table provided some information with respect to character development. It is worth noting at this time that Charlie was involved in these exchanges 122 times, or $92 \%$ of the time, a fact that will be discussed in the context of research question three. Two English examples involving the characters that most frequently engaged in this behavior are presented in Figure 4.2.

Figure 4.2 Examples of between-turn continuity

a. Liliana: ...You are like 'simple American boy', hey? (\#74)

Charlie: American yes, simple no. (\#75)

b. Charlie: So what do you see? (\#138)

Liliana: I see pretty gypsy girl... (\#139)

Changing our focus now to the 267 times that demonstrated between-turn switches, in other words, when the language of the previous turn's last word was different from the current turn's first word, the balance between English and Spanish was noteworthy. Of 249 instances involving these two languages, 128 times a turn began in Spanish when the previous turn ended in English, whereas 121 times the reverse was true: a turn began in English when the previous turn ended in Spanish. One example from each of these two contexts is drawn from the most common characters employing this form of CS and is presented in Figure 4.3.

Figure 4.3 Examples of between-turn switches

a. Liliana: ...¿¿Has vuelto por tu futuro? (\#127)

Liliana: ... Have you come back for your fortune? Charlie: Well fortune telling is hooey, but since I don't got no ideas...(\#128)

b. Charlie: ...I'll bet you think you can read every guy like a book. (\#77) Liliana: Déjame intentar. (\#78)

Liliana: Let me try. 
Table 4.2, Between-turn switches by character and language pair, provides additional information regarding the frequency and direction of the switches. Similar to what was found when describing between-turn continuity, Charlie was involved in a high number of these cases. Charlie's language use profile will be presented and discussed when answering research question three, but it is important to point out that of the 121 turns exhibiting a Spanish to English switch, he played a part in 96 , or $79 \%$, of them. With regard to English to Spanish switches totaling 128, he participated as either the speaker-in four turns, or the addressee-in 101 turns, for a total of 105 turns, or $82 \%$.

Table 4.2. Between-turn switches by character and language pair.

\begin{tabular}{|l|r|r|r|r|r|r|r|r|r|r|}
\hline Character & $(\mathrm{A}) \mathrm{S}$ & $(\mathrm{E}) \mathrm{F}$ & $(\mathrm{E}) \mathrm{S}$ & $(\mathrm{F}) \mathrm{E}$ & $(\mathrm{F}) \mathrm{S}$ & $(\mathrm{R}) \mathrm{E}$ & $(\mathrm{R}) \mathrm{S}$ & $(\mathrm{S}) \mathrm{E}$ & $(\mathrm{S}) \mathrm{R}$ & Total \\
\hline Charlie & 0 & 0 & 4 & 2 & 1 & 2 & 0 & 96 & 0 & 105 \\
\hline Don Armando & 1 & 0 & $18^{\mathrm{a}}$ & 0 & 0 & 0 & 0 & 2 & 0 & 21 \\
\hline Liliana & 0 & 2 & $87^{\mathrm{b}}$ & 0 & 2 & 0 & 2 & 10 & 4 & 107 \\
\hline Rose & 0 & 0 & $19^{\mathrm{c}}$ & 0 & 0 & 1 & 1 & 13 & 0 & 34 \\
\hline Total & 1 & 2 & 128 & 2 & 3 & 3 & 3 & 121 & 4 & 267 \\
\hline
\end{tabular}

Language pair codes: (A)S = Arabic-Spanish; (E)F = English-French; (E)S = English-Spanish; $(\mathrm{F}) \mathrm{E}=$ French-English; (F)S = French-Spanish; (R)E = Romani-English; (R)S = RomaniSpanish; (S)E = Spanish-English; (S)R = Spanish-Romani.

${ }^{a}$ Of this number, 1 represents an occurrence in response to Charlie's utterance.

${ }^{\mathrm{b}}$ Of this number, 83 represent occurrences in response to Charlie's utterances.

${ }^{c}$ Of this number, 17 represent occurrences in response to Charlie's utterances.

The remaining 18 occurrences of between-turn switches made use of English or Spanish in conjunction with one of the other three languages present in the script: Arabic, French, and Romani. Figure 4.4, Examples of between-turn switches involving French or Romani along with English and Spanish, demonstrates the diversity and depth of language use with selected examples. 
Figure 4.4 Examples of between-turn switches involving French or Romani along with English and Spanish

a. Liliana and Charlie used French and English between turns on two occasions:

i. Liliana: ...Los poemas están a salvo dentro de grandpére. (\#193)

Liliana: ...The poems are safe inside grandfather.

Charlie: Wow, there must be hundreds in there! (\#194)

ii. Liliana: ...Let me tell you a story I learned from Grandmére. (\#287)

Liliana: ...Let me tell you a story I learned from Grandmother. Charlie: $O K$, why not. (\#288)

Examples 'a.i' and 'a.ii' in Figure 4.4 show that the French words were kinship terms that could be used as names or terms of address, depending on the language and the context, and they were inserted into prepositional phrases, one Spanish and the other English, respectively. A detailed discussion of insertion is presented in the context of research question two.

Figure 4.4 (Con't.) Examples of between-turn switches involving French or Romani along with English and Spanish

b. French and Spanish used between turns by Liliana and Charlie:

i. Charlie: ...you call your violin grandpére? (\#194)

Liliana: Sí, era de grandpére... (\#195)

Charlie: ...you call your violin grandfather?

Liliana: Yes, it was grandfather's...

ii. Charlie: ...writin' like your grandmére. (\#256)

Liliana: Me gustaría ir a la escuela... (\#257)

Charlie: ...writin' like your grandmother.

Liliana: I would like to go to school...

Similar to the situation presented in the previous examples, Figure 4.4.b

illustrates how the French words consisted of kinship terms but took place within otherwise English noun phrases. Charlie inserted these words-which could be considered B because Liliana had already used them and clearly established whom 
they referred to-into his native language. As previously noted, insertion is more fully described in relation to research question two.

Figure 4.4 (Con't.) Examples of between-turn switches involving French or Romani along with English and Spanish

c. Charlie and Liliana switched from Romani to Spanish in two instances:

i. Charlie: So she was adopted, a gadje? (\#190)

Liliana: $S i$, she loved reading... (\#191)

Charlie: So she was adopted, a non-gypsy?

Liliana: Yes, she loved reading...

ii. Charlie: ...you will finally have your čeiz. (\#451)

Liliana: ;Muchos dias de gran fiesta y celebración! (\#452)

Charlie: ...you will finally have your wedding party.

Liliana: Many days of big party and celebration!

The two exchanges presented in Figure 4.4.c were particularly significant to this study because they showed Charlie using Romani words previously used and defined, upon his request, by Liliana. Charlie was being portrayed as willing to incorporate words and traditions that would transform him into a gypsy. The audience would learn later on in the script that Charlie was, in fact, a gypsy; therefore, this linguistic behavior enhanced character development. I will discuss this situation in greater detail later while providing the answer to research question three.

\section{Within-turn Phenomena}

Now that the language found in between-turn continuity and between-turn switches has been described, it is appropriate to move the discussion to how language behaved within a character's turn. The data showed that within-turn switches occurred in 211 turns. As was explained in the previous chapter, there was a one-to-one relationship between occurrences and turns in the case of between-turn switches. 
However, this relationship was more complex in cases of within-turn switches, as can be observed in the following list displaying the total number of occurrences by character:

- Charlie: 36 occurrences taking place in 30 turns.

- Don Armando: 58 occurrences occurring in 21 turns.

- Liliana: 296 occurrences appearing in 113 turns.

- Rose: 106 occurrences happening in 47 turns.

Figure 4.5, Example of within-turn switches, illustrates the complexity of accounting for occurrences in this type of situation. Because Liliana engaged in CS during the turn, it was counted as one turn showing within-turn switches. However, she alternated and inserted elements; therefore, two CS occurrences were documented in this turn. The alternated element consisted of the English clause "We have always lived by our," while the inserted element was the Spanish noun "tradiciones" 'traditions.'

Figure 4.5 Example of within-turn switches

Liliana: Nuestras costumbres no cambian. Sólo el tiempo pasa. We have always lived by our tradiciones. (\#181)

Liliana: Our costumes don't change. Only time goes by. We have always lived by our traditions.

\section{Research Question One Summary}

Table 4.3, Number and percentage of turn switches, is presented to summarize the results necessary to answer research question one. As can be observed in the table, on the row labeled "Turns showing switches of any type, adjusted," the overall 
frequency with which switches took place in the script analyzed was $78 \%$, arrived at when dividing the total number of turns showing switches of any type by the total number of turns.

Table 4.3. Number and percentage of turn switches.

\begin{tabular}{|l|r|r|r|r|r|r|r|}
\hline \multirow{2}{*}{ Type of turn } & \multicolumn{5}{|c|}{ Character } & \multirow{2}{*}{ Total } & \multirow{2}{*}{$\%$} \\
\cline { 2 - 9 } Turns showing within-turn switches & \multicolumn{1}{|c|}{ C } & CD & DA & \multicolumn{1}{c|}{ L } & R & & \\
\hline Turns showing between-turn switches & 105 & 0 & 21 & 113 & 47 & 211 & 46 \\
\hline Turns showing switches of any type & 135 & 0 & 42 & 220 & 81 & 478 & 104 \\
\hline $\begin{array}{l}\text { Turns showing within-turn and } \\
\text { between-turn switches }\end{array}$ & $(17)$ & $(0)$ & $(12)$ & $(74)$ & $(19)$ & $(122)$ & $(27)$ \\
\hline $\begin{array}{l}\text { Turns showing switches of any type, } \\
\text { adjusted }\end{array}$ & 118 & 0 & 30 & 146 & 62 & 356 & 78 \\
\hline Turns not showing switches of any type & 65 & 3 & 6 & 11 & 18 & 103 & 22 \\
\hline Total turns & 183 & 3 & 36 & 157 & 80 & 459 & 100 \\
\hline
\end{tabular}

Character codes: $\mathrm{C}=$ Charlie; $\mathrm{CD}=$ Charlie's Dad; $\mathrm{DA}=$ Don Armando; $\mathrm{L}=$ Liliana; $\mathrm{R}=$ Rose

${ }^{a}$ This number needs to be subtracted from the calculation of "Turns showing switches of any type" in order to avoid counting the same occurrence twice.

Footnote 'a' in Table 4.3 mentions that simply adding the turns showing within-turn switches and those showing between-turn switches could have resulted in double counting those turns that showed both types of switches. An example illustrating this situation is presented in Figure 4.6.

Figure 4.6 Example of between-turn and within-turn switches in the same turn

Charlie: ...Don't touch me, you thief! (\#69)

Liliana: ¿Por qué? Is that what mommy told you? No hables... (\#70)

Liliana: Why? Is that what mommy told you? Don't talk...

Despite this necessary adjustment, the high percentage of turns showing switches of any type $-78 \%$-along with the percentages addressing the frequency of turns showing 
within-turn switches and between-turn switches, $46 \%$ and $58 \%$, respectively, provided ample support to the claim that CS was an important linguistic feature of the script of Mi Vida Gitana.

\section{Research Question Two}

In the above paragraphs, I presented examples and data documenting betweenturn and within-turn switches, along with a preview of language usage by character. I used this information to address research question one, and having successfully answered that question, I now move the remainder of the analysis of form section to the study of CS occurrences. Table 4.3, Number and percentage of turn switches, provided the tallies regarding switches in relation to turns, but as previously mentioned, the number of CS occurrences was higher due to the possibility of multiple instances within any given turn. Table 4.4 presents the number of occurrences subject to analysis in this section.

Table 4.4. CS occurrences by character and by type of turn.

\begin{tabular}{|l|r|r|r|r|r|r|}
\hline \multirow{2}{*}{ Type of CS occurrence } & \multicolumn{5}{|c|}{ Character } & \multirow{2}{*}{ Total } \\
\cline { 2 - 7 } & \multicolumn{1}{|c|}{ C } & CD & DA & L & R & \\
\hline Occurrences in within-turn switches & 36 & 0 & $58^{\mathrm{a}}$ & $296^{\mathrm{a}}$ & 106 & $4^{2}$ \\
\hline Occurrences in between-turn switches & 105 & 0 & 21 & 107 & 34 & 267 \\
\hline Total number of occurrences & 141 & 0 & 79 & 403 & 140 & 763 \\
\hline
\end{tabular}

Character codes: $\mathrm{C}=$ Charlie; $\mathrm{CD}=$ Charlie's Dad; $\mathrm{DA}=$ Don Armando; $\mathrm{L}=$ Liliana; $\mathrm{R}=$ Rose

a These numbers include the five occurrences of Congruent Lexicalization, which contain multiple switches/occurrences within themselves.

Using the numbers displayed in the above table and following the methodology described in the previous chapter, in this section I analyze each occurrence and classify it as a case of insertion, alternation, or congruent lexicalization. Within each 
one of these categories, I also examine the syntactic form and function of each occurrence. Table 3.1, Examples of data coding, and its surrounding paragraphs provided a detailed explanation of the actual methodology employed. The discussion presented in the remainder of this section relates to research question two and seeks to provide information to generate a useful answer. I conclude this section with a summary of the most commonly occurring CS elements in the script. I also offer some observations regarding the similarities and differences of this behavior as compared to the language used by bilinguals in a natural context.

Research Question 2. What specific types of elements are most commonly codeswitched and how are they used?

In order to answer this question, representative examples and a detailed discussion of the 71 occurrences of insertion, 687 occurrences of alternation, and 5 occurrences of congruent lexicalization are presented in the following three sections.

\section{Insertion}

It was for this CS process that two structural models were useful. Muysken's (2000) typology was instrumental in identifying cases of insertion, while MyersScotton's $(1992,1993 a, 2002)$ Matrix Language Frame (MLF) model guided the recognition of the matrix language (ML) and embedded language (EL). As previously mentioned, the data collected from the script of Mi Vida Gitana included 71 cases of insertion. Table 4.5, Insertion by syntactic element, including number of types and 
tokens, presents these syntactic elements along with the number of types and tokens for each of the elements utilized in CS of the insertional kind.

\section{Table 4.5. Insertion by syntactic element, including number of types and tokens.}

\begin{tabular}{|l|r|r|}
\hline Syntactic Element & $\begin{array}{c}\text { \# of } \\
\text { Types }\end{array}$ & $\begin{array}{c}\text { \# of } \\
\text { Tokens }\end{array}$ \\
\hline Adjectives & 2 & 8 \\
\hline Nouns & 20 & 49 \\
\hline Noun Phrases & 7 & 7 \\
\hline Prepositional Phrases & 6 & 6 \\
\hline Verbs & 1 & 1 \\
\hline Total & 35 & 71 \\
\hline
\end{tabular}

\section{Adjectives}

These syntactic elements occurred only as insertion, an expected behavior because of adjectives' close relationship to the nouns they modify. The adjectives used were "gadje(s)" 'non-gypsy(s)' (7x) and “españoles” 'Spanish'(1x). The adjective “gadje(s)" was always inserted by Liliana-four times into English ML structures and

three times into Spanish ML structures. Figure 4.7 demonstrates the typical use of this word.

Figure 4.7 Inserted adjectives

a. Romani adjective embedded into an English ML structure

Liliana: ...As if you knew how easy it was to make a buck, rich gadje tourist. (\#66)

Liliana: ...As if you knew how easy it was to make a buck, rich nongypsy tourist. 
Figure 4.7 (Con't.) Inserted adjectives

b. Romani adjective embedded into a Spanish ML structure

Liliana: ....No teníamos dinero para medicinas gadjes.... (\#175)

Liliana: ...We didn't have money for non-gypsy medicines....

The examples in Figure 4.7 point to "gadje(s)" having been fully borrowed on Liliana's part. In the case of "españoles," Charlie inserted the Spanish adjective into an English ML structure (see Figure 2.1.b.i for this occurrence).

\section{Nouns}

These syntactic elements were the most common insertion types and were found embedded into English and Spanish ML structures. I have included in this category single-word nouns as well as certain noun phrases that form a single word, such as "DNA" and "grandmére" 'grandmother.' As a result, I will utilize the term noun as a cover term to refer to both single-word nouns and single-word noun phrases. There were three English nouns-"Frenchy," "euros," and "DNA" (1x each)-embedded in Spanish ML structures and 10 Spanish nouns-“tejanos" 'Texans' and "Texas” (3x each), “palmas” 'palms' (2x), “tradiciones” 'traditions,' "calle” 'street,' "músico” 'musician,' "familia” 'family,' “Capitán” 'Captain,' "primo” 'cousin,' and "suegra” 'mother-in-law' (1x each)-embedded in English ML structures. There were also 2 French nouns-“grandmére" 'grandmother' (7x) and "grandpére” 'grandfather' (9x)inserted in either English or Spanish ML structures. Finally, Romani nouns were inserted in English ML structures eight times while the insertion occurred in Spanish ML structures seven times. The Romani nouns inserted were "gadje" 'non-gypsy' (7x), “čeiz" 'wedding party/exchange’ (3x), "tanana" 'sexy dance' and "bibaxt" 'bad 
luck' ( $2 \mathrm{x}$ each), and "mahrime" 'unclean' ( $1 \mathrm{x})$. The small number of different nouns used from both French and Romani, two and five respectively, and their repeated occurrences seemed to point to the possibility of B instead of CS. As was the case in Kuehlhorn's study, the data for the present analysis was limited to only one script and made the possibility of categorically classifying switches as B difficult, to say the least (2008, p. 61). Nonetheless, Muysken and Myers-Scotton both identified nouns as the most common element utilized in this process. In Muysken's words “nouns are the class of elements borrowed par excellence and also the prime example of insertion under categorial equivalence" (2000, p. 75).

It is important to note that, regardless of what the embedded and matrix languages were, inserted nouns functioned as subjects, direct objects, and objects of prepositional phrases, as anticipated by Muysken (2000). A summary of the functions served by inserted nouns and noun phrases is illustrated in Table 4.6.

Table 4.6. Functions of inserted nouns $(\mathrm{N})$ and noun phrases (NP).

\begin{tabular}{|l|r|r|r|}
\hline Function & N & NP & Total \\
\hline Subject & 6 & 2 & 8 \\
\hline Direct Object & 22 & 3 & 25 \\
\hline Object of Prepositional Phrase & 21 & 2 & 23 \\
\hline Total & 49 & 7 & 56 \\
\hline
\end{tabular}

Some examples of the six inserted nouns that functioned as subjects are presented in Figure 4.8, Inserted nouns as subjects. It is interesting to point out, as evidenced from these examples, that English noun insertions were never found as subjects in the data analyzed. 
Figure 4.8 Inserted nouns as subjects

a. Spanish noun

Liliana: Your familia are blue jeans? (\#261)

Liliana: Your family are blue jeans?

b. French noun

Liliana: ...But grandmére was rebel... (\#187)

Liliana: ... But grandmother was rebel...

c. Romani noun

Don Armando: ...los gadjes no son honorables... (\#339)

Don Armando: ...the non-gyspsies are not honorable... (\#339)

Figure 4.9, Inserted nouns as direct objects, shows some of the 22 times when inserted nouns functioned as direct objects in the verb phrase of the ML. It was not surprising to observe that nouns agreed in gender and number, when applicable, with the surrounding ML elements since those elements provided the overall structure for the entire utterance.

Figure 4.9 Inserted nouns as direct objects

a. English noun

Liliana: ... ¿y solo tienes tres euros? /juəroz/ (\#161)

Liliana: ... and you only have three euros?

b. Spanish noun

Charlie: ...My relatives are tejanos. (\#260)

Charlie: ...My relatives are Texans.

c. French noun

Charlie: I like your grandmére. ... (\#188)

Charlie: I like your grandmother. ...

d. Romani noun

Liliana: I don't need hero gadjes looking out for me ... (\#68)

Liliana: I don't need hero non-gypsies looking out for me ...

[Note: In this example, "hero" is an adjective and "gadjes" is a plural noun.] 
There were 21 instances when the inserted noun functioned as the object of a prepositional phrase. The examples in Figure 4.10, Inserted nouns as objects of prepositional phrases, where the preposition is underlined for clarity, illustrate some of the typical contexts where these CS occurrences were found. As was the case with inserted nouns filling the direct object position of the sentence, inserted nouns functioning as object of prepositional phrases came from all four languages. However, English elements represented the smallest number in both cases, with two and one occurrence, respectively.

Figure 4.10 Inserted nouns as objects of prepositional phrases

a. English noun

Liliana: ¿Una prueba del $D N A$ ?... (\#379)

Liliana: A DNA test?...

b. Spanish noun

Liliana: I see...girl in future of gadje boy from Texas. /tehas/ (\#139)

Liliana: I see...girl in future of non-gypsy boy from Texas.

c. French noun

Liliana: ...Let me tell you a story I learned from grandmére. (\#287)

Liliana: .... Let me tell you a story I learned from grandmother.

d. Romani noun

Don Armando: ... Nunca confíes en un gadje ... (\#333)

Don Armando: ... Never trust a non-gypsy ...

Noun Phrases

Inserted noun phrases came only from English and Spanish. The fact that the script included neither French nor Romani noun phrases was another argument in favor of considering occurrences involving those two languages as instances of B. This is the case because noun phrases are a kind of EL island and as Myers-Scotton 
claimed, EL islands have to be structurally well-formed in the EL (1993a). However, throughout the script, the characters did not show enough language proficiency in French and Romani to create such well-formed elements.

Even though English and Spanish supplied inserted noun phrases in the script, there was some disparity in that only two English noun phrases occurred in Spanish ML structures, once in the subject position and once in the direct object position, whereas Spanish noun phrases occurred in English ML structures, once as a subject, twice as direct objects, and twice as objects of prepositional phrases, for a total of five occurrences. This distributional pattern was similar to that exhibited by nouns, as illustrated in Table 4.6, Functions of inserted nouns (N) and noun phrases (NP). Figure 4.11 provides examples of each of the functions served by noun phrases in the two MLs where they occurred.

Figure 4.11 Inserted noun phrases

a. English noun phrases embedded into Spanish ML structures

i. Subject

Liliana: ....así que Márquez boy no entiende bien español? (\#153)

Liliana: ...so Márquez boy does not understand Spanish well?

ii. Direct object

Liliana: ...tienes tu libertad y mucho por qué vivir-your music! (\#381)

Liliana: ...you have your freedom and much to live for-your music!

b. Spanish noun phrases embedded into English ML structures

i. Subject

Liliana: ...Besides el capitán decides what is best... (\#255)

Liliana: ...Besides the captain decides what is best...

ii. Direct object

Don Armando: ... it will be very costly to send mi primo away... (\#364)

Don Armando: ... it will be very costly to send my cousin away... 
Figure 4.11 (Con't.) Inserted noun phrases

iii. Object of prepositional phrases

Liliana: ...Tell me about tus padres Charlie. (\#205)

Liliana: ...Tell me about your parents Charlie.

One of the English noun phrases inserted in the script (Figure 4.11.a.i) created a situation that made more evident the language ability differences between Liliana and Charlie. Liliana uttered Charlie's last name with a distinct Spanish accent, with the first syllable carrying the stress, as would be anticipated given the etymological origin of the name. However, Charlie used it throughout the play with the stressed being placed on the second syllable.

\section{Prepositional Phrases}

Similar to the treatment of the other syntactic elements previously presented, prepositional phrases were also considered occurrences of insertion, alternation, or congruent lexicalization depending on their function within the utterance and the surrounding elements. It is appropriate to mention here that Muysken's typology was silent with respect to the treatment of elements that served either a syntactic or a semantic function, as was the case with many of the prepositional phrases occurring in the script of Mi Vida Gitana. In order to consistently apply Muysken’s typology to current data, I considered cases of insertion those prepositional phrases that contributed syntactically to the utterance, whereas those prepositional phrases serving more of a semantic function were classified as alternation. Using this criterion, there were six prepositional phrases classified as insertion and embedded into English ML structures-Spanish (3x), French (2x), and Romani (1x). Even though there were six 
distinct prepositional phrases, it is worth mentioning that four of them started with the same Spanish or French preposition, “en” 'in' (2x) and “en, a [sic]” 'in' (2x), respectively. Examples of inserted prepositional phrases are presented in Figure 4.12.

Figure 4.12 Inserted prepositional phrases

a. Liliana: ... what are you doing en España? (\#159)

Liliana: ...what are you doing in Spain?

b. Liliana: ...it's all $a$ [sic] français so let me translate for you... (\#199)

Liliana: ...it's all in French so let me translate for you...

c. Liliana: ... as God wills and con baxt we will be together, forever. (\#458)

Liliana: ....as God wills and with luck we will be together, forever.

Figure 4.12, where the relevant phrase is underlined for clarity, demonstrates that inserted prepositional phrases occurred at the end of the utterance (example 'a') or they acted as complements to the verbs and provided critical information necessary to fully understand the utterance (examples ' $b$ ' and 'c'). As previously mentioned, it could be argued that were the prepositional phrases not present, the utterances would have been incomplete or syntactically unsound.

\section{Verbs}

There was only one occurrence classified as a verb insertion and it occurred in a compound verb phrase. When addressing Liliana, Don Armando inserted a Romani verb into a Spanish ML structure conveying a meaning that was both culturally and emotionally charged. Figure 4.13, Inserted verb, presents this occurrence and exemplifies that continuing the utterance in Spanish by using the word "ensuciarte" 'get dirty' or the phrase "hacerte impura" 'become impure' might have downplayed the importance of Romani traditions and customs. 
Figure 4.13 Inserted verb

Don Armando: Cuidado, no puedes mahrime. We have... (\#109)

Don Armando: Be careful, you can't become unclean. We have...

Although there were other cases where verbs and verb phrases were codeswitched, this was the only one deemed of the insertional kind because of the inseparability of the compound verb phrase. As will be shown in the next section addressing alternation, whenever other compound verb phrases occurred, they were never comprised of elements from different languages.

This concludes the discussion of CS occurrences considered instances of insertion. One of the most telling observations arising from this analysis was the predominant use of nouns, by themselves, and in noun and prepositional phrases. This observation will be further discussed in the summary portion of this section and in direct response to research question two. The analysis moves now to CS occurrences classified as alternation.

\section{Alternation}

The CS phenomenon most frequently observed in the data was alternation. This CS strategy was used 420 times in within-turn switches and in all 267 occurrences of between-turn switches, as I have explained in the previous chapter. A summary showing the specific syntactic elements that made up these numbers is presented in Table 4.7, Alternation in within-turn and between-turn switches. 
Table 4.7. Alternation in within-turn and between-turn switches.

\begin{tabular}{|l|r|r|r|}
\hline Syntactic Element & $\begin{array}{c}\text { Occurrences } \\
\text { in within- } \\
\text { turn } \\
\text { switches }\end{array}$ & $\begin{array}{c}\text { Occurrences } \\
\text { in between- } \\
\text { turn } \\
\text { switches }\end{array}$ & Total \\
\hline Adverb & 16 & 46 & 62 \\
\hline Adverbial Phrase & 11 & 13 & 24 \\
\hline Noun & 7 & 6 & 13 \\
\hline Noun Phrase & 15 & 13 & 28 \\
\hline Prepositional Phrase & 12 & 5 & 17 \\
\hline Verb Phrase & 8 & 0 & 8 \\
\hline Interjection & 1 & 17 & 18 \\
\hline Term of Address ${ }^{\text {a }}$ & 35 & 1 & 36 \\
\hline Clause & 237 & 141 & 378 \\
\hline$\bullet \quad$ Independent Clause & 59 & 24 & 83 \\
\hline$\bullet \quad \begin{array}{l}\text { Independent Clause preceded } \\
\text { by Conj. }\end{array}$ & 12 & 0 & 12 \\
\hline $\begin{array}{l}\text { Independent Clause preceded } \\
\text { by Adv. }\end{array}$ & 7 & 1 & 8 \\
\hline$\bullet \quad$ Dependent Clause & 420 & 267 & 687 \\
\hline Clause Totals & 166 & 481 \\
\hline Total & & & \\
\hline
\end{tabular}

${ }^{a}$ Although considered separately for this study, Terms of Address are nouns or noun phrases from a syntactic form point of view.

\section{Adverbs and Adverbial Phrases}

There were 16 instances of alternation using adverbs and 11 occurrences involving adverbial phrases in within-turn switches, whereas the number of occurrences was 46 and 13, respectively, in between-turn switches. This high number of occurrences, totaling 86 , supported Muysken's claim that "nouns and adjectives are likely to be insertions, while discourse markers and adverbs may be alternations" (2000, p. 97). Although the majority of alternated adverbs and adverbial phrases 
occurred between English and Spanish, or vice versa, these elements were found in a variety of language combinations. Alternation from Spanish to English took place 18 times for adverbs and 3 times for adverbial phrases, whereas the switching from English to Spanish occurred 35 times with adverbs and 15 times with adverbial phrases. The nine remaining occurrences of adverb alternation involved languages beyond English and Spanish exclusively. Four times the alternation went from a Spanish clause to a Romani adverb and involved Don Armando and Liliana. The other five adverb alternations were found twice in within-turn switches-going from Spanish to Romani (Liliana: “Capitán, da" 'Captain, yes') and from Romani to English (Liliana: “da. Yes, Sir” 'yes. Yes, Sir')-and three times in between-turn switches.

These three instances are presented in Figure 4.14.

Figure 4.14 Adverb alternation in between-turn switches involving French or Romani along with English and Spanish

a. From French to English

Liliana: ...Let me tell you a story I learned from Grandmére. (\#287)

Charlie: $O K$, why not. (\#288)

Liliana: ...Let me tell you a story I learned from Grandmother. Charlie: $O K$, why not.

b. From French to Spanish

Charlie: ...you call your violin grandpére? (\#194)

Liliana: Sí, era de grandpére... (\#195)

Charlie: ...you call your violin grandfather?

Liliana: Yes, it was grandfather's...

c. From Romani to Spanish

Charlie: So she was adopted, a gadje? (\#190)

Liliana: Si, she loved reading... (\#191)

Charlie: So she was adopted, a non-gypsy?

Liliana: Yes, she loved reading... 
The situation was equally varied-when considering the languages involved-for the remaining six adverbial phrases; however, these phrases were only used by Liliana and only found in within-turn switches. One time each the alternation took place between French and English ("Plus ou moins, more or less" 'More or less, more or less'), French and Spanish (“mon chéri, por favor" 'my dear, please'), and Romani and Spanish ("gadje. A ver" 'non-gypsy. Let's see'). The last three cases showed an adverbial phrase in French preceded by English elements, such as in the following example: "go with mommy, au revoir" 'go with mommy, good-bye.'

In terms of the specific types or elements used, the 86 occurrences resulted from 35 different adverbs or adverbial phrases found in the script. The only English adverbs repeated were "ok" (6x), "well" (5x), and "yeah" (3x), with the variations "yes" (2x) and "yep" (1x). Likewise, the only Romani type repeated was the adverb “da" 'yes' (5x). In contrast, repeated Spanish elements included adverbs-“sí" 'yes' (14x), "bueno" “well' (11x), "no" (6x), and "mañana" 'tomorrow' (2x)-and adverbial phrases-“a ver" 'let's see’ (3x), “claro que sí” ‘of course’ (3x), and “¿de verdad?” 'really? (2x). Finally, one French adverbial phrase occurred multiple times in the script-“au revoir”' 'good-bye' $(2 x)$.

With regard to the functions of alternated adverbs and adverbial phrases, they were employed in a variety of functions, a summary of which is presented in Table 4.8, Functions of alternated adverbs (Adv) and adverbial phrases (AdvP). 
Table 4.8. Functions of alternated adverbs (Adv) and adverbial phrases (AdvP).

\begin{tabular}{|l|r|r|r|r|r|}
\hline \multirow{2}{*}{ Function } & \multicolumn{2}{|c|}{ Within-turn } & \multicolumn{2}{|c|}{ Between-turn } & \multirow{2}{*}{ Total } \\
\cline { 2 - 5 } $\begin{array}{l}\text { Response to Command or Call for } \\
\text { Action }\end{array}$ & 6 & 2 & 17 & 7 & 32 \\
\hline Response to Questions & 3 & 2 & 11 & 3 & 19 \\
\hline Discourse Markers & 4 & 2 & 18 & 1 & 25 \\
\hline Time Alignment & 2 & 3 & 0 & 1 & 6 \\
\hline Interruption & 1 & 0 & 0 & 1 & 2 \\
\hline Emblematic Switching & 0 & 2 & 0 & 0 & 2 \\
\hline Total & 16 & 11 & 46 & 13 & 86 \\
\hline
\end{tabular}

The most common use of these syntactic elements was in response to a command or a call for action. Figure 4.15, Alternated adverbs and adverbial phrases in response to commands, shows four examples of this type of occurrence. The most frequent adverbs used in response to commands were "da dom" 'yes' (5x), "no" (5x) “sí" 'yes' (3x), and "ok” (3x). "Claro que sí” 'of course' (3x) and “¿de verdad?” 'really?' (2x), were the only repeated adverb phrases fulfilling this function.

Figure 4.15 Alternated adverbs and adverbial phrases in response to commands

a. Within-turn switches

i. Charlie: C'mon with me! (\#49)

Liliana: Wait, no señor. (\#50)

Liliana: Wait, no, sir.

ii. Don Armando: ...puedes mendigar por tu cena. (\#44)

Liliana: Da, Dom Capitán, da. Yes, Sir... (\#45)

Don Armando: ... you can beg for your dinner.

Liliana: Yes, captain, yes. Yes, Sir... 
Figure 4.15 (Con't.) Alternated adverbs and adverbial phrases in response to commands

b. Between-turn switches

i. Don Armando: ....y regresa a tu trabajo. (\#339)

Liliana: Da dom... (\#340)

Don Armando: ... and go back to your job.

Liliana: Yes...

ii. Charlie: ...Come talk to me. (\#122)

Liliana: Claro que sí, mi gadje hero... (\#123)

Liliana: Of course, my non-gypsy hero...

Adverbs and adverbial phrases were also used to respond to explicit questions, 14 and 5 times, respectively. Two relevant examples are provided in Figure 4.16, Alternated adverbs and adverbial phrases in response to questions. This function made use of the adverb "sí" 'yes' (11x); making it similar to the function discussed previously. The similarities were even more evident when considering that in some cases of within-turn switches the response did not always occur immediately following the question, but repeated a similar answer in more than one language (Figure 4.16.a), a situation that could be seen as accommodating to a diverse audience.

Figure 4.16 Alternated adverbs and adverbial phrases in response to questions

a. Within-turn switch Charlie: Are you sure it's for real? (\#388)

Liliana: Yes, I know... Sí, las pócimas... (\#389)

Liliana: Yes, I know... Si, the potions...

b. Between-turn switch

Charlie: Did you say stoned to death? (\#178)

Liliana: Sí, es verdad... (\#179)

Liliana: Yes, it's true...

The third most common function of adverbs and adverbial phrases was to act as discourse markers, in other words, to make the transition between the languages 
smoother. One important observation is that the same adverbs and adverbial phrases were employed repeatedly: "bueno" "well' (9x), "well” (5x), "ok" (4 x), and "a ver" 'let's see' (3x). Two examples with "a ver," the only adverbial phrase used as a discourse marker, are illustrated in Figure 4.17.

Figure 4.17 Alternated adverbial phrases as discourse markers

a. Within-turn switch

Liliana: ... but I like you. A ver. (\#149)

Liliana: ... but I like you. Let's see.

b. Between-turn switch

Charlie: I'd love to hear one of her poems... (\#198)

Liliana: A ver, it's all a [sic] français so let me translate... (\#199)

Liliana: Let's see, it's all in French so let me translate...

Other uses of adverbs and adverbial phrases were to provide time information“mañana," 'tomorrow' (2x), "until then," "lo más pronto posible” 'as soon as possible,' “ojalá rápidamente” 'hopefully quickly,' and "hace mucho tiempo" 'a long time ago' (1x each)-and to interrupt an utterance-"here" and "basta ya" "enough already' (1x each). The last function of adverbial phrases identified in the script was emblematic switching. Liliana used the French collocation "au revoir" 'goodbye' $(2 \mathrm{x})$ when saying goodbye to Charlie, after he had asked her whether she could speak French.

\section{Nouns and Noun Phrases}

Alternations in within-turn switches involved nouns and noun phrases in 7 and 15 instances, respectively, while the number of occurrences in between-turn switches totaled 6 and 13, respectively. The alternation went from Spanish to English 3 times in the case of nouns and 11 times in the case of noun phrases. The occurrences were 
more numerous when the alternation worked in the other direction, from English to Spanish, with 6 nouns and 16 noun phrases. The remaining four nouns and one noun phrase involved alternations among English, French, Romani, and Spanish as well as the use of the lone Arabic expression found in the script-"mashallah" "What Allah has willed' $(2 \mathrm{x})$. Similar to noun and noun phrase alternations consisting of only English and Spanish, alternated elements from these languages occurred in within- and between-turn switches. Figure 4.18, presents three examples to illustrate the use of elements from these languages.

Figure 4.18 Noun and noun phrase alternation involving Arabic, French, or Romani along with English and Spanish

a. Within-turn switch

Rose: ...for the judge, here, make it so, mashallah. (\#365)

Rose: ...for the judge, here, make it so, what Allah has willed.

b. Between-turn switch

i. Charlie: .... So, if it was against the rules, how did she learn? (\#188)

Liliana: Grandmére fue diferente. ... (\#189)

Liliana: Grandmother was different. ...

ii. Charlie: ... you will finally have your čeiz. (\#451)

Liliana: ;Muchos días de gran fiesta y celebración! (\#452)

Charlie: ... you will finally have your wedding party.

Liliana: Many days of big party and celebration!

With regard to the specific types or elements used, the alternation of nouns and noun phrases showed a wide variety. The total number of different elements was 38 , with only the following types occurring in multiple occasions: "mashallah" "What Allah has willed,' “los Romanis" 'Romanis,' and “cuentos” 'tales' (2x each). In terms of their functions, nouns and noun phrases classified as alternation could be divided 
into two main groups, intra-sentential and extra-sentential, and several subgroups. A summary of these functions is illustrated in Table 4.9.

Table 4.9. Functions of alternated nouns (N) and noun phrases (NP).

\begin{tabular}{|c|c|c|c|c|c|}
\hline \multirow{2}{*}{ Function } & \multicolumn{2}{|c|}{ Within-turn } & \multicolumn{2}{|c|}{ Between-turn } & \multirow{2}{*}{ Total } \\
\hline & $\mathrm{N}$ & $\mathrm{NP}$ & $\mathrm{N}$ & NP & \\
\hline \multicolumn{6}{|l|}{ Intra-sentential } \\
\hline - $\quad$ Subject & 0 & 0 & 2 & 1 & 3 \\
\hline - Direct Object & 4 & 5 & 0 & 0 & 9 \\
\hline - Object of Prepositional Phrase & 0 & 2 & 0 & 0 & 2 \\
\hline \multicolumn{6}{|l|}{ Extra-sentential } \\
\hline - Repeated Information & 0 & 4 & 3 & 8 & 15 \\
\hline - $\quad$ Plot Advancing & 1 & 4 & 0 & 2 & 7 \\
\hline - Response to Question & 0 & 0 & 1 & 2 & 3 \\
\hline - $\quad$ Emblematic Switching & 2 & 0 & 0 & 0 & 2 \\
\hline Total & 7 & 15 & 6 & 13 & 41 \\
\hline
\end{tabular}

Alternated nouns and noun phrases functioned as subjects twice and once, respectively; and they acted as direct objects, four times and five times, in that order. Conversely, only noun phrases were employed as objects of prepositional phrases in two cases. Occurrences of all these functions can be observed in Figure 4.19, which presents English and Spanish examples.

Figure 4.19 Alternated nouns and noun phrases as intra-sentential elements

a. Subjects

i. Charlie: ...I could play music... and we could play together (\#250)

Liliana: Capitán will not allow it. (\#251)

Liliana: The captain will not allow it.

ii. Charlie: ... why would anybody hate that? (\#200)

Liliana: Los Romanis learn by telling and singing... (\#201)

Liliana: Romanis learn by telling and singing... 
Figure 4.19 (Con't.) Alternated nouns and noun phrases as intra-sentential elements

b. Direct objects

i. Don Armando: ... spin your cuentos, mi pajarita. ¿Cuánto has sacado...(\#117)

Don Armando: ... spin your tales, my little bird. How much have you made...

ii. Liliana: ...you just make for me muchos problemas. Sabes, mejor me voy... (\#58)

Liliana: ...you just make for me many problems. You know, I better go...

c. Objects of prepositional phrases

i. Liliana: ...I work for mi capitán, y si trabajo ... (\#171)

Liliana: ...I work for my captain, and if I work ...

ii. Liliana: ... school is not for los Romanis. Mi gente lee... (\#255)

Liliana: ...school is not for Romanis. My people read...

When comparing the examples presented in Figure 4.19.a with those

previously illustrated in Figure 4.8, Inserted nouns as subjects, and Figure 4.11.a.i and

b.i, Inserted noun phrases, they could be seen as occurrences of insertion. However, I decided to classify them as cases of alternation because many of these nouns and noun phrases happened at the beginning of the turn and, therefore, there was no ML in which they could have been embedded. While classifying these occurrences as alternation, it is important to mention that Myers-Scotton would likely disagree and say that there was indeed a ML and the Spanish noun and noun phrases were simply embedded or inserted into English ML structures.

The rationale for classifying cases as those observed in Figure 4.19.b as occurrences of alternation was that they marked or signaled the initiation of the use of another language that continued into the following utterance. Recall from the discussion of Muysken's typology in chapter two that one of his diagnostic features 
for alternation is that several constituents in sequence occur in the switched language. However, applying Muysken's typology to these occurrences was not without problems because he had not provided exhaustive examples and some of the diagnostic features seemed to carry over from one CS type to another as well as they appeared to be in conflict with one another.

A similar challenge to the one just discussed existed with the two noun phrases presented in Figure 4.19.c. These two noun phrases shared two noteworthy similarities: they were in Spanish and they occurred as objects of prepositional phrases beginning with the English preposition "for." A comparison of these examples with those presented in Figure 4.10, Inserted nouns as objects of prepositional phrases, and Figure 4.11.a.iii, Inserted noun phrases, shows that all noun phrases were strongly connected to the verbs. Without the prepositional phrase that contained those noun phrases, it could be argued that the utterance would have been incomplete; in other words, they seemed to act more as complements of the verb instead of adjuncts, a typical function served by inserted prepositional phrases. However, I decided to classify them as alternation because they signaled the beginning of a Spanish utterance that continued across sentence boundaries. Once again, Muysken's diagnostic features were difficult to apply to current data because they seemed to contradict each other. On the one hand, insertion cases were those consisting of single constituents and selected elements, such as complements, while on the other hand, alternation occurrences were those comprised of several constituents. 
Even though Muysken's typology was designed to explain intra-sentential CS, he provided some guidance on how to account for elements that occurred beyond the sentence boundary. He mentioned the importance of considering the "structural position of the switch: if the switch takes place at a major clause boundary, alternation is a plausible option" $(2000$, p. 99). This diagnostic feature served as the foundation for considering certain nouns and noun phrases instances of extra-sentential alternation. Similar to what was observed with adverbs and adverbial phrases, extrasentential nouns and noun phrases were not syntactically connected to surrounding elements. Figure 4.20, Alternated noun phrases as extra-sentential elements, provides examples of some of these occurrences. Nouns and noun phrases provided similar information in another language 15 times (examples ' $a$ '); they advanced the plot without the need for a lengthy dialogue or explanation seven times (examples 'b'); and they occurred in response to questions or other situations taking place in the script three times (example 'c'). The emblematic switching of nouns consisted of the Arabic noun "mashallah" 'What Allah has willed,' which was used once by Rose and once by Liliana.

Figure 4.20 Alternated noun phrases as extra-sentential elements

a. Similar information NP

i. Within-turn switches

Charlie: ...A gypsy life is... what I've needed, mi vida gitana. (\#432)

Charlie: ...A gypsy life is...what I've needed, my gypsy life.

ii. Between-turn switches

Liliana: ...mi valiente y noble soldadito. (\#367)

Liliana: ...my brave and noble little soldier. Charlie: Not that brave. (\#368) 
Figure 4.20 (Con't.) Alternated noun phrases as extra-sentential elements

b. Plot advancing NP

i. Within-turn switches

Liliana: ...haz tu promesa...No regrets. Este es un pacto... (\#273)

Liliana: ...make your promise...No regrets. This is a pact...

ii. Between-turn switches

Rose: Trabajo con la embajada y basta ya. ;Fuera!... (\#229)

Don Armando: My mistake señora, lo siento... (\#230)

Rose: I work with the embassy and that's it. Out!...

Don Armando: My mistake madam, I'm sorry...

c. Response to questions

Don Armando: ...¿Cuánto has sacado el día de hoy? (\#117)

Don Armando: ... How much have you made today?

Liliana: Ten euros. /juəroz/ (\#118)

\section{Prepositional Phrases}

It is appropriate to repeat at this point that I classified as occurrences of alternation those prepositional phrases that contributed semantically, rather than syntactically to the utterance. As previously mentioned, Muysken's typology did not

directly address the treatment of elements that served either a syntactic or a semantic function; therefore, I deemed certain prepositional phrases occurring in within-turn switches occurrences of alternation because they did not add to the syntactic wellformedness of the utterance, but rather they contributed semantically. In addition, as I mentioned in the methodology chapter, all between-turn switches were considered cases of alternation because the existence of a shared structure was not possible; therefore, prepositional phrases starting a turn were included in this section. There were 12 instances of alternations involving prepositional phrases in within-turn switches while there were five such occurrences in between-turn switches. In terms of the languages involved, 10 times these phrases were in Spanish following a previous 
English utterance and five times the reverse was true, going from Spanish to English.

The remaining two prepositional phrases alternated between French and Spanish and English and French, respectively. Examples involving English and Spanish alternation and the context in which they were found are shown in Figure 4.21, where the relevant phrase is underlined for clarity.

Figure 4.21 Alternated prepositional phrases

a. Within-turn switches

i. Rose: ...el peregrinaje juntos for our religious trek. I did it ... (\#20)

Rose: ...the pilgrimage together for our religious trek. I did it ...

ii. Liliana: ...I had to work in street too, como mi mamá para pagarle. Pero ella dijo nada de sexo... (\#175)

Liliana: ...I had to work in street too, like my mother in order to pay him. But she said no sex...

b. Between-turn switches

i. Liliana: ...¿¿Dónde vives? (\#217)

Charlie: On the calle forty five... (\#218)

Liliana: ...Where do you live?

Charlie: On the street forty five...

[Note: In this example, Charlie's response is significant because it violates English well-formedness; it uses overall Spanish surface structure, even though only a word, the noun "calle," is drawn from that language.]

ii. Charlie: ...they are way friendly. (\#262)

Liliana: ¿Como los Romanis españoles? (\#263)

Liliana: Like Spanish Romanis?

iii. Liliana: ...y vamos a estar arrugados y grises. (\#414)

Charlie: Like your grandpére and... (\#415)

Liliana: ... and we are going to be wrinkled and gray.

Charlie: Like your grandfather and...

Of the five occurrences going from Spanish to English, three took place in within-turn switches and two occurred in between-turn switches. Two of the former involved Rose and the preposition "for" (see Figure 4.21.a.i for an example) while the 
two latter had Charlie as the speaker (see Figure 4.21.b.i and b.iii). With respect to Spanish prepositional phrases preceded by English elements, the significance lies on the fact that Liliana uttered seven out of 10 of those prepositional phrases; six in within-turn switches and one in between-turn switches (see examples 'a.ii' and 'b.ii,' respectively, in Figure 4.21). Another interesting fact is that six of those switches began with the preposition "como" 'like' (5x) and "like" (1x) (see Figure 4.21, examples 'a.ii,' 'b.ii,' and 'b.iii') which served to create a comparison and to provide additional semantic information.

Charlie pronounced the same Spanish prepositional phrase, "Hasta la vista" 'see you later' $(2 \mathrm{x})$, once after an English utterance and once following a French utterance. In both cases the prepositional phrase was considered an occurrence of alternation because of the phrase's status as a collocation and its emblematic nature. The last alternated prepositional phrase-"De la France" 'From France' (1x)-was said by Liliana in response to an English question asked by Charlie, "Where do you come from?"

\section{Verb Phrases}

The analysis of the script included eight instances of alternations involving eight different verbs and verb phrases, seven alternating a Spanish subject with an English predicate and one alternating French and Spanish. All of them occurred in within-turn switches, which is not surprising because in order for them to have occurred in between-turn switches, one character would have had to utter the subject while another would have needed to finish the utterance with the predicate. The 
rationale for classifying these occurrences as alternation instead of insertion was that they consisted of phrasal or compound verbs or they were followed by direct objects in the same language and, therefore, consisted of several constituents in sequence. Two examples of these verb phrases are presented in Figure 4.22.

Figure 4.22 Alternated verb phrases: Compound phrase (a), followed by direct object (b)

a. Liliana: ...un simple y guapo niño ...gets kicked out of school? (\#163)

Liliana: ... a simple and handsome boy ...gets kicked out of school?

b. Liliana: ...y él murió abrazándola. Y mi mamá save [sic] the poems and hide [sic] them here. (\#193)

Liliana: .... and he died embracing her. And my mother saved the poems and hid them here.

The examples presented in Figure 4.22 mirrored the situation found in the entire script from the standpoint that Liliana was the character who codeswitched these elements most frequently. Charlie was also involved in one instance classified as verb phrase alternation but the use of the verb phrase resulted from what Muysken labeled correction or self-repair (2000, p. 102). Figure 4.23 illustrates this instance when Charlie began his turn in Spanish but switched mid-way, arguably, due to his likely lack of ability in that language.

Figure 4.23 Alternated verb phrase: Self-repair

Charlie: Cas... Get married? ... (\#277)

Charlie: Get marr... Get married? ...

Before leaving the discussion of verbs and verb phrases, it is worth pointing out that, similar to the situation discussed in relation to alternated nouns, noun phrases, and prepositional phrases, verb phrases classified as alternation were problematic for Muysken's typology. I opted to classify the verb phrases in Figure 4.22 as occurrences 
of alternation because they signaled the initiation of longer, more complex switches. However, other analysts such as Myers-Scotton could argue that the Spanish noun phrases preceding verbs and verb phrases were simply inserted into English ML structures and, therefore, those elements should have been considered cases of insertion.

\section{Interjections}

Another CS element found in the script and classified as a case of alternation was interjections, which appeared once in within-turn switches and 17 times in between-turn switches. This distribution was not really surprising when considering that interjections tend to express emotion and, therefore, they are more likely to be uttered in response to another utterance. In addition, they also tend to stand alone or be utterance initial.

With respect to the language of these interjections, six were said in English while the rest were uttered in Spanish. The elements considered interjections totaled nine and were used with the following frequency: "oh" $(5 x)$, "ay" 'oh' $(3 x)$; "cuidado" 'be careful,' "gracias" 'thanks,' and "what" (2x each); and "ajá" 'right,' "hola” 'hello,' “olé" 'wow,' and “thanks" (1x each). I should mention that one of the interjections located in the script, "oh," could be considered either an English or a Spanish interjection; therefore, I used the language of words that followed it to determine the language of such occurrences. Figure 4.24, Examples of interjection "oh," shows occurrences in the two languages to contrast this situation. 
Figure 4.24 Examples of interjection "oh"

a. Liliana: ...Don Armando podría matarte. (\#297)

Liliana: ...Don Armando could kill you.

Charlie: Oh, I'm trained for war... (\#298)

b. Charlie: No one wants me back home. (\#252)

Liliana: $O h$, yo creo que todos querrían... (\#253)

Liliana: $O h$, I think everybody would like...

In terms of the characters involved in the use of interjections, all four

characters present on stage used them to one extent or another; however, it was

Charlie who used English interjections five times and Liliana who used Spanish ones

in nine cases. Figure 4.25 illustrates the lone occurrence found in within-turn switches

and one example with the same interjection used in between-turn switches.

Figure 4.25 Examples of interjections

a. Within-turn switches

Liliana: ... find another way out. Ay, Grandmére, espero que... (\#1)

Liliana: ... find another way out. $O h$, Grandmother, I hope that...

b. Between-turn switches

Charlie: ...I got a pack of gum too. (\#134)

Liliana: $A y$, a ver, OK, sólo cinco minutos... (\#135)

Liliana: $O h$, let's see, OK, only five minutes...

The use of interjections seemed to add flavor to the script-particularly when

Spanish words were uttered-because some of them they did not have an exact

equivalent in English. Jonsson argued "one possible English alternative [for "ay"]

would be alas but this is semantically unsuitable in some contexts . . . and also sounds

archaic" (2010, p. 1300). Another interesting observation with regard to interjections

is that most of them were followed by words in the same language. This is important 
because the language of the interjection seemed to announce the language of the utterance.

\section{Terms of Address}

As shown in Table 4.7, Alternation in within-turn and between-turn switches, there were 36 occurrences of CS involving terms of address, most of which took place in within-turn switches. My interest in analyzing this specific type of noun and noun phrase was to determine how they interacted with elements of other languages and to investigate their possible effect on creating character traits. A more detailed discussion of the later aspect is presented in the following section, which addresses research question three and issues of function. As previously mentioned in footnote ' $a$ ' to Table 4.7, Alternation in within-turn and between-turn switches, terms of address are nouns and noun phrases that by forming a single, unique constituent and sometimes being embedded in a ML structure, could have been considered occurrences of insertion. However, I decided to treat them as cases of alternation because, as was the case with adverbs and interjections, they were extra-sentential elements. They could also be seen as emblematic or tag-switching, another criterion put forth by Muysken as indicative of alternation cases. Before I continue with this discussion, I should state that there were many more cases of nouns and noun phrases functioning as terms of address, but they happened in the same language as the preceding words or at the beginning of a turn unrelated to its predecessor; therefore, they were not considered occurrences of CS. There were 14 different types of terms of address identified as alternation, but only six of them occurred multiple times- "Capitán” 'Captain' (9x), "mon chéri” 'my 
dear' (7x), "gadje" 'non-gypsy' (6x), and "soldier/rich boy," "mon ami”" 'my friend,' and "policía" 'police' ( $2 \mathrm{x}$ each). The most commonly recurring terms of address are presented in Figure 4.26.

Figure 4.26 Examples of term of address

a. Don Armando: ...Aléjate de ellos. (\#105)

Liliana: Just doing my job, Capitán. (\#106)

Don Armando: ... Stay away from them.

Liliana: Just doing my job, Captain.

b. Charlie: ...I don't want to kill and I sure didn’t want to lose my dad. (\#212)

Liliana: Do not be sad, mon chéri. Tú no estás solo... (\#213)

Liliana: Do not be sad, my dear. You are not alone...

c. Don Armando: ...Véte gadje. Mantenga a su hijo lejos... (\#101)

Don Armando: ...Go away non-gypsy. Keep your son away...

The examples presented in Figure 4.26 demonstrate the variety of contexts in which terms of address occurred in the script. It is important to point out that whenever a French or Romani term of address was used, it occurred at the end of the turn (3x), or was followed by either English (2x) or Spanish (9x) elements. This observation is not surprising because members of the audience were not expected to have the necessary fluency to understand longer switches in either of those languagesFrench and Romani. The context in which English and Spanish terms of address were found was equally diverse, although they tended to occur more often in turn final positions (8x). Finally, in four cases a Spanish term of address-“"Capitán" (3x) and "mijo" 'my son' (1x)-was embedded in an otherwise English utterance.

Similar to what was observed in regard to interjections, all four characters present on stage codeswitched terms of address to one extent or another. However, the 
relationship between the words and the characters who used them could provide some information with regard to character development. Liliana (8x) and Rose (1x) addressed Don Armando with the word "Capitán" and by doing so, recognized his authority as the gypsy leader. Similarly, "mon chéri" was used exclusively by Lilianaas a sign of endearment-when addressing Charlie, while "gadje" was uttered by Liliana and Don Armando (3x each) in reference to Charlie and helped to establish him as an outsider.

\section{Clauses}

Clauses comprised the highest incidences of alternation found in within-turn switches and between-turn switches, with 315 and 166 occurrences, respectively. As mentioned in the literature review chapter, there were several diagnostic features taken from Muysken's typology that motivated me to classify clauses as alternation. The cases presented in Figure 4.27, Examples of independent clause alternation, illustrate how these switches consisted of lengthy and complex switches of non-selected elements, one of the criteria mentioned by Muysken to consider certain CS occurrences as alternation. This complexity is particularly evident in example ' $a$,' in which the pronoun's referent is found in a clause occurring in another language.

Figure 4.27 Examples of independent clause alternation

a. Don Armando: Then flirting with his brother! A ese ya lo han prometido a alguien más... (\#44)

Don Armando: Then flirting with his brother! He has been already promised to somebody else... 
Figure 4.27 (Con't.) Examples of independent clause alternation

b. Liliana: ...she snuck books into her tent no matter how much she was punished. $A$ pesar de tantos problemas que causaba a ella no le importaba. She refused to change. (\#276)

Liliana: ... she snuck books into her tent no matter how much she was punished. Despite all the problems that she caused, she did not care. She refused to change.

The majority of occurrences-237 and 141 instances in within-turn and between-turn switches, respectively-involved the alternation of independent clauses similar to those presented in the above examples and did not contain any special characteristic other than the fact that they constituted occurrences of CS. Consequently, I will focus the analysis on occurrences when independent clauses were connected with conjunctions (83 times) or adverbs (12 times), or when an independent clause occurred in one language and its dependent clause happened in another (eight times).

Table 4.10, Conjunctions used in alternation, provides an exhaustive list of the conjunctions used, along with the number of occurrences. The fact that connecting conjunctions were found $17 \%$ of the time clauses were alternated pointed to the possibility of addressing the needs of monolingual members of the audience. Even though monolingual speakers might not fully understand the preceding clause, the use of conjunctions could be seen as giving continuity to the utterance and encouraging audiences to make connections and inferences. This was even more plausible when considering the equitable use of English and Spanish conjunctions; out of 83 occurrences, 38 involved English and 45 involved Spanish. 
Table 4.10. Conjunctions used in alternation.

\begin{tabular}{|c|c|c|c|}
\hline Conjunction & $\begin{array}{c}\text { Occurrences } \\
\text { in within-turn } \\
\text { switches }\end{array}$ & $\begin{array}{l}\text { Occurrences } \\
\text { in between- } \\
\text { turn switches }\end{array}$ & Total \\
\hline \multicolumn{4}{|l|}{ English } \\
\hline - $\quad$ and & 9 & 3 & 12 \\
\hline - $\quad$ and now & 1 & 0 & 1 \\
\hline - $\quad$ and then & 3 & 0 & 3 \\
\hline - but & 6 & 3 & 9 \\
\hline - $\quad$ or & 1 & 0 & 1 \\
\hline - so & $2^{\mathrm{a}}$ & $9^{\mathrm{a}, \mathrm{b}}$ & 11 \\
\hline - $\quad$ then & 1 & 0 & 1 \\
\hline \multicolumn{4}{|l|}{ Spanish } \\
\hline - $\quad$ así que 'so' & $7^{\mathrm{a}}$ & $1^{\mathrm{a}}$ & 8 \\
\hline - entonces 'then' & 0 & $3^{\mathrm{a}}$ & 3 \\
\hline - $\quad$ o 'or' & 2 & 1 & 3 \\
\hline - $\quad$ pero 'but' & 7 & 3 & 10 \\
\hline - $\quad$ y 'and' & 18 & 1 & 19 \\
\hline - $\quad$ y entonces 'and then' & $2^{\mathrm{a}}$ & 0 & 2 \\
\hline Total & 59 & 24 & 83 \\
\hline
\end{tabular}

${ }^{\mathrm{a}}$ These four conjunctions $(24 \mathrm{x})$ introduced resultative clauses that showed cause and effect relationships.

${ }^{\mathrm{b}}$ In addition to introducing a resultative clause, this conjunction functioned as a discourse marker.

Examples with the most common conjunctions in within-turn and between-turn switches, other than those introducing resultative clauses, are presented in Figure 4.28, with the conjunctions double-underlined for clarity.

Figure 4.28 Examples of clause alternation with conjunctions

a. Within-turn switches

i. Liliana: ...digo el futuro and acquire things for my people. (\#147)

Liliana: ...I tell the future and acquire things for my people.

ii. Liliana: We are like 1000 years old yू nuestro futuro ha estado... (\#275)

Liliana: We are like 1000 years old and our future has been... 
Figure 4.28 (Con't.) Examples of clause alternation with conjunctions

b. Between-turn switches

i. Charlie: ...then I'll enlist. (\#15)

Rose: ¿ $\underline{\underline{\text { Pero }}}$ por qué te enlistarías en la infantería?... (\#16)

Rose: But why would you enlist in the army?...

ii. Rose: ...juntas le enseñaremos a este Gitano su futuro. (\#433)

Rose: ...together we will teach this Gypsy his future.

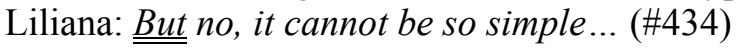

As noted in footnote ' $a$ ' to Table 4.10, Conjunctions used in alternation, four conjunctions-“so" (11x), “así que" ‘so' $(8 \mathrm{x})$, “entonces” ‘then’ $(3 \mathrm{x})$, and “y entonces” 'and then' $(2 \mathrm{x})$-of which there were 24 tokens in total demonstrated a cause and effect relationship between the two clauses connected. Figure 4.29, Examples of clause alternation with resultative conjunctions, illustrates this situation with three of the most common conjunctions. The use of these resultative conjunctions served a similar function as conjunctions in general, but they had the potential of helping monolingual speakers understand the plot even more by requiring them to engage in induction and deduction processes.

Figure 4.29 Examples of clause alternation with resultative conjunctions

a. Within-turn switches

i. Liliana: ...tengo que tocar el violín... so I can make money. (\#157)

Liliana: ...I have to play the violin...so I can make money.

ii. Rose: ...The military has been very good to us asi que creo que la milicia es lo que te conviene. (\#38)

Rose: ... The military has been very good to us so I think the army is the most convenient.

b. Between-turn switches

i. Rose: ...Necesitaba comenzar un futuro mejor, una vida mejor. (\#431)

Rose: ...I needed to start a better future, a better life.

Charlie: So I'm a gypsy. (\#432) 
Figure 4.29 (Con't.) Examples of clause alternation with resultative conjunctions

ii. Liliana: Me gustaría ir a la escuela....and learn to write stories. (\#257)

Charlie: i $\underline{\underline{\text { Entonces }}}$ ven conmigo! (\#258)

Liliana: I would like to go to school... and learn to write stories.

Charlie: Then come with me!

There were 12 cases of within-turn switches where the clauses were connected with adverbs that demonstrated either temporal alignment or served to introduce new information. In the first case, the adverbs used were "now" (4x), "ahora" 'now' $(2 x)$, and "después" 'later' (1x). The second function of connecting adverbs was served by “besides" (3x) and "además" 'besides' (2x). Relevant examples are illustrated in Figure 4.30.

Figure 4.30 Examples of clause alternation with adverbs

a. Temporal alignment

Don Armando: Era un arreglo perfecto. Now another meeting will have to... (\#44)

Don Armando: It was a perfect arrangement. Now another meeting will have to...

b. Introduction of new information

Liliana: Mi gente nunca me dejaría ir. Besides you just said that no one wants you there. (\#259)

Liliana: My people would never let me go. Besides you just said that no one wants you there.

The last issue to be analyzed in relation to the alternation of clauses is that of dependent and independent clauses, which took place primarily in within-turn switches. Figure 4.31, Alternation of dependent and independent clauses, shows instances representative of this type of switch found in the data. 
Figure 4.31 Alternation of dependent and independent clauses

a. Within-turn switches

i. Rose: ...After your father died hicimos el peregrinaje juntos... (\#20)

Rose: ...After your father died we did the pilgrimage together...

ii. Liliana: ...si hacemos un truco maybe we can get out of trouble... (\#301)

Liliana: ...if we play a trick maybe we can get out of trouble...

b. Between-turn switches

Don Armando: ... todo lo que toca se marchita y muere... (\#352)

Don Armando: ...everything that you touch withers and dies...

Rose: Only if I want it to... (\#353)

A noteworthy observation occurring in within-turn switches is that whenever the dependent clause was in Spanish, the subordinating conjunctions used were "si" 'if' (2x) (see Figure 4.31.a.ii for an example) and "porque" 'because' (1x). This occurred in contrast with the various conjunctions used in English dependent clauses"after" (Figure 4.31.a.i), "if," "now that," and "since" (1x each). The only time that a between-turn switch involved dependent and independent clauses is presented in Figure 4.31.b. This lone occurrence in 481 clauses $(0.002 \%)$ and the fact that withinturn switches involving dependent and independent clauses amounted to only $0.015 \%$ of the total alternated clauses might be arguments in support of the claim that using this type of element or structure and communicating a clear message to diverse audiences could be very difficult.

This brings the discussion relating to alternation to an end. Several findings are worth mentioning such as the widespread alternation of independent clauses as well as the use of adverbs and adverbial phrases. Both of these issues will be discussed in greater detail shortly when I provide the answer to research question two. 
Having now described extensively insertion and alternation occurrences of CS, I will focus the rest of the analysis of form section on those occurrences classified as congruent lexicalization.

\section{Congruent Lexicalization}

The type of CS occurrence least used in the script of Mi Vida Gitana was congruent lexicalization, with only five cases identified. The reasons for the limited use of this CS process will be discussed in the summary section; however, it seems fitting at this point to present and discuss the instances where congruent lexicalization was employed. All five occurrences are presented in Figure 4.32.

\section{Figure 4.32 Occurrences of congruent lexicalization}

a. Liliana: ... Tú no entiendes, mi grandmére wrote. (\#183)

Liliana: ...You don't understand, my grandmother wrote.

b. Liliana: ...y mi mamá taught me how to read estos poemas. (\#195)

Liliana: ... and my mother taught me how to read these poems.

c. Liliana: ...tal como tú vas a pelear en la guerra, mi gente will risk everything hasta morir por amor. (\#285)

Liliana: ...just like you go to fight in a war, my people will risk everything even dying for love.

d. Don Armando: ...Todo el mundo knows that you killed mi primo, y ningún Romani creerá... (\#348)

Don Armando: ... The entire world knows that you killed my cousin, and not even one Romani will believe...

e. Liliana: ...tienes que cuidar a tu madre like tu papá said. (\#412)

Liliana: ...you have to take care of your mother like your father said.

It is important to point out from the occurrences presented in Figure 4.32 that two out of three characters whose linguistic and national background would indicate they had the potential to employ this type of CS did, indeed, utilize it to varying 
degrees. Liliana used it four times while Don Armando made use of it once. This observation is relevant to the issues raised by research question three and, therefore, will be addressed more thoroughly in the context of that question.

Returning to the congruent lexicalization phenomenon itself, as mentioned in the literature review and methodology chapters, there were certain diagnostic features that helped me to classify the utterances presented in Figure 4.32 as occurrences of congruent lexicalization. One of those features, linear and structural equivalence, stated that the order in which constituents were organized had to be the same or quite similar. This situation is illustrated in the above examples by looking at the way that the gloss corresponds to the original text. Although some diagnostic features were similar to those used to classify occurrences as insertion, the fact that several constituents (Figure 4.32.b and d) and single words (Figure 4.32.a and e) were switched made me consider these as cases of congruent lexicalization, since Muysken described it as a CS process much more involved and complex than insertion. Another reason why I considered the above occurrences congruent lexicalization instead of insertion or even alternation was that the subject happened in one language-mostly Spanish-the verb or verb phrase occurred in another language-English in most casesand the rest of the predicate-if there was one and whether consisting of a direct object or a prepositional phrase-was uttered in the original language. Example 'c' in Figure 4.32, Occurrences of congruent lexicalization, shows this situation and it also presents an instance where congruent lexicalization involved dependent and independent clauses. Unlike cases of alternation, which showed entire dependent or independent 
clauses occurring exclusively in one language or the other, this occurrence of congruent lexicalization combined the two languages and could have been directed to bilingual audience members because of its complexity. I should indicate that the same turn containing this occurrence also contained complete, similar ideas in both English and Spanish-"we have to follow rules and the code" and "tal como ustedes... tenemos tradiciones" 'just like you... we have traditions,' so as to not forsake monolingual speakers in the audience.

Before leaving this discussion about congruent lexicalization, I would like to remind readers of some of the issues I encountered while applying Muysken's typology to current data. As indicated in the methodology chapter and repeated during the discussion of alternated nouns, noun phrases, prepositional phrases, and verb phrases, some CS occurrences found in the script of Mi Vida Gitana did not fit Muysken's typology perfectly, in the sense that diagnostic features for different CS processes seemed to account for or explain the same occurrence. This is undoubtedly the situation in the cases classified as congruent lexicalization. Nouns and noun phrases included in this CS category could have been analyzed as instances of insertion, if the unique constituent feature were followed. Likewise, longer switches involving several predicate elements could have been considered alternation occurrences, if the length and complexity feature were adhered to. While discussing CS involving English and Spanish in Gibraltar, Muysken stated "the collocation of two expressions, a verb and a complement, is the site for a code-mix. Often the verb is in the dominant language ... and the complement an inserted constituent [italics 
added]" (2000, p. 147). Although the diagnostic features would point to such an occurrence as a case of insertion, Muysken considered it "revelatory of congruent lexicalization" (p. 147). This type of ambiguity represented a real challenge when deciding the most appropriate category in which to place CS occurrences.

\section{Research Question Two Summary}

The discussion presented in this section yielded the information necessary to arrive at the answer to research question two. CS in the script of Mi Vida Gitana showed repeated use of nouns, particularly in insertion occurrences, and to a lesser extent in alternation and congruent lexicalization; a high frequency of alternation of independent clauses and adverbs; and limited occurrences of congruent lexicalization.

The high number of occurrences involving nouns supported the results of previous studies and claims made by such diverse scholars as Lipski, Muysken, and Myers-Scotton. Since nouns have specific referents, the fact that CS in Mi Vida Gitana made such extensive use of these syntactic elements seemed to equate the linguistic behavior expected of bilingual speakers and could be seeing as echoing Lipski's observation "language switches [of the] lexical substitution [type] usually involves nouns or idiomatic expressions, less frequently other elements" (1985, p. 54). An important observation with regard to CS involving nouns and noun phrases is the fact that English and Spanish played very different roles in this process. English seemed to function as the language providing the overall structure for the nouns and noun phrases to be inserted into, while Spanish was the language that supplied the majority of this type of elements. This observation is more compelling when considering that 
Spanish nouns and noun phrases were inserted and alternated 20 and 23 times, respectively, compared to English's 5 occurrences of insertion and 15 occurrences of alternation. Upon examining data more closely and considering the context in which the play was performed-in terms of the audience's background, I propose this was the case because a bigger segment of the audience was believed to be more proficient in English than Spanish. A final comment related to inserted and alternated nouns and noun phrases is that many of these elements-whether occurring in French, Romani, or Spanish, and, to a lesser extent, in English-were repeated several times throughout the script and, therefore, could be seen as a contributing factor in the understanding of the story on the part of the diverse audience. This point that will be further addressed when discussing reiterations in the context of research question four.

The most recurring type of CS occurrence was the alternation of clauses. While analyzing CS in literature, Lipski had found "the frequency of code switches at sentence boundaries is quite high in literature, which reflects the preference for separating propositions by language categories, even in highly integrated bilingual literature" $(1985$, p. 81$)$. It could be argued that if alternation of clauses was expected to take place when reaching a bilingual audience, the nature of the audience attending Mi Vida Gitana's performances-bilingual and monolingual speakers-would make this type of CS process even more common and necessary. It is also important to highlight that many of these clauses began with some type of conjunction; this was the case in $17 \%$ of the occurrences. As mentioned before, I argued that the use of conjunctions could have a positive effect on the audience's comprehension because, as Lipski put it 
"any sentence containing two clauses conjoined ... represents a mental image in which discrete situations are postulated from the outset.... the conjunction represents two equivalent clauses and also two equivalent types of context” (1985, p. 48).

The second most common syntactic element used in alternation was adverbs. As mentioned before, adverbs tended to consist of extra-sentential responses and discourse markers, and as such, confirmed Muysken's as well as Myers-Scotton's expectations who declared that " adverbial phrases ... are adjuncts ... outside the predicate-argument structure projected by the main clause verb" (Myers-Scotton, 2002, p. 141).

The last observation I discuss in order to answer research question two does not deal with a CS process commonly found in the script, but rather with the absence of such process, namely, congruent lexicalization. I had originally expected to see many more occurrences of congruent lexicalization in the script of Mi Vida Gitana based on Muysken's and Myers-Scotton's claims. Using Spanish and English data originally collected by Sankoff and Poplack, Muysken observed it was "remarkable for how many categories there is a bi-directional pattern suggesting congruent lexicalization" (2000, p. 235). Similarly, Myers-Scotton argued that with higher proficiency in both languages, EL islands went down and "switching between CPs becomes very frequent as well as switching between sentences, which, of course, may include more than one CP” (2002, p. 149). Given the overall high number of occurrences and the fact that I had identified several EL islands, I was anticipating finding numerous cases of congruent lexicalization. However, data from the script of 
Mi Vida Gitana only included five such occurrences. It could be argued that the ambiguity of some of the diagnostic features contributed to the realization of such a low number of occurrences. At the same time, I propose that this might have also been the case because this type of CS occurrence would have been more difficult to understand by "beginner bilinguals" and completely incomprehensible to monolingual speakers.

This concludes the discussion of CS processes and elements and the analysis of form. Results from the analysis of function are presented in the following section.

\section{Analysis of Function}

The remaining research questions necessitate the analysis to move from a pure structural point of view to a more functional standpoint. Before looking at the data in search of answers to research questions three and four, it is imperative to mention that CS in the script of Mi Vida Gitana served a dual function: contributing to the artistic embellishment of the play and communicating a message to a diverse audience. This dual purpose is discussed in the context of the two remaining research questions.

This section begins with a general discussion of the various languages used in the script and continues with language use profiles for each character. The observations from this discussion provide the answer to research question three. The second part of this section contains the analysis and examples of how CS could be a factor in the comprehension of the story, particularly, for monolingual members of the audience; in other words, it generates the information needed to answer research question four. 


\section{Research Question Three}

Without leaving completely aside the analysis of form already presented, because some of the findings from the previously addressed questions could garner some valuable insight relevant to the issue at hand, research question three seeks to understand how CS contributed to the creation of authentic characters and, consequently, a more believable story.

Research Question 3. What is the function, if any, of CS with respect to character development?

The following paragraph provides a summary assessment of the overall language usage in the play. That paragraph is followed by a visual representation of the total number of words uttered by each character and classified according to the various languages. A few general observations are made based on this visual representation and are followed by a more detailed, personalized account of how language choices might have contributed to character development.

At first, it seemed that Liliana and Don Armando's use of both English and Spanish was presented primarily to aid monolingual audiences understand the play because one would not expect this linguistic behavior on the part of Spanish speakers talking to each other. However, Liliana's balanced use of the two languages could also be seen as necessary for a gypsy girl whose survival depends on dealing with tourists, as evidenced by her statement "Tendré muchos problemas si no llevo dinero a casa" 'I will have many problems if I don't take home some money.' A similar claim could be 
made with respect to Don Armando; his interactions with tourists, as expressed in Liliana's statement "We meet so many tourists" seemed to have allowed him to acquire certain language skills. Rose's equitable use of English and Spanish was appropriate in light of her statement "This is my home...y aquí necesitas hablar español” ‘... and here you need to speak Spanish.’ Likewise, Charlie's predominant use of English was in line with his declaration "The Captain only wanted me to speak English, 'cause we're American first, Texan second and Latino last, and that was beat into me."

A close look at the specific languages used by each character could provide valuable, additional information to answer the question at hand. Table 4.11 provides a visual representation of the language used by each character by showing the number of words pronounced in each language.

Table 4.11. Language usage by character, by words.

\begin{tabular}{|l|r|r|r|r|r|r|}
\hline Character & Arabic & English & French & Romani & Spanish & Total \\
\hline Charlie & 0 & 3,076 & 7 & 4 & 138 & 3,225 \\
\hline Charlie's Dad & 0 & 268 & 0 & 0 & 0 & 268 \\
\hline Don Armando & 0 & 266 & 0 & 11 & 685 & 962 \\
\hline Liliana & 1 & 1,553 & 57 & 25 & 1,547 & 3,183 \\
\hline Rose & 1 & 1,038 & 0 & 0 & 713 & 1,752 \\
\hline Total & 2 & 6,201 & 64 & 40 & 3,083 & 9,390 \\
\hline
\end{tabular}

In addition to using the information illustrated in Table 4.11, it is useful to analyze each character's involvement in between-turn continuity and between-turn switches. During the discussion surrounding research question one (see Table 4.1, Between-turn continuity by character and language pair, and Table 4.2, Between-turn 
switches by character and language pair), I pointed out that Charlie was the character most involved in between-turn continuity when the language at hand was English. He was also the character who most frequently started his turn in English when the previous turn ended in Spanish-96 times-and whose interlocutors started their turns in Spanish even though he ended his in English-101 times. Of this last number, it is worth mentioning that Liliana was involved in 83 instances. This behavior on the part of both Charlie and Liliana was important for their development as characters, as will be shown shortly. Charlie, on the one hand, was represented as an American young man who had not finished high school, did not have much of an education and, therefore, was unable to fluently express himself in any other languages but English. Liliana, on the other hand, was portrayed as a much more bilingual speaker of both English and Spanish.

I also pay special attention to the number of occurrences of within-turn switches because their frequency and the context in which these occurrences took place could be relevant to arrive at the answer to the question at hand. As previously mentioned in the context of research question one, the number of occurrences of within-turn switches for Don Armando, Liliana, and Rose was at least double the number of turns in which they were found (58/21=2.76 for Don Armando; $296 / 113=2.62$ for Liliana; and 106/47=2.26 for Rose). However, this number was much lower for Charlie-36/30=1.2. This noticeable difference began to show what Charlie's character was like. Once again, his language of choice was English and his CS ability was mostly limited to a few insertions and emblematic switches. 
Before discussing each character individually, I would like to comment on the disparity of between-turn and within-turn switches by Charlie and Liliana as well as their non-equivalent use of English and Spanish. I had expected similar patterns in language use since they were the main characters and had the highest number of overall turns at 183 and 157, respectively. However, upon closer examination, I attributed this disparity of usage and lack of usage of CS to character development because it portrayed Charlie and Liliana as very distinct individuals. Another important issue was Liliana's use of CS could have an impact on Spanish monolingual audience members' comprehension of the story. Without Liliana's consistent use of the two languages, Charlie's predominant use of English could have left this sector of the audience at a loss. In other words, Liliana's CS and her use of Spanish, in particular, helped counterbalance Charlie's use of English. This point will be further discussed when addressing research question four and, most specifically, the use of reiterations.

\section{Charlie}

Charlie's character was portrayed as a young man struggling with his identity. Even though most of his utterances were only in English, he used words from four out of the five languages found in the script. Throughout the script Charlie used some Spanish, although he acknowledged his lack of ability in that language as evidenced by the utterance "Is that some kinda' Spanish sayin'?" Even though this example did not constitute an instance of CS, per se, Charlie showed his desire to learn Spanish when talking to his mother and saying “Lily's givin' me Spanish lessons. Doesn't that 
make you happy?" The total number of Spanish words used by Charlie presented in Table 4.11, Language usage by character, by words, might be a bit misleading when considering that he sang the same song, which consisted of 34 Spanish words, twice. Nonetheless, there were a few words he uttered in Spanish that contributed to developing his character as one searching for his true identity. One Spanish word Charlie used repeatedly was "tejanos" 'Texans' $(3 \mathrm{x})$. The fact that he pronounced the word in this language was a testimony of his identity crisis because he used it to refer to himself and people like him. Myers-Scotton claimed "marked choices have the special value of evoking an 'otherness"” (1998c, p. 66), so when he chose to use a marked element instead of using the unmarked word, Texans, it could be seen as giving the audience a glimpse into the struggles he was facing. Another Spanish phrase he used several times was "mi amor" 'my love' $(3 \mathrm{x})$. This expression was particularly important because, as Myers-Scotton noted, "instances of marked terms of address . . . contribute to the development of the narrative. . . The phrases foreshadow what is going to happen" (1998b, p. 11). The first time he said the phrase had a humorous tone because he used it in front of his mother after Liliana had called him "mi vida" 'my life;' however, the last one was very solemn and occurred in response to Liliana's question regarding the sincerity of his request "Liliana, will you please be my partner?"

The four Romani words he used throughout the script made more sense when the play reached its climax and the audience discovered that Charlie was the son of a gypsy. It is important to mention that all four Romani words he used had been 
previously used and defined by Liliana. Although he used some French words early in the script by uttering the collocation "Parlez-vous français?" 'Do you speak French?,' his use of this language was later limited to a few inserted nouns-"grandmére" 'grandmother' and "grandpére" 'grandfather' (2x each).

\section{Charlie's Dad}

Although he never physically appeared on any of the scenes of the play, Charlie's Dad was an important character because his voice-overs helped to move the story along and further develop Charlie's character. Charlie's Dad used English exclusively and this lack of CS contributed to understanding Charlie's situation. Charlie's Dad expected him to use English-"The Captain only wanted me to speak English"-whereas his mother demanded that he speak Spanish-“en mi casa aprenderás maneras y español, ¡como los españoles!” ‘in my home you will learn good manners and Spanish, like Spaniards!'

As was observed in Charlie's case, his CS, although limited, served to create a specific persona; in contrast, his dad's lack of CS worked to produce a different type of character. It is important to consider this use of linguistic behavior as a possible tool employed by the playwright in order to develop characters.

\section{Don Armando}

Don Armando's CS served the dual function aforementioned, in the same way that Liliana's and Rose's did, as will be seen later. On the one hand, his mixing of English and Spanish while talking to Liliana was not the expected linguistic behavior between people living in Spain; therefore, I argue that using these two languages in 
their interactions helped monolingual audiences understand what happened in the scene. On the other hand, Don Armando's predominant use of Spanish when speaking with Rose did fit the anticipated behavior because they were both Spaniards; therefore, I claim that such language use contributed artistically to the script and helped to create a certain type of character. Throughout the script Don Armando used several Romani words, which contributed to make him a more convincing gypsy leader. Unlike Liliana, he did not explain their meaning, but trusted that the audience was able to follow along by using the program notes and the definitions previously given by Liliana. Although the second option was valid in some cases, several of the Romani words were initially uttered by Don Armando, which made relying on the program notes more important for audience members. Somewhat surprising is the fact that he did not use any Romani words, other than "gadje" 'non-gypsy,' when dealing with Rose. A possible explanation for this is that said language was employed mostly to add flavor to the play and, since neither he nor Rose translated Romani words during their turns, audiences would have to depend too much on outside sources to comprehend such elements.

\section{Liliana}

The noticeable balance of English and Spanish use on Liliana's part made it difficult to identify marked and unmarked choices, following the MM's guidelines. Nonetheless, Myers-Scotton recognized that certain speakers 
present themselves as enablers in that they make it possible for a conversation to take place. . . By utilizing their ability to switch from one code to another they show off their linguistic repertoire and therefore show themselves as multidimensional individuals. (1998a, p. 26)

Liliana’s English-Spanish CS could be seen as fitting Myers-Scotton's profile and also helping to create a character that was culturally diverse. Liliana's desire to communicate with Charlie and engage him in conversation was observed throughout the script. During one of the exchanges between Charlie and Liliana, she said "y cómo un simple y guapo niño como tú, ¿cómo se dice, gets kicked out of school?” 'and how is it that a simple and handsome boy like you, how do you say it,...' In another scene, she said "Hang out like laundry?" in response to Charlie's invitation to spend time together. The fact that she used the expression "¿cómo se dice?” "how do you say it?' and was uncertain and curious about the meaning of English expressions provided some insight into her efforts to use English.

With regard to Liliana's use of French, it contributed to her credibility. She answered "De la France" 'From France' in response to Charlie's question "where do you come from?" and, in another scene, she stated "After we got here...” It is important to mention that Liliana's use of French words and expressions was mostly limited to inserted nouns and noun phrases-many of them, kinship terms, emblematic switches, and alternated terms of address. This specific and limited use of French could also provide some information about the playwright's expectations as they relate to the language proficiency of the audience. Further CS involving French might have 
been confusing for the audience or, at least, required more explanations and translations by the characters present in those conversations.

Similar to the situation presented by the use of French, Romani's use granted credibility to Liliana. The use of this language was also limited, therefore reducing the need for lengthy translations and explanations. However, Romani's unfamiliarity compared to French made it necessary to inform the audience of the meaning of Romani words. Program notes distributed during the performance served this purpose but Liliana also filled this responsibility during some scenes. What is interesting about her use of Romani words was that immediately after using them, she provided an explanation or translation. Sometimes this occurred at the request of Charlie-her most frequent interlocutor-but in other instances, her explanations were not prompted by anybody in the scene; therefore, they could be seen as serving the previously mentioned dual function of CS in the script: artistic and communicative. Figure 4.33 provides two relevant examples, one from each context-requested and non-requested explanation, regarding Liliana's role in facilitating audience's comprehension.

Figure 4.33 Examples of Romani words translated or explained in the script

a. Charlie: ...walk me through this thing. What's a chay-eez [čeiz]? (\#280) Liliana: Se supone que es el mejor momento para una chica. On the night of the wedding everyone brings gifts of gold... (\#281)

Charlie: ...walk me through this thing. What's a wedding party? Liliana: It is supposed to be the best time for a girl. On the night of the wedding everyone brings gifts of gold...

b. Don Armando: ...puedes mendigar por tu cena. (\#44)

Liliana: Da, Dom Capitán, da. Yes, Sir Capitán, sí. (\#45)

Don Armando: ... you can beg for your dinner. Liliana: Yes, captain, yes. Yes, Sir captain, yes. 
In the second example (Figure 4.33.b), the Romani words "da dom" 'yes' were immediately translated into their English and Spanish equivalent, "yes" and "sí" "yes" respectively. Since the meaning of the words had been established upon their first occurrence, Liliana used them repeatedly throughout the script. However, in those later cases, there was no translation or explanation because of the formulaic structure of the response as well as its similarity to the original utterance, "Da, dom Capitán" 'Yes, captain.'

One last observation with regard to Liliana's use of CS is related to her way of addressing Don Armando. Throughout the script, she used the Spanish noun "Capitán" 'captain' (8x) as a term of address, which had the connotation of submission to his authority. However, on the last scene, she referred to him by his name and, by doing so, distanced herself from his command and signaled the beginning of a new era in her life.

Rose

As previously mentioned, Rose's use of English and Spanish reflected her national background. However, her use of CS seemed to be more aligned with helping the audience understand the story rather than with developing a character. This is the conclusion arrived at when considering that she addressed Charlie in both English and Spanish, even though he used mostly English with her. In contrast, Rose spoke almost exclusively in English when addressing Don Armando, whose primary language was Spanish. In spite of the above claims, what is noteworthy with regard to CS and character development in Rose's case was her lack of CS involving Romani. Toward 
the end of the script, her true identity as a gypsy woman was revealed; however, up to that point in the script and even after it, she did not utter any Romani words. Not engaging in English-Romani and Spanish-Romani CS helped to develop her character, particularly when viewed against her statement "It's not easy being a gypsy, especially when no one's watching your back." In contrast to Liliana's situation, where CS permeated most of her interactions in order to create a multifaceted persona, it was Rose's linguistic choice to minimize this type of CS that helped to develop her character as a gypsy woman haunted by her past.

\section{Research Question Three Summary}

It has become evident during this discussion that CS in the script of Mi Vida Gitana served multiple purposes. Originally, it seemed that the sole function of having the characters use various languages, particularly English and Spanish, was to communicate a clearer message to a diverse audience. This was the case in light of the apparently oddness of people from Spain using English in their daily conversations. However, upon further analysis of the linguistic behavior of characters, it was determined that there was a more subtle purpose for CS. Charlie's attempts to use Spanish could be seen as an expression of his desire to fit into Liliana's life. Liliana and Don Armando's use of English demonstrated the reality of life for gypsies bound to interact with tourists for survival. Rose's balanced use of English and Spanish illustrated her background. In addition, CS involving French and Romani had the function of creating more credible and authentic characters, particularly in the case of Liliana and Don Armando. Alternatively, the absence of CS containing Romani 
elements on Rose's part helped the audience to see her character as that of somebody hiding a secret and escaping a previous life.

\section{Research Question Four}

Research question three dealt primarily with the functions CS served within the script, that is, how it was used to aid in character development. In contrast, research question four seeks to analyze the possible functions CS in the script served with regard to audience's comprehension.

Research Question 4. How does CS contribute to communicating an understandable message to diverse audiences?

As seen throughout the study, the separation of form and function-although somewhat arbitrary-was useful because it allowed for a clearer analysis of data. Similar to research question three, the focus of the current question is mostly functional; however, some mention of form is necessary to generate an appropriate response. The discussion presented here follows the order outlined in the methodology chapter and moves from reiterations, to gap-filling, to conjunctions and responses. It is important to mention and adhere to Jonsson's claim that these focal areas "are not mutually exclusive and several instances of CS could fit into more than one category" and "no list can ever claim to be exhaustive" (2010, p. 1298). As was done with the previous portions of the study, a summary directly addressing the research question asked concludes the section. 


\section{Reiterations}

Throughout the script there were numerous examples of reiterations that had the potential of assisting monolingual audiences understand the story. To set the tone, the first scene of the play used this technique to expand on the words and scenery displayed: Liliana was in prison and was pondering her situation by saying "this concrete and iron will never let me escape. ¿Cuánto tiempo pasaré en esta prisión?” '...How much longer will I spend in this prison?' Even though the playwright did not translate word for word, the images that the English utterance brought to mind were similar to those its Spanish counterpart generated. During that same first scene, Rose was discussing with Charlie what his options were, after being expelled from military academy. She said "those opportunities are gone, ahora tenemos que empezar todo de nuevo" "...now we have to start everything again.' Once more, despite the fact that the phrases were not literal translations of each other, they conveyed very similar meanings, which had the potential of helping either a monolingual English speaker or a monolingual Spanish speaker to follow the story. Needless to say, an EnglishSpanish bilingual speaker would likely understand all the words used during this scene. Figure 4.34 shows a few more examples of this CS function.

Figure 4.34 Reiterations by the same character

a. Don Armando: ...I know that woman from somewhere, ella me recuerda alguien... (\#113)

Don Armando: ...I know that woman from somewhere, she reminds me of somebody... 
Figure 4.34 (Con't.) Reiterations by the same character

b. Liliana: ...make pact with knife...haz tu promesa como un Romani. Este es un pacto de sangre para toda tu vida. (\#273)

Liliana: ...make pact with knife...make your promise like a Romani. This is a blood pact for all your life.

c. Rose: ...All of the charges have been dropped. Ella está libre. (\#419)

Rose: ...All of the charges have been dropped. She is free.

d. Charlie: So...I'm a gypsy...A gypsy life is what I've always wanted, mi vida gitana. (\#432)

Charlie: So...I'm a gypsy...A gypsy life is what I've always wanted, my gypsy life.

Although there were some cases when the reiterations consisted of literal translations, particularly when only single words were uttered in both languages, in many instances the reiterations found in the script were of the paraphrasing type. Jonsson stated that Moraga "does not write in translation, since she does not want to insult her bilingual audiences by making them hear everything twice" (2010, p. 1305). In light of this quote, one must wonder whether the playwright of Mi Vida Gitana purposely used comparable expressions instead of direct translations in order to maintain all sectors of the audience engaged.

Many more instances of reiteration were found between two characters, mostly during conversations involving Liliana and Charlie. It is worth repeating that without Liliana's consistent use of the two languages, Charlie's predominant use of English could have left one sector of the audience at a loss. By way of example, during one of their first encounters Charlie asked Liliana "You work for your dad?" to which she replied, “That's not my dad, he’s my boss...tengo que trabajar” '...I have to work.' It could be argued from this example that similar ideas were expressed without the need 
to translate exactly what the other character was saying. Other examples of this CS

function were found throughout the script and a sample of those is illustrated in Figure 4.35 .

Figure 4.35 Reiterations between two characters

a. Charlie: ... it was pretty cool how you acted like you were my girlfriend... (\#140) Liliana: Ser tu enamorada era solo para fingir... (\#141)

Liliana: Being your lover was only to pretend...

b. Don Armando: ....QQuieres vivir en las calles? (\#337)

Don Armando: ... Do you want to live on the streets?

Liliana: I'm not going to be homeless... (\#338)

c. Don Armando: La arrestarán por robar y pasará varios días en la cárcel...(\#354)

Don Armando: They will arrest her for stealing and she will spend a few days in prison...

Rose: I want her in jail for more than just a few days... (\#355)

d. Charlie: ...told me to stay at home and take care of my mother. (\#411)

Liliana: ...tienes que cuidar a tu madre... (\#412)

Liliana: ... you have to look after your mother...

Gap-filling

Adhering to Jonsson's statement that "all languages are equally rich in that they have equal possibilities of expression ... [but] single words in one language and their counterparts in another language often have different connotations" (2010, p. 1304), this section explores how the use of multiple languages might have resulted in a better script. There were a few instances where words were drawn from a language other than the one predominant in the utterance in order to convey a more specific and significant meaning. I will focus the discussion on two such 'gaps' that were filled with Romani words which, as discussed in the context of research question three, seemed to also have an artistic motivation. A number of times these words and phrases 
did not constitute an integral part of the sentence, particularly in the case of terms of address, yet they seemed to have the function of shifting the tone of the scene or calling attention to specific aspects of the story. This claim is validated by MyersScotton's (1993b) discussion of CS as a marked choice, or marked CS, presented earlier in the study.

Liliana and Don Armando used the word "gadje" 'non-gypsy' repeatedly when addressing or referring to Charlie. Although this word could have been replaced with another, such as 'foreigner' or 'stranger,' its explicitness served to increase the artistic value of the script. As mentioned before, Liliana explained the meaning of this word to Charlie; therefore, using "gadje" did not impair the audience's understanding but rather contributed to the development of the story.

Another emotionally charged word that was used in Romani and served to add flavor and authenticity to the script was “mahrime” 'unclean.' Don Armando used it while talking to Liliana "Then flirting with his brother! They must think you are already mahrime acting like a puta" '...unclean acting like a whore.' Even though the word was not overtly defined or explained, the context in which it was first uttered provided enough information for all sectors of the audience to understand its meaning.

\section{Conjunctions and Responses}

The use of conjunctions was briefly discussed in the context of research question two. It is important to emphasize that the high incidence of coordinating conjunctions-“"and" (12x), "but" (9x), "pero" 'but' (10x), and "y" 'and' (19x)-could be seeing as contributing to the continuity and fluidity of the script. Whenever a clause 
began with this type of word, audience members were encouraged to follow the story more closely and to associate the surrounding utterances. Figure 4.36 provides a few representative examples of this CS technique with the relevant words italicized and the conjunction underlined.

Figure 4.36 Conjunctions and reiterations

a. Liliana: ... The gypsies called them brother and said, "Dance for love!" $y$ los soldados comenzaron a bailar... (\#289)

Liliana: ...The gypsies called them brother and said, "Dance for love!" and the soldiers started to dance...

b. Rose: ...they did the cutting in tengo el cuchillo ensangrentado! (\#353)

Rose: ...they did the cutting and I have the bloody knife!

c. Don Armando: ...llevaré el cuchillo ensangrentado a la policía y les diré que Liliana lo ha matado, and then she will have the crime pinned to her. (\#360)

Don Armando: ...I will take the bloody knife to the police and I will tell them Liliana has killed him, and then she will have the crime pinned to her.

These examples show, once again, that because of their linguistic and national background, the three characters who had the potential to employ this type of CS did, indeed, utilize it to varying degrees. It could be argued that the use of conjunctions in combination with reiterations clarified the message transmitted in the story and addressed the needs of monolingual audience members. A case could also be made with regard to how a script filled with this use of conjunctions and reiteration might result in a play more accessible to a variety of audiences.

With respect to CS in the context of responses to questions, I had originally anticipated that answers containing adverbs, such as "bueno" 'well,' "sís" 'yes,' "no," "well," and "yes" could contribute to comprehension on the part of monolingual 
audience members. However, simply relying on the occurrence of those elements to determine comprehension could skew the results of the study in favor of bilingual audience members, at least to the extent that those members were familiar with or aware of some formulaic expressions. Figure 4.37 shows a few examples of this type of exchange, with the relevant words-adverbs-italicized for clarity.

\section{Figure 4.37 Responses to questions with adverbs}

a. Rose: Your girlfriend? (\#96)

Liliana: Si Señora, esperábamos el momento justo para decírselo... (\#97)

Liliana: Yes madam, we were waiting for the right moment to tell you...

b. Charlie: OK, so you get married for the loot? (\#282)

Liliana: No, Charlie, hay mucho más que eso... (\#283)

Liliana: No, Charlie, there is a lot more than that...

Since many of the responses containing adverbs were not translated or did not consist of cognates, it was necessary to look beyond these elements to find out what could aid monolingual audiences understand the story. Once again, the use of repeated words or reiterations was prevalent in this area. Similar to what was observed with conjunctions and reiterations, adverbs and reiterations seemed to work together to communicate a clearer message. This manner of writing was in agreement with Callahan's claim "there are various forms of contextual translation. ... The contiguity of the two [utterances] helps the reader [the audience, in the case of performance art pieces] decipher meaning, especially when a question appears in one language and its response in the other" (2004, p. 106). During the same discussion, she quoted Rudin (1996) as saying this type of CS could be called "an action-reaction scheme in which the content of a Spanish entry can be deduced by the reaction in English" (as cited in 
Callahan, 2004, p. 106). Examples illustrating this finding are included in Figure 4.38

with the relevant words italicized and the adverbs underlined.

Figure 4.38 Responses to questions with adverbs and reiterations

a. Liliana: ¿Has vuelto por tu futuro? (\#128)

Liliana: Have you come back for your fortune?

Charlie: Well fortune telling is hooey, but since I don't got no ideas 'bout my future... (\#129)

b. Charlie: Are you sure it's for real? (\#388)

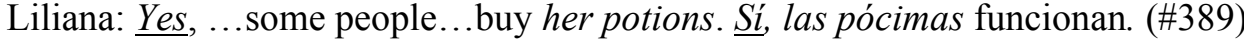

Liliana: Yes, ... some people...buy her potions. Yes, the potions work.

c. Liliana: Are you sure he is being arrested today? (\#441)

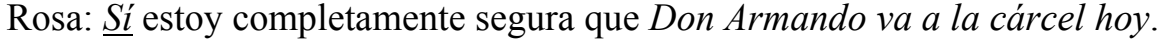
(\#442)

Rosa: Yes I am completely sure that Don Armando is going to prison today.

In addition to responding to questions by combining adverbs with reiterations, the script contained reiterated clauses to answer certain questions. This phenomenon was similar to those presented previously, but it is a little bit more complex because the answers in the switched language had to make reference to the original question. Some examples of this intricate manner of writing are included in Figure 4.39.

Figure 4.39 Responses to questions with reiterations

a. Don Armando: ... ¿ Te gustó el joven? (\#107)

Liliana: No sé, Capitán. I do not care about him... (\#108)

Don Armando: .... Did you like the young man?

Liliana: I don't know, Captain. I do not care about him...

b. Liliana: What happened to your father? (\#207)

Charlie: Murió en Irak, le dispararon. I'm supposed to go there too, and die like him. (\#208)

Charlie: He died in Iraq, they shot him. I'm supposed to go there too, and die like him. 
Figure 4.39 (Con't.) Responses to questions with reiterations

c. Liliana: ...¿QQué es esto? (\#234)

Charlie: It's a song...preparé una pequeña canción para ti. (\#235)

Liliana: ...What is this?

Charlie: It's a song...I prepared a little song for you.

\section{Research Question Four Summary}

This section provided several examples and discussion relating to how some CS processes and elements could have an impact in the audience's comprehension of the play. The frequent use of reiterations, by themselves or in connection with conjunctions and responses, could point to the playwright's understanding of audiences' needs. Simply repeating the same utterance in two or more languages would only make the play longer and bore the audience. In the words of SilvaCorvalán "the main function of language [is] a means of social communication ... the speaker would consciously suppress [switching] in a situation where it could create a communication breakdown" (1982, p. 73). Likewise, an argument could be made in relation to how the playwright used CS to avoid such communication breakdown. In addition, the manner in which Romani words were used to fill gaps and added to the artistic value of the script could be seen as another resource the playwright had to convey a compelling story.

It has become obvious during this study that writing for a diverse audience is a complex and difficult process. The use of CS in the form of reiterations, gap-filling, and conjunctions and responses seemed to keep the audience engaged and attentive to what was happening on stage. These were only a few of the uses of CS in the script of 
Mi Vida Gitana but they showed that CS could have a positive impact on the effective communication of messages.

\section{Conclusion}

This chapter has presented a detailed analysis of CS as it was observed in the script of Mi Vida Gitana. The analysis focused on form in order to answer the first two research questions and addressed both the frequency of CS as well as the most common CS processes and codeswitched elements found in the data. The focus of the analysis then shifted to function in order to generate the responses for the last two research questions and included discussions relating to character development and audience's comprehension. Throughout the analysis, I illustrated the results with relevant examples taken from the actual script of Mi Vida Gitana.

I continue this study in the following chapter by summarizing the various findings and including a brief discussion of the study's relevance in relation to the teaching of languages and CS research. The chapter also includes a section of lessons learned from applying the various typologies and models to data collected from the script of Mi Vida Gitana. It concludes with remarks relating to the study's limitations and suggestions for further research involving CS. 


\section{Chapter V}

\section{CONCLUSION}

This chapter summarizes the main results of the previous chapter as they relate to the four research questions driving this study. In addition, the next two sections after the result link those results to pedagogical issues and to current CS research, respectively. The following section addresses the lessons learned from applying the various typologies and models to data collected from the script of Mi Vida Gitana. The chapter concludes with the study's limitations and provides suggestions for further research involving CS.

As evidenced throughout the analysis, this study had a dual focus and used both quantitative and qualitative methods to arrive at the results. It is important to note that the combination of methods allowed me to address the issues raised by the questions posed more thoroughly, and they complemented each other well in order to achieve this goal.

\section{Results and Research Questions}

Research Question 1.

\section{What Is the Frequency with Which CS Occurs Throughout the Script?}

The discussion surrounding this question made reference to such topics as between-turn and within-turn phenomena and turns and occurrences. I presented frequency counts and examples that served to illustrate the overall situation found in the script as well as the linguistic behavior of the characters in the play. Incidences of between-turn switches and within-turn switches were calculated and resulted in frequencies of $58 \%$ and $46 \%$, respectively. These numbers were adjusted in order to 
avoid double counting those turns that showed both types of switches, but this calculation still produced a frequency of $78 \%$. In other words, some form of CS, whether happening between characters' utterances or occurring within the same character's turn, was identified in more than three-fourths of the script. With regard to the number of CS occurrences, the script contained 763 cases identified as such. The size of both these figures led me to argue that CS was an important linguistic feature of the script of Mi Vida Gitana. The implications of the above claim in terms of how the high frequency impacted character development and audience's comprehension were presented in the context of research questions three and four and will be summarized shortly.

Research Question 2.

What Specific Types of Elements Are Most Commonly Codeswitched, and How Are They Used?

The diversity of CS present in the script was extensive. Occurrences classified as insertion, alternation, or congruent lexicalization were found in most scenes of the script and were employed to varying degrees by all characters appearing on stage. The alternation of independent clauses was the most common CS type and element with a total of 378 occurrences. This number was even higher, amounting to 481 cases, when adding dependent clauses and independent clauses that began with either an adverb or a conjunction. It is important to repeat that a sector of the audience was expected to be bilingual but two other segments of the audience were presumed to be either English monolingual or Spanish monolingual. The fact that the most common CS occurrence 
took place inter-sententially could be seen as a tool used by the playwright to separate complete propositions and ideas in order to reach all members of the audience.

CS involving nouns and noun phrases was the second most common type of occurrence found in the script. These syntactic elements were employed in all three CS contexts-insertion, alternation, and congruent lexicalization, 56, 41, and 5 times, respectively-and served a variety of syntactic functions. They acted as subjects, direct objects, objects of prepositional phrases, as well as fulfilled a variety of extrasentential functions. It is also worth mentioning that the occurrence of CS nouns and noun phrases was even higher when combining the above numbers with those occurrences classified as term of address-36 additional occurrences. Even though the internal structure of English and Spanish noun phrases does not always match up perfectly, there is still a high level of syntactic, linear equivalence between the two languages which may facilitate the use of these elements in English-Spanish CS. Whatever the rationalization for the CS of nouns-which includes lack of knowledge, temporary inaccessibility of lexical items, greater explicitness, and emphasis (Lipski, 1985, 2005; McClure, 1998), it is of undeniable value when its use enhances or sustains communication and understanding among the parties involved. A similar claim could be made in regard to adverbs and adverbial phrases, the third most frequently codeswitched elements in the script.

The alternation of adverbs and adverbial phrases, which amounted to 62 and 24 occurrences, respectively, was another widespread CS process utilized in Mi Vida Gitana's script. The fact that many of these elements occurred extra-sententially and 
acted as responses and discourse markers pointed to the possibility of CS as emblematic and formulaic; that is, certain collocations and expressions acted as a single unit. What this means is that a high degree of bilingualism was not a necessary requisite for comprehension and, given the diversity of the audience, the playwright's use of adverbs and adverbial phrases could be seen as accommodating to the diverse nature of the audience.

Somewhat surprising was the lack of CS of the congruent lexicalization type. However, upon closer examination, I realized that the complexity of congruent lexicalization presupposed a level of bilingualism beyond what was anticipated for a considerable sector of the audience.

\section{Research Question 3.}

What Is the Function, if any, of CS with Respect to Character Development?

The data analysis showed that CS fulfilled an important function in terms of helping to develop characters. Myers-Scotton (1998b) addressed this situation and discussed the implications of marked and unmarked language choices. Charlie's predominant use of English and sporadic usage of Spanish served to make his CS more salient and, in the words of Myers-Scotton, marked, which in turn aided in constructing a certain kind of persona. On the other hand, Liliana's frequent CS involving English, Spanish, Romani, and French contributed to establish her character as cosmopolitan and perhaps afforded her credibility with the audience. Likewise, Don Armando's use of English and Spanish, in general, and his insertion and alternation of Romani elements, in particular, helped to portray him as a true gypsy leader. Finally, Rose's lack of CS involving Romani elements could be seen as a factor in developing 
her character as that of a gypsy woman who throughout the majority of the script preferred to keep that fact a secret. It is important to note that in the same way that CS had a function in developing the personality of the various characters in the script, this linguistic phenomenon could be used in naturally occurring conversations to portray a certain image and help develop a particular personality (Myers-Scotton, 1998a, 1998b, 1998c).

\section{Research Question 4. \\ How Does CS Contribute to Communicating an Understandable Message to Diverse Audiences?}

The data analysis indicated three main uses of CS as a tool to aid in audience's comprehension of the story. The most important one was, without a doubt, the use of reiterations. Whether it was the same character or his or her interlocutor who repeated similar information, CS of this kind contributed to communicating the script's message in a dynamic and artistic way. As mentioned before, literal translations could have resulted in a much longer and tedious play, plagued by redundancies and repetitions. Although treated as a different category, it should be mentioned that conjunctions and responses also made extensive use of reiterations in order to clarify ideas and dialogues. Finally, the use of CS to fill gaps, whether lexical or cultural, could also be seen as having an impact on the audience's comprehension. Given that the gaps analyzed in this study were filled with Romani words, it is important to call attention to the two approaches the playwright utilized in order to assist in audience's understanding. Once again, the use of reiterations was one such approach and reliance on program notes was the other. 
CS in Mi Vida Gitana and Language Teaching

Given Teatro Milagro's success-evidenced by their long history of producing bilingual plays in Portland-and my motivation as a language educator, I would like to comment on a few issues observed in the script that could impact language teaching. The predominant use of CS throughout the script and the variety of elements involved might be seen as indications that CS plays a role in the acquisition process of some learners. It is important to mention that rather than creating a breakdown in communication, CS seems to improve communication and encourage the continuation of the interaction. This point of view has been shared by a number of scholars who have studied English-Spanish CS in a classroom context. Huerta-Macías and Quintero (1992) found that those engaging in CS, mainly the teacher and children, did so in order to communicate more effectively, convey meaning, and establish a welcoming environment. These scholars claimed "language was, in effect, secondary; communication of meaning as the families engaged in discussions of issues significant to their lives was primary" (p. 84).

Likewise, Hughes, Shaunessy, Brice, Ratliff, and Alvarez McHatton (2006) proposed that "code switching . . . becomes a social, cultural, and linguistic tool that allows them [speakers] to integrate their experiences of two languages and two cultures into a cohesive whole" (p. 10). Hughes et al. sought to review the existing research thoroughly and listed several purposes for CS: to compensate for a language deficiency or lack of ability; to establish membership in a particular group; to convey a certain effect or attitude; to signal a different intention on the part of the speaker; to 
evade misunderstandings by utilizing a more suitable term from another language; and to "clarify, emphasize, separate facts from feelings, and achieve a certain dramatic effect"' (p. 16).

The fact that the script did not contain many occurrences of congruent lexicalization could also have pedagogical implications. According to Lipski (1985)who referred to a similar process as fluent switching in the context of syntactic congruency-and Muysken (2000), this type of CS would require a high level of understanding of the structure of the languages involved. Even Myers-Scotton (1993a), who focused her earlier research on intra-sentential CS, recognized that a certain proficiency level on the part of speakers was needed to engage in CS. It is in light of these claims that language educators should be aware that learners using this type of CS are doing so because they might have attained a level of understanding of the two languages that allows them to incorporate elements from both languages into the conversation and not because they might be deficient or lacking competence.

CS in the script of Mi Vida Gitana also contributed to the creation of certain personality traits and characteristics and to the development of community dynamics. Scholars as diverse as Gumperz (1982), Muysken (2000), and Myers-Scotton (1993b, 1998a, 1998b, 1998c) have agreed with this notion of CS. Consequently, it seems appropriate to remind language educators that speakers could be using this linguistic process or behavior in order to establish the type of relationship they desire to have with peers and people in authority positions. 
One final observation drawn from the study that could be relevant to language teaching relates to the communicative functions served by CS. I concluded that rather than being an impediment to comprehension of the play, CS was a way to connect with a diverse audience, particularly through the use of reiterations. Reyes (2004) recognized that "those speakers with the greatest degree of bilingual communicative competence are the ones who most frequently use CS as a strategy to meet their conversational goals [italics added]" (p. 93). Taking into account CS's role in the communicative process, linguists have tried to influence educators and prescriptivists. Liebscher and Dailey-O'Cain, 2005 maintained “incorporating . . code-switching into the classroom is both worthy and appropriate" (p. 235). Huerta-Macías and Quintero (1992) advocated for the rightful place of CS in the classroom as "part of a holistic approach to . . literacy that allows each participant to use his/her languages in a natural, meaningful way" (p. 87), while Hughes et al. encouraged "teachers and parents to recognize that code switching is a strategy of great semantic power" (2006, p. 22). Without personally advocating for the use of CS in the classroom, I suggest that $\mathrm{CS}$ be, at a minimum, considered a positive force in the acquisition process. I make this claim because CS seems to help overcome communication barriers and one of our goals as language educators is to help in the development of learners' communicative competence.

CS in Mi Vida Gitana and Current CS Research

The methodology used and the results arrived at during this current study are not only relevant to language teaching, but they have also contributed to the 
documentation of CS in a context that had not been the focus area of previous research. While referring to the current CS literature, Jonsson recognized that the majority of studies of English-Spanish CS have been focused on conversational occurrences of this phenomenon and that "there is still, on the whole, a lack of studies on code-switching in writing" (2010, p. 1297)

Another contribution of this study to the current CS research is the usefulness of combining two analytical perspectives and various models to explain this linguistic phenomenon, as previously claimed by Auer (1998) and Toribio (2002) and done by Kuehlhorn (2008). By analyzing CS in the script of Mi Vida Gitana from both a structural point of view and a functional approach, this study resulted in a more complete representation of the various issues arising when CS is observed. Likewise, the combination of multiple typologies and models to account for CS occurrences generated deeper conclusions and afforded a way of comparing the viability of those models, as I will explain in the following section.

The results of the current study also agree with findings of scholars who have previously researched CS on data similar to those observed in Mi Vida Gitana, that is to say, written and literary texts involving English-Spanish CS. Callahan (2002, 2004), who focused her analysis on structural issues, and Jonsson (2010), who directed her efforts to documenting functional aspects of CS, arrived at similar results to those presented in the current study when conducting their studies. Without discussing the frequent CS of nouns and noun phrases, which as mentioned earlier could be attributed to specific referents attached to these syntactic elements, it is noteworthy that the most 
frequent type and element codeswitched in the script, alternation of clauses, corresponds to Lipski's results. He observed "bilingual literature exhibits intersentential code switches, where ... entire sentences ... are produced in a single language, with switches occurring at principal phrase or sentence boundaries" (1985, p. 78).

Lessons Learned from Applying Various Typologies and Models to Current Data This section contains information about how the various typologies and models used in the study were useful in accounting for the CS found in the data, both from a structural and a functional point of view.

As previously mentioned in the methodology chapter, I decided to rely mostly on Muysken's typology for the structural analysis. The three-tiered typology seemed to provide a comprehensive continuum to account for all occurrences of CS. However, as I started coding and analyzing data, the diagnostic features Muysken presented were not as indisputable as I had anticipated and I encountered some difficulties when classifying occurrences as one of the three CS processes he proposed. This issue was mentioned during the discussion of insertion and alternation of nouns, noun phrases, prepositional phrases, and verb phrases, but it was even more relevant in the context of congruent lexicalization. It was for this particular CS process that the diagnostic features were very similar to those presented for the other two processes and, therefore, it seemed that congruent lexicalization was a "catch all" category. Consequently, I did not feel completely comfortable classifying occurrences as belonging to this category because I considered it squishy and lax. Although I utilized 
Myers-Scotton's MLF model only in the context of insertion, I could not help but wonder how it could be used to explain some of the CS found throughout the script of Mi Vida Gitana. This was particularly the case during those occurrences for which Muysken's typology left room for challenges. Recall that in those cases I included brief commentary on how Myers-Scotton and other analysts might have treated such CS instances. Having utilized the work of both scholars to conduct this study, I have come to the conclusion that since Myers-Scotton's MLF model was explained more explicitly, using it would have resulted in a more consistent analysis of CS occurrences in the script.

With regard to the functional models I used, both Gumperz's (1982) functions and Myers-Scotton's (1993b, 1998a, 1998b) MM seemed to match up quite accurately with data arising from the script, despite the fact they were not originally developed to account for $\mathrm{CS}$ in an artistic context. It is important to mention that some of the functions and uses proposed by these scholars were not applicable given the nature of data analyzed; however, to the extent that CS in the script of Mi Vida Gitana could be seen as approximating CS in naturally occurring conversations, Gumperz's and Myers-Scotton's works included useful examples to relate their research to current data and, therefore, I was able to provide a plausible explanation for the functions CS served in the script of Mi Vida Gitana. The usefulness of these models was also in line with Lipski's (1985) claim that CS found in literary texts, although not spontaneous, could still provide valuable information related to the linguistic and social functions served by this phenomenon. 


\section{Limitations of This Study}

The first and major limitation of this study was that data came from a single theatre script. In addition, it should be noted that language in the arts is not simply driven by the communication of a message but by the delivery of that message. Aviram stated "literary texts use the material ordinarily used for communication to deliver surprise, which pleases the reader [the audience, in the case of performance art pieces], edifies him or her, sharpens readerly skills, and performs other functions associated with aesthetic experience rather than with communication per se" $(1998, \mathrm{p}$. 106). Taking all these issues into account, the main risk of the study consisted in utilizing the language found in the script of Mi Vida Gitana to make generalizations about other bilingual plays, in particular, and CS and bilingualism, in general. In order to mitigate the risk of making such generalizations, findings arising from the current analysis were not extended to other contexts and were only intended to document how CS was used in this script. Nonetheless, the similarities found between the type of CS present in the script and that observed by other scholars in spontaneous bilingual conversations granted validity to the current study and placed it as a starting point for future studies. It is important to refer to Lipski's words who stated “we must not seal off the literary artefact entirely from sociolinguistic criteria, for to do so would create the paradoxical configuration of two grammars, one for literature and one for normal speech events" (1985, p. 76).

A second limitation was that the script might only be representative of the language used by the author of the script analyzed. Although this constituted a 
limitation of the current study, it should be noted that Dañel Malán is the primary, original playwright at Teatro Milagro and the study provided an unprecedented opportunity to examine how this author utilized CS.

Finally, a third limitation of the current study was that in order to work with manageable data, utterances were grouped and classified into a limited number of categories that could be applied to the languages found in the script. This classification and coding method might have come at the expense of combining similar but not equivalent elements and structures within the same category.

Even though the limitations were concrete, the knowledge that was generated from this research as well as the opportunity to be a pioneer in empirically documenting bilingualism and CS at Teatro Milagro warranted the completion of the study. At the same time, I hope that the successes achieved by this research, as finite and limited as they might be, could act as a springboard for future investigations of CS.

\section{Suggestions for Further Research}

The outcomes of this study offer some important knowledge with respect to the use of CS in bilingual plays involving English and Spanish. Given that Spanish represents the language of the biggest immigrant group nowadays in the United States, continued research in this area could provide an even deeper appreciation for how bilinguals in the United States communicate. Likewise, comparative studies involving multiple scripts by the same or different playwrights may offer more generalizable results. Finally, studies of scripts produced in areas where the audience includes a 
higher number of bilingual speakers-such as border zones-in contrast to scripts written in regions where the presence of bilinguals is not as strong would be of particular interest. 


\section{REFERENCES}

Auer, P. (1998). Introduction: Bilingual conversation revisited. In P. Auer (Ed.), Code-switching in conversation (pp. 1-24). London: Routledge.

Aviram, A. F. (1998). Literariness, markedness, and surprise in poetry. In C. Myers-Scotton (Ed.), Codes and consequences (pp. 101-123). New York, NY: Oxford University Press.

Callahan, L. (2002). The matrix language frame model and Spanish/English codeswitching in fiction. Language and Communication, 22 (1), 1-16. doi:10.1016/S0271-5309(01)00018-0

Callahan, L. (2004). Spanish/English codeswitching in a written corpus. Amsterdam, The Netherlands: John Benjamins Publishing Company.

Eastman, C. M. (1992). Codeswitching as an urban language-contact phenomenon. In C. M. Eastman (Ed.), Codeswitching (pp. 1-18). Clevedon, Australia: Multilingual Matters.

Gumperz, J. J. (1982). Discourse strategies. New York: Cambridge University Press.

Howard-Hill, T. (1998). Villanous boys: On some marked exchanges in Romeo and Juliet. In C. Myers-Scotton (Ed.), Codes and consequences (pp. 124-135). New York, NY: Oxford University Press.

Huerta-Macías, A. \& Quintero, E. (1992). Code-switching, bilingualism, and biliteracy: A case study. Bilingual Research Journal, 16 (3 \& 4), 69-90. Retrieved from http://brj.asu.edu/

Hughes, C. E., Shaunessy, E. S., Brice, A. R., Ratliff, M. A., \& Alvarez McHatton, P. (2006). Code switching among bilingual and limited English proficient students: Possible indicators of giftedness. Journal for the Education of the Gifted, 30 (1), 7-28. Retrieved from http://vnweb.hwwilsonweb.com.proxy.lib.pdx.edu/hww/Journals/getIssues.jht $\underline{\text { ml? sid }=\text { HWW:EDI\&id }=05876}$

Jacobson, R. (1998). Introduction. In R. Jacobson (Ed.), Codeswitching worldwide (pp. 1- 12). Berlin, Germany: Mouton de Gruyter.

Jonsson, C. (2010). Functions of code-switching in bilingual theater: An analysis of three Chicano plays. Journal of Pragmatics, 42 (5), 1296-1310.

doi:10.1016/j.pragma.2009.08.012 
Koike, D. A. (1987). Code switching in the bilingual Chicano narrative. Hispania, 70 (1), 148-154. Retrieved from http://www.jstor.org/pss/343692

Kuehlhorn, S. E. (2008). English as a Bollywood language: Hindi-English codeswitching in the Indian film Kal Ho Naa Ho (Tomorrow may not be). Unpublished master's thesis, Portland State University, Portland, Oregon.

Liebscher, G. \& Dailey-O'Cain, J. (2005). Learner code-switching in the contentbased foreign Language classroom. The Modern Language Journal, 89 (2), 234-247. Retrieved from http://www.jstor.org/stable/3588683

Lipski, J. M. (1985). Linguistic aspects of Spanish-English language switching. Tempe, Arizona: Arizona State University. Center for Latin American Studies.

Lipski, J. M. (2005). Code-switching or borrowing? No sé so no puedo decir, you know. In L. Sayahi \& M. Westmoreland (Eds.), Selected proceedings of the second workshop on Spanish sociolinguistics (pp. 1-15). Somerville, MA: Cascadilla Proceedings Project.

Malán, D. (2006). Mi Vida Gitana [My Gypsy Life]. Unpublished play manuscript for Teatro Milagro. Portland, Oregon.

Martínez, M. (2002). Still treading water: Recent currents in Chicano theater. In L.A. Ramos García (Ed.), The state of Latino theater in the United States (pp. 1529). New York, NY: Routledge.

McClure, E. (1998). The relationship between form and function in written national language-English codeswitching: Evidence from Mexico, Spain, and Bulgaria. In R. Jacobson (Ed.), Codeswitching worldwide (pp. 125-150). Berlin, Germany: Mouton de Gruyter.

Muysken, P. (2000). Bilingual speech: A typology of code-mixing. Cambridge: Cambridge University Press.

Myers-Scotton, C. (1992). Comparing codeswitching and borrowing. In C. M. Eastman (Ed.), Codeswitching (pp. 19-39). Clevedon, Australia: Multilingual Matters.

Myers-Scotton, C. (1993a). Duelling languages. Oxford: Clarendon Press.

Myers-Scotton, C. (1993b). Social motivations for codeswitching. Oxford: Clarendon Press. 
Myers-Scotton, C. (1998a). A theoretical introduction to the markedness model. In C. Myers-Scotton (Ed.), Codes and consequences (pp. 18-39). New York, NY: Oxford University Press.

Myers-Scotton, C. (1998b). Introduction. In C. Myers-Scotton (Ed.), Codes and consequences (pp. 3-17). New York, NY: Oxford University Press.

Myers-Scotton, C. (1998c). Marked grammatical structures: Communicating intentionality in The Great Gatsby and As I Lay Dying. In C. Myers-Scotton (Ed.), Codes and consequences (pp. 62-88). New York, NY: Oxford University Press.

Myers-Scotton, C. (2002). Contact linguistics: Bilingual encounters and grammatical outcomes. New York: Oxford University Press.

Myers-Scotton, C. (2006). Multiple voices: An introduction to bilingualism. Malden, MA: Blackwell Publishing.

Poplack, S. (1980). Sometimes I'll start a sentence in Spanish y termino en español: Toward a typology of code-switching. Linguistics, 18 (7/8), 581-618.

Reyes, I. (2004). Functions of code switching in schoolchildren's conversations. Bilingual Research Journal, 28 (1), 77-98. Retrieved from http://brj.asu.edu/

Rindler Schjerve, R. (1998). Codeswitching as an indicator for language shift? Evidence from Sardinian-Italian bilingualism. In R. Jacobson (Ed.), Codeswitching worldwide (pp. 221-247). Berlin, Germany: Mouton de Gruyter.

Silva-Corvalán, C. (1982). Code-shifting patterns in Chicano Spanish. In E. ElíasOlivares (Ed.), Spanish in the U.S. setting: Beyond the Southwest (pp. 69-87). Rosslyn, VA: National Clearinghouse for Bilingual Education.

Silva-Corvalán, C. (1990). Current issues in studies of language contact. Hispania, 73 (1), 162-176. Retrieved http://www.jstor.org/stable/343006

Toribio, A. J. (2002). Spanish-English code-switching among US Latinos. International Journal of the Sociology of Language, 158 (1), 89-119. Retrieved from http://www.reference-global.com.proxy.lib.pdx.edu/loi/ijs1

Treffers-Daller, J. (1992). French-Dutch codeswitching in Brussels: Social factors explaining its disappearence. In C. M. Eastman (Ed.), Codeswitching (pp. 143156). Clevedon, Australia: Multilingual Matters. 
Treffers-Daller, J. (1998). Variability in code-switching styles: Turkish - German code-switching patterns. In R. Jacobson (Ed.), Codeswitching worldwide (pp. 177-198). Berlin, Germany: Mouton de Gruyter. 


\section{APPENDIX}

\section{Mi Vida Gitana PLOT SUMMARY}

Mi Vida Gitana 'My Gypsy Life' was a play performed by Teatro Milagro in Portland, Oregon during the month of January 2006 and in selected states through November of that year. The play told the story of two young people, Liliana and Charlie, from different and conflicting backgrounds who defiantly fall in love and fight against all odds for that love.

The story begins with Liliana, a young gypsy girl in Spain, lamenting her current situation of being imprisoned and reading one of many letters she sends to Charlie, her young lover from the United States. As she is finishing this monologue, the play takes the audience to a previous time when Charlie and his mother, Rose, are adamantly arguing. They both have moved to Spain after the death of Charlie's father, Rose's husband, in Iraq. Rose is trying to convince Charlie to continue his studies in Spain since he has been expelled from a military academy in the United States and is using her control of financial resources as a way of persuading him. While they continue this argument, Liliana and Don Armando, the gypsies' leader, enter the stage discussing Liliana's inappropriate behavior. Charlie rescues Liliana from a sure beating at the hands of Don Armando, and they storm off stage together.

The second scene shows Liliana and Charlie getting to know each other and Charlie deciding to simulate a serious relationship to upset her mother. Don Armando finds out about this relationship, which would undoubtedly interfere with his plan to 
marry Liliana off to a wealthy gypsy from the tribe, but is put at ease when Liliana claims that her only interest is to make some money off of Charlie.

The third scene shows Liliana and Charlie talking about their lives and realizing that they have more in common than they originally thought: they both have lost significant members of their family and are at odds with those currently taking care of them. Charlie becomes intrigued with Liliana's story and the gypsy life. He sees it as adventurous and marked by high ideals, yet he does not understand many of its customs and traditions.

The fourth scene begins with a brief encounter between Rose and Don Armando in which he accuses her of being a gypsy. This scene is followed with a meeting between Liliana and Charlie. They continue getting to know each other and after Charlie performs a song in Spanish for Liliana, she encourages him to follow his dream of being a musician. Since Liliana is fond of writing, Charlie invites her to be with him and to pursue her dream of becoming a writer. Liliana accepts but according to Romani tradition, a promise is not enough, so they make a blood pact. Immediately after, Charlie becomes aware that in order to have Liliana as his wife he needs to pay Don Armando a better price than what was offered by her current fiancé. The only other way to break the engagement is for Liliana to loose lose her virginity, in which case she would not be suitable for marriage in the gypsy tradition. Liliana is not ready for this to happen so they decide to play a trick on both Rose and Don Armando and simply pretend that they had sex by dirtying a bed sheet. Rose enters the scene, sees Charlie and Liliana, and accuses her of being a thief. Liliana storms off and Charlie 
and his mother enter into another argument. Charlie gets so upset that he leaves his mother who finds the knife from the blood pact and the stained bed sheet.

The fifth scene consists primarily of a conspiracy developed between Rose and Don Armando to end Charlie and Liliana's relationship by framing Liliana for a murder. The next scene begins with an imprisoned Liliana being visited by Charlie who agrees to bring poison to end both their lives, as established by the blood pact they had made earlier, because living apart from each other is not something they could bear. The sixth scene ends with Rose finding out that the two young lovers are about to commit suicide.

The seventh and final scene has Charlie and Liliana getting ready to end their lives when Rose runs in to stop them. Rose confesses that Liliana was framed, but seeing their true love and high morals, she makes everything right by clearing Liliana's name and sending Don Armando to prison. She also admits her gypsy upbringing and encourages Charlie and Liliana to take their vows according to gypsy traditions. 